\title{
Observational estimates of dynamic topography through space and time
}

\author{
Mark Hoggard, ${ }^{*, a, b}$ Jacqueline Austermann, ${ }^{b}$ Cody Randel $^{b} \&$ Simon Stephenson $^{c}$
}

\author{
${ }^{a}$ Department of Earth and Planetary Sciences, Harvard University, USA. \\ ${ }^{b}$ Lamont-Doherty Earth Observatory, Columbia University, USA. \\ ${ }^{c}$ Department of Earth Sciences, University of Oxford, UK. \\ *www.mjhoggard.com; mark.hoggard@anu.edu.au \\ Cite as: Hoggard, M.J., J. Austermann, C. Randel, \& S. Stephenson (2021). Observational estimates of dynamic topography \\ through space and time, in Mantle convection and surface expressions (Eds: H. Marquardt, M. Ballmer, S. Cottaar, \\ \& J. Konter), AGU Geophysical Monograph Series, Washington, DC, Chapter 15. doi: 10.1002/9781119528609.ch15
}

\begin{abstract}
Earth's mantle undergoes convection on million-year timescales as heat is transferred from depth to the surface. Whilst this flow has long been linked to the large-scale horizontal forces that drive plate tectonics and supercontinent cycles, geologists are increasingly recognising the signature of convection through transient vertical motions in the rock record, known as "dynamic topography". A significant component of topography is supported by lithospheric isostasy, and changes in lithospheric thermal structure are sometimes included in the definition of dynamic topography. An additional component arises from active flow within the underlying convecting mantle, and this process causes dynamic topography that has lengthscales varying from $10,000 \mathrm{~km}$ down to $500 \mathrm{~km}$ and typical amplitudes of $\pm 1 \mathrm{~km}$. Transient uplift and subsidence events are often slow, but might evolve at rates as fast as $500 \mathrm{~m} \mathrm{Myr}{ }^{-1}$ over cycles as short as $\sim 3 \mathrm{Myr}$, leading to periodic overwriting of the geological record that results in complex interpretational challenges. Despite these difficulties, a growing number of observational and computational studies have highlighted the important role of dynamic topography in fields as diverse as intraplate magmatism, sedimentary stratigraphy, landscape evolution, paleo-shorelines, oceanic circulation patterns, and ice sheet stability. This review provides a brief overview of our current understanding of the topic and explores some basic insights that can be gained from simple three-dimensional numerical simulations of mantle convection under different convective regimes. We summarise a suite of observational techniques used to estimate dynamic topography, and finish by laying out some key unanswered questions to stimulate debate and inspire future studies.
\end{abstract}

The generation and movement of heat through the mantle gives rise to lateral density heterogeneity and convective flow. These buoyancy anomalies and their motion act to push Earth's surface up or pull it down, resulting in an evolving pattern of vertical deflections known as dynamic topography. Over the last decade, there has been growing recognition of the influence of dynamic topography on surface processes including landscape evolution, stratigraphic development of sedimentary basins, oceanic circulation, paleo-shoreline migration, and ice sheet dynamics (Braun et al., 2013; Petersen et al., 2010; Spasojević \& Gurnis, 2012; Poore et al., 2006; Rovere et al., 2014; Austermann et al., 2015). In turn, identification of the fingerprint of dynamic topography within the rock record can be used to gain insights into the structure and dynamics of the Earth's mantle (Hager et al., 1985; Gurnis et al., 2000; Flament, 2019). The potential relevance of dynamic topography to such a diverse range of fields has led to a proliferation of studies investigating this important topic using theoretical, observational, and computational approaches (Ghelichkhan \& Bunge, 2016; Hoggard et al., 2016; Arnould et al., 2018). Despite considerable advances arising from this work, several controversies remain that are the focus of considerable ongoing investigation. Examples include how best to define dynamic topography, the length scales and rates over which it changes, the driving mechanisms primarily responsible for its temporal evolution, and which geological observations are appropriate for constraining this behaviour.

In this review, we first provide a brief overview of convective regimes within the mantle and their variable signature in Earth's dynamic topography. This genetic link between the surface and deep interior constitutes the most fundamental motivation for studying dynamic topography, and therefore provides important context. Next, we review observational constraints that can be used to infer dynamic topography, both its present-day spatial pattern and its temporal evolution. We finish by outlining several important outstanding challenges in this research area.

\section{Convective regimes and their surface expression}

The Earth acts as a giant heat engine, with transfer of thermal energy between various sources and sinks giving rise to many of the geological processes that have sculpted its surface. Heat is simultaneously generated in the interior of the mantle (primarily from the decay of radioactive nuclides) and supplied from below by the core (Lay et al., 2008). This heat is transferred to the surface of the mantle where it continuously escapes by conduction through the lithosphere.

\subsection{Thermal convection of the mantle}

On geological timescales, the mantle deforms as a fluid and can be modelled using the principles of conservation of mass, momentum, and energy. Some basic insights into its firstorder behaviour have been obtained from simple fluid dynamical analysis. Deformation of mantle rocks is often treated as a Newtonian process, where the rate of strain is linearly related to the driving deviatoric stress, and the effects of inertia can be neglected. The resulting balance between pressure, gravitational and viscous forces in such a fluid leads to the Stokes equation, which depends on a dimensionless parameter known as the Rayleigh number. Its magnitude quantifies the timescale of conductive heat transport over that of convective transport across the mantle, and gives an indication of convective vigour. Thus, systems with low Rayleigh numbers efficiently transfer heat by conduction, whilst high Rayleigh numbers correspond to vigorous thermal convection. For a 
simple isoviscous layer heated from below, the Rayleigh number, $R a_{B}$, is given by

$$
R a_{B}=\frac{\rho g \alpha \Delta T d^{3}}{\kappa \eta}
$$

where $\rho$ is the density of material at surface conditions, $g$ the gravitational acceleration, $\alpha$ the coefficient of thermal expansion, $\Delta T$ the temperature difference between upper and lower boundaries, $d$ the layer depth, $\kappa$ the thermal diffusivity, and $\eta$ the kinematic viscosity (Turcotte \& Schubert, 2002). In the case of a purely internally heated fluid, the Rayleigh number, $R a_{H}$, is instead evaluated using

$$
R a_{H}=\frac{\rho^{2} g \alpha H d^{5}}{\kappa \eta k}
$$

where $H$ is the rate of internal heat generation per unit mass and $k$ is the thermal conductivity. Analysis of the stability of small temperature perturbations within a fluid reveals that a critical transition occurs at $R a \approx 10^{3}$ in either heating scenario, above which the layer begins to undergo thermal convection (Rayleigh, 1916).

There is considerable ongoing debate over the relative magnitude of internal heat generation within the mantle versus basal heating from the core (Lay et al., 2008; Nimmo, 2015). However, adopting approximate estimates of the various parameters in Equations (1) and (2), either definition yields Rayleigh numbers for the mantle from $10^{6}$ up to $10^{9}$, depending on whether layer depth is taken to be only the upper $670 \mathrm{~km}$ or the whole depth of the mantle (e.g. Knopoff, 1964). Thus variations in temperature within the mantle give rise to buoyancy variations that drive vigorous flow. Although this analysis is predicated upon a simple system with several approximations and assumptions, the order of magnitude is thought to be valid for more realistic mantle rheologies that include the pressure and temperature dependence of parameters such as viscosity and thermal expansivity, resulting in spatial variation of the Rayleigh number (e.g. Parmentier et al., 1976).

Both computational simulations and laboratory experiments on analog systems show that, at these Rayleigh numbers, convection is vigorous, can develop multiple layers, and exhibits a strongly time-dependent planform (Busse, 1978; Machetel \& Yuen, 1986; Weinstein \& Olson, 1990; Yuen et al., 1994; Davies \& Davies, 2009). Convection cells develop that have isothermal cores bounded by thin layers where conductive heat transfer dominates (Turcotte \& Oxburgh, 1967). These thermal boundary layers form at the top of the mantle as hot material rises to the surface and spreads horizontally, gradually cooling to generate progressively thicker oceanic lithosphere (McKenzie, 1967). When the thickness exceeds a critical value, the thermal boundary layer destabilises and begins to participate in convection (Huang \& Zhong, 2005). On Earth, these downwellings are thought to be dominated by sinking slabs, although smaller-scale convective rolls and drips have also been suggested (Richter, 1973; McKenzie et al., 1974; Balachandar et al., 1992; Parmentier et al., 1994). Importantly, some regions of thick continental lithosphere are anomalously buoyant and viscous due to chemical depletion, so do not destabilise in this manner (Jordan, 1975). Buoyant instabilities within the lower thermal boundary layer at the core-mantle boundary are expected to generate isolated upwelling plumes and sheets (e.g. Olson et al., 1987). The planform of these various features is expressed in dynamic topography on the overlying surface.

\subsection{Dynamic topography: A definition}

Lateral density variations in the mantle and convective flow produce temporally evolving radial stresses, $\sigma_{r r}(t)$, that act on Earth's surface. These radial stresses are balanced by vertical deflections of the surface, which are generally referred to as dynamic topography. The magnitude of these radial stresses depends on the viscosity of the mantle and the depth, wavelength, and size of the buoyancy anomaly (Parsons \& Daly, 1983; Forte \& Peltier, 1991). The amplitude of resulting dynamic topography, $\delta a(t)$, depends upon the buoyancy of the fluid displaced at the surface (i.e. air- versus waterloaded) according to

$$
\delta a(t)=\frac{\sigma_{r r}(t)}{g \Delta \rho}
$$

where $g=9.8 \mathrm{~m} \mathrm{~s}^{-2}$ is the acceleration due to gravity at the Earth's surface, and $\Delta \rho$ is the density difference between mantle and displaced surface fluid. The existence of these surface deflections was first alluded to by Pekeris (1935) and is generated by three interwoven processes. Firstly, buoyancy associated with variations in the thickness and thermal structure of the upper boundary layer (lithosphere) is isostatically compensated at the surface (Figure 1a). This process is particularly well-expressed in oceanic regions, whereby average water-loaded basement depths subside by $\sim 3.5 \mathrm{~km}$ as the plate ages, conductively cools, and increases in density (Richards et al., 2018). This first-order behaviour of oceanic lithosphere has been comprehensively studied and is wellunderstood (e.g McKenzie, 1967; Parsons \& Sclater, 1977; Stein \& Stein, 1992). However, the contribution of lithospheric isostasy in continental regions is an area of considerable ongoing research (e.g. Guerri et al., 2015; Ball et al., 2019; Davies et al., 2019; Klöcking et al., 2020; Lamb et al., 2020). In particular, treatment of cratonic lithosphere is complicated by the fact that some of its buoyancy arises from chemical depletion, which may be sufficiently extensive that its high intrinsic buoyancy and viscosity only allows it to passively affect convective flow without participating in it (Jordan, 1978; Jain et al., 2019). The second process arises from variations in temperature and chemical composition within the asthenosphere and deeper mantle. This lateral heterogeneity causes density anomalies that can, even in the absence of vertical flow, be isostatically compensated at the surface (Figure 1b). Thirdly, the flow field itself produces pressure gradients and vertical deviatoric stresses that exert tractions on the overlying plate (Figure 1c). A standard assumption in mantle convection modelling is that inertial forces are negligible, such that the flow field is entirely driven by buoyancy anomalies. This assumption inextricably links these second and third processes.

There is general consensus that crustal isostasy should not be considered part of dynamic topography, but definitions in the literature beyond this starting point tend to diverge, including and excluding various of the aforementioned processes (Flament et al., 2013). Some studies treat dynamic topography as the deflections caused by buoyancy in the lower mantle, whilst others include shallower features up to a depth of $\sim 200 \mathrm{~km}$, or even all sub-lithospheric structure (e.g. Hager et al., 1985; Ricard et al., 1993; Conrad \& Husson, 2009; Steinberger, 2016). Lithospheric isostasy (process $a$ in Figure 1) is commonly excluded from the definition, as it tends to dominate contributions from other processes and is difficult to model accurately due to the complex density structure of continental lithosphere. Nevertheless, several studies do incorporate lithospheric isostasy in the definition (e.g. Forte et al., 1993; Moucha et al., 2008; Glišović \& Forte, 2016). 
Processes giving rise to dynamic topography:

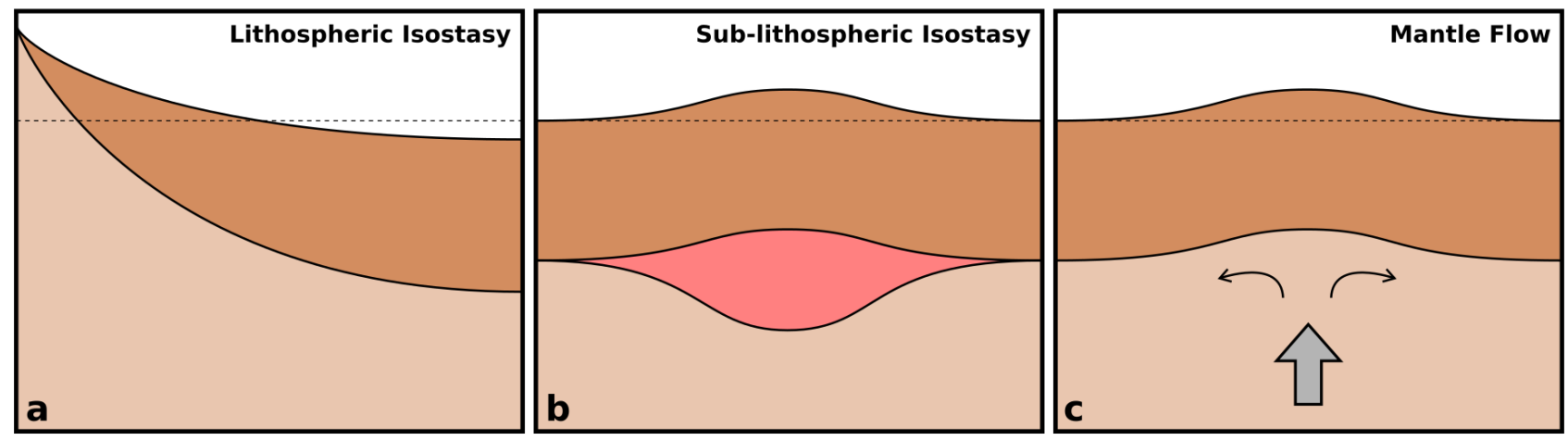

Mechanisms driving changes in dynamic topography:

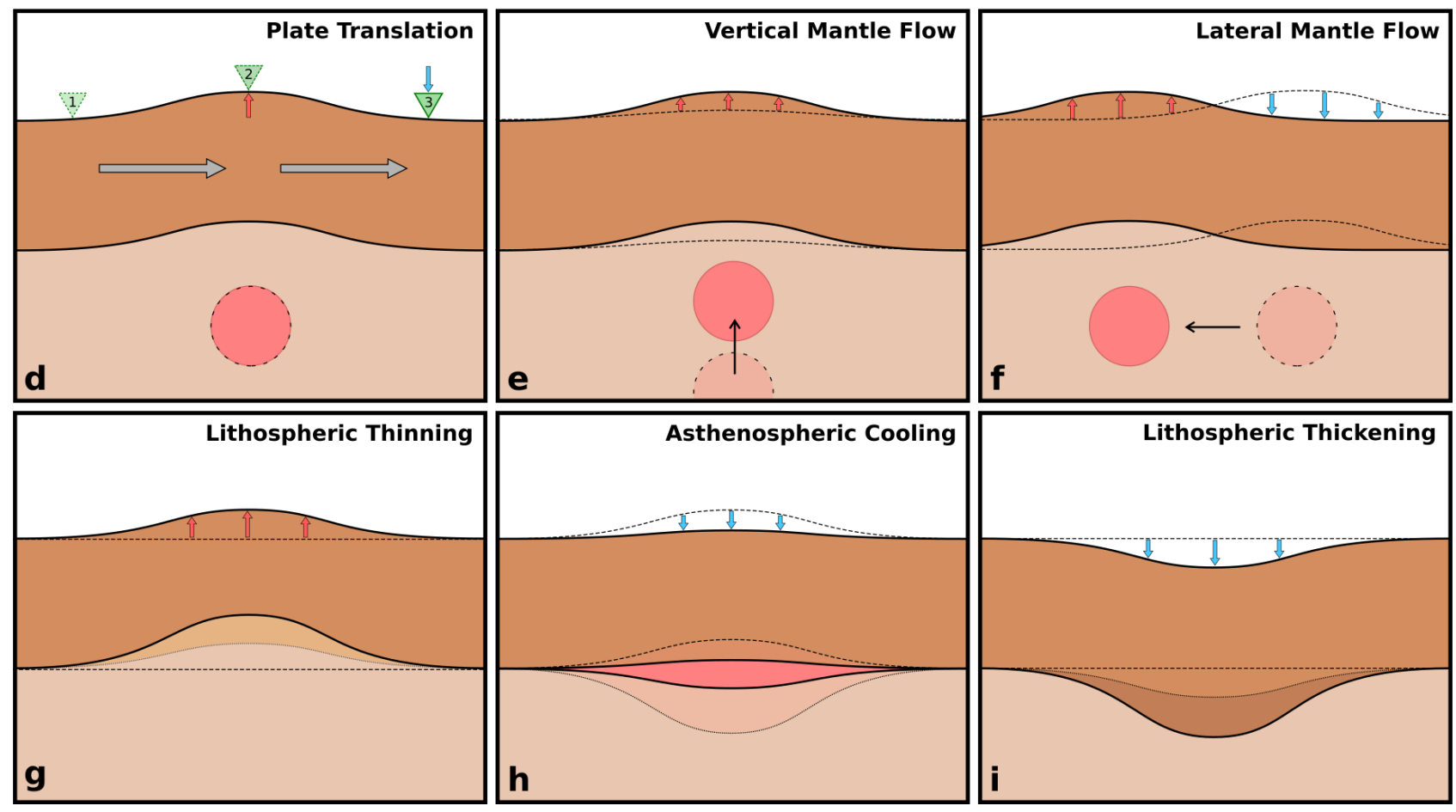

Figure 1: Processes producing dynamic topography and mechanisms causing evolving vertical motion. Top row = three processes causing dynamic topography: (a) lithospheric isostasy (both oceans and continents); (b) isostasy within the convecting mantle (asthenosphere and deeper); (c) mantle flow. Lower panels = mechanisms causing changing vertical motion at the surface: (d) lateral translation of plate across underlying convective planform; (e) evolving vertical flow field; (f) lateral advection of convecting mantle; (g) lithospheric thinning (e.g. by thermal erosion); (h) cooling of temperature anomalies; (i) lithospheric thickening (e.g. during oceanic spreading or following horizontal extension).

Finally, it is also possible to subtract all isostatic contributions and consider flow induced topography in isolation (only process $c$ in Figure 1; e.g. Molnar et al., 2015). Whilst these alternative definitions have resulted in significant confusion in the literature, none of them is necessarily incorrect, but rather they aim to understand and explain different processes (e.g. isostatic effects arising from the lithosphere versus deeper mantle flow). The salient point is that a consistent definition of dynamic topography should be used when comparing model predictions either with one another or against observational constraints.

A consequence of dynamic topography arising from these three processes is that evolving vertical motions can be a result of changes in any of the individual components. Firstly, as the lithospheric plate translates laterally over temperature anomalies in the convecting mantle, any point at the surface undergoes alternating cycles of uplift and subsidence (Figure 1d; Sandiford, 2007; Czarnota et al., 2013). The greatest rates of change associated with this mechanism will occur when short-wavelength temperature anomalies are located beneath fast moving plates, such as in Australia or the Pacific Ocean. Secondly, the amplitude and spatial extent of dynamic topography changes as vertical mantle flow progresses. This occurs, for example, above a subducting slab or upwelling plume head (Figure 1e; Gurnis et al., 2000; Spasojević et al., 2009; Eakin et al., 2014). Thirdly, temperature anomalies can flow laterally beneath the plate, producing a progressing wave of uplift and subsidence (Figure 1f). This lateral advection mechanism is thought to be particularly prevalent where plume heads impact the base of the plate and subsequently spread horizontally within a low viscosity asthenospheric channel, such as around Iceland (Vogt, 1971; Hartley et al., 2011). Fourthly, excess heat can thermally erode and thin the lithospheric mantle, producing uplift of the overlying surface (Figure 1g; Klöcking et al., 2020). Fifthly, over time, the layer of hot plume head material can 

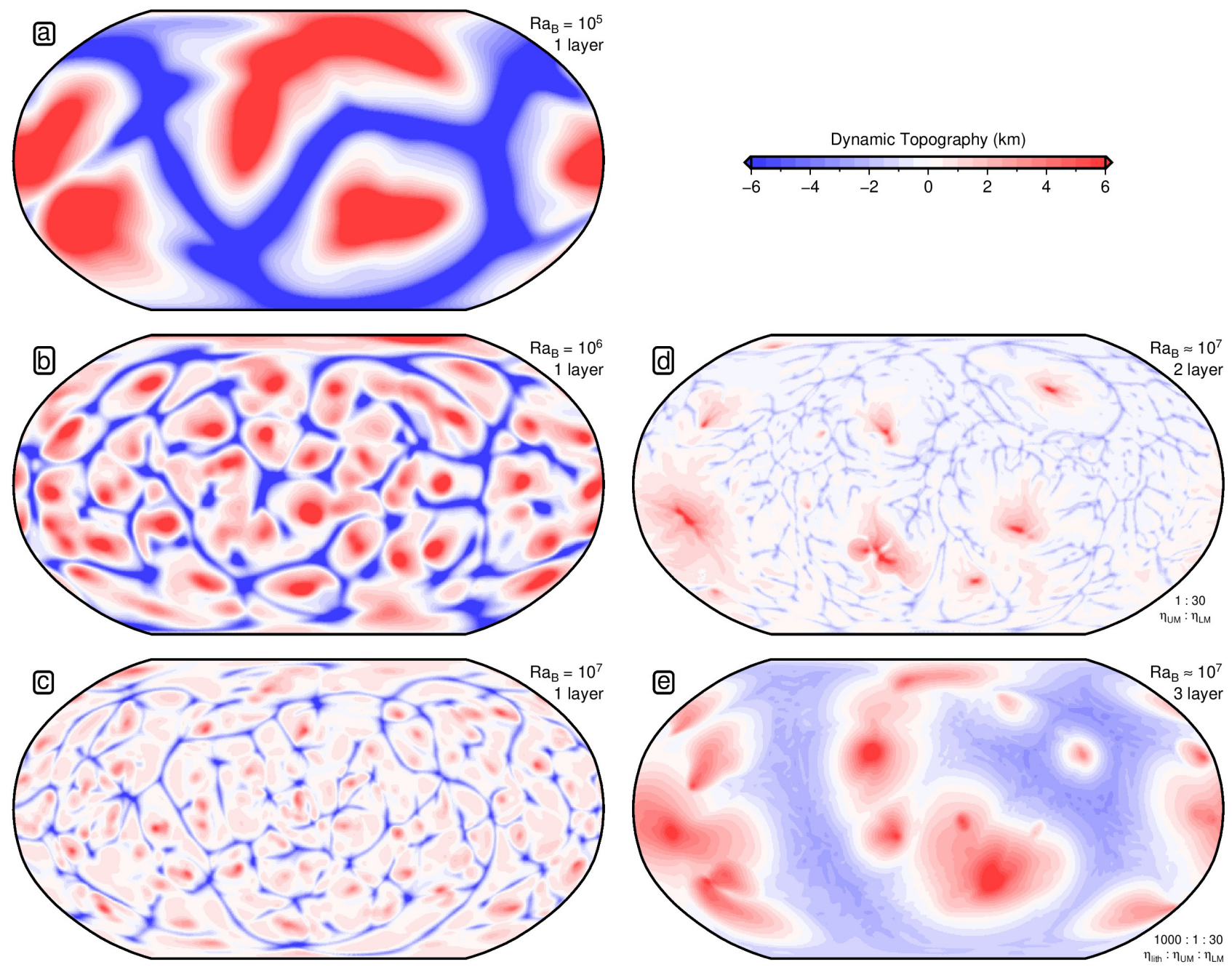

Figure 2: Synthetic dynamic topography fields for simple convection simulations within ASPECT using a threedimensional mantle shell. Dynamic topography is calculated using Equation (3) assuming an air-load and includes the contributions from flow field, lithospheric and asthenospheric isostasy (processes $a, b$ and $c$ in Figure 1). (a) Isoviscous run with $R a_{B}=10^{5}$. (b) Isoviscous run with $R a_{B}=10^{6}$. (c) Isoviscous run with $R a_{B}=10^{7}$. (d) Run with factor of 30 viscosity jump across $670 \mathrm{~km}$ between the upper mantle, $\eta_{U M}$, and lower mantle, $\eta_{L M}$, at $R a_{B} \approx 10^{7}$. (e) Same as $d$, but also including a $100 \mathrm{~km}$-thick lithosphere, $\eta_{l i t h}$, that is 1000 times more viscous than the underlying upper mantle. All grids and parameter files are in the associated OSF database.

cool by conduction, causing subsidence (Figure 1h; Anderson, 1982). Finally, conductive cooling of the lithosphere causes it to thicken and increase in density, driving subsidence of the overlying surface (Figure 1i; McKenzie, 1978). It should be noted that an additional seventh mechanism also operates, whereby convection-induced changes in the gravity field generate relative vertical motions in the geological record (Austermann \& Mitrovica, 2015). However, this effect is generally very small (particularly at shorter wavelengths) and is highly correlated with the pattern of solid Earth deformation driven by the first six mechanisms.

These six mechanisms can act simultaneously or in isolation to produce complex patterns of vertical motion. Spatial length scales can be highly variable, and are limited at short wavelengths by the flexural rigidity of the lithosphere (Colli et al., 2016; Arnould et al., 2018; Golle et al., 2012; Sembroni et al., 2017). There is also an interplay between timescales of these different mechanisms. The rate of dynamic topography change due to plate translation is controlled by plate speed, the two evolving flow mechanisms depend on convective flow velocity and therefore mantle viscosity, whilst cooling asthenosphere and lithospheric modification depend upon warming and cooling of shallow material and therefore evolve over conduction timescales. Some of the fastest rates of inferred vertical motion are up to $0.5 \mathrm{~mm} \mathrm{yr}^{-1}$ and appear to be associated with lateral mantle flow within the astheno- sphere (mechanism $f$ in Figure 1; Hartley et al., 2011), whilst conductive cooling at lithospheric scales occurs on 10s Myr timescales and produces rates as slow as $0.01 \mathrm{~mm} \mathrm{yr}^{-1}$ (mechanisms $h$ and $i$ in Figure 1; Parsons \& Sclater, 1977). Furthermore, there is a complicated interaction between differential plate translation (mechanism $d$ in Figure 1) and the other five mechanisms. For example, the plate is mechanically coherent and so sites of lithospheric thinning and thickening travel horizontally with the plate, in a fixed position with respect to the overlying surface. In a similar manner, downwellings are generated by instabilities within the thermal boundary layer at the top of the mantle, and are therefore more likely to track horizontally with the plate than upwellings, which are sourced from depth and are less likely to be directly coupled to surface plate motion.

\subsection{Simple convection simulations}

Here, we illustrate in Figure 2 the effect of varying the convective vigour of the mantle on the resulting pattern of dynamic topography, where all three processes causing surface deflections have been included. The purpose of these simulations is to demonstrate that global patterns of dynamic topography are strongly sensitive to convective regime, and to provide a first-order understanding of this relationship. The simulations are intentionally kept simple to convey these key points, and more complex rheologies and thermal properties would 
be required to make them more Earth-like.

Our finite element simulations are performed using the ASPECT code (version 2.2.0-pre) where we adopt a threedimensional spherical shell that is heated from below (Kronbichler et al., 2012; Heister et al., 2017). We perform five incompressible simulations at a range of Rayleigh numbers using different radial viscosity profiles. Three are isoviscous, a fourth includes a lower viscosity upper mantle, and a fifth also incorporates a high viscosity lithospheric lid (see caption of Figure 2). Free-slip boundary conditions are applied at the top and bottom of the domain, and net rotation is removed. Models are initialised with minor density perturbations around a constant mantle temperature profile and run forward through time until they reach steady state, which is achieved when the root-mean-squared (r.m.s.) surface velocities stabilise. Runs take between 0.5-15 Gyr to reach steady state and use adaptive mesh refinement in the upper boundary layers (uppermost $200 \mathrm{~km}$ ) and at grid cells with large thermal gradients, such that the most well-resolved features have a resolution of $\sim 10 \mathrm{~km}$. While this resolution limits the degree to which boundary layer dynamics are resolved, we believe that it is sufficient to correctly simulate first-order differences in convective regimes. Dynamic topography is calculated based on Equation (3) using the consistent boundary flux method to calculate radial stresses at the surface (Zhong et al., 1993). This definition therefore includes the contributions from flow field, lithospheric and asthenospheric isostasy (all three processes $a, b$ and $c$ in Figure 1). All parameter files are included in the accompanying OSF database.

At $R a_{B}=10^{5}$, convection is relatively sluggish and produces long-wavelength, plume-like swells surrounded by lows above downwelling sheets that are stationary through time (Figure 2a). The r.m.s. amplitude of air-loaded dynamic topography is $6.9 \mathrm{~km}$, with peak amplitudes of $-17 \mathrm{~km}$ and $+32 \mathrm{~km}$. Figures $2 \mathrm{~b}-2 \mathrm{c}$ show that increasing to $R a_{B}=10^{6}$ yields an r.m.s. amplitude of $2.8 \mathrm{~km}$ (peak amplitudes of $\pm 13 \mathrm{~km}$ ), whilst at $R a_{B}=10^{7}$ the r.m.s. drops to $1.3 \mathrm{~km}$ $(-7.5 \mathrm{~km}$ to $+5.5 \mathrm{~km})$. Thus by raising the Rayleigh number,

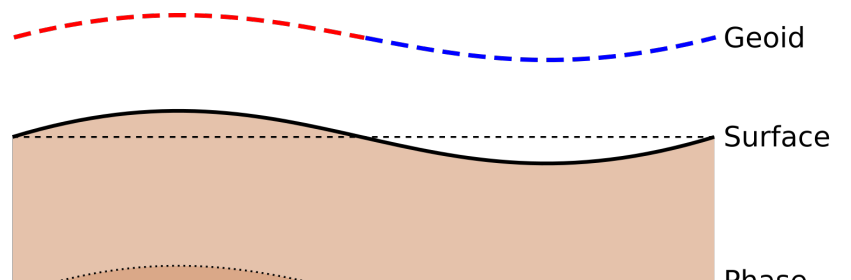

Transition

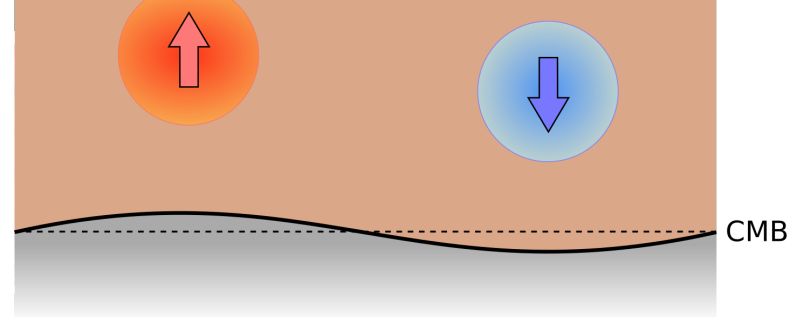

Figure 3: Schematic cartoon of lower mantle flow and associated boundary deflections. Vertical deflections of the geoid, surface, mantle phase transitions and core-mantle boundary (CMB) are driven by a hot, buoyant, upwelling anomaly (red) and a cold, dense, sinking anomaly (blue). Note that mass anomalies associated with these internal buoyancy variations and with the flow-driven boundary deflections are opposite in sign. Competition between these sources results in the amplitude and sign of geoid height deflections depending upon the buoyancy anomaly magnitude, its wavelength and burial depth, and the viscosity of the mantle (Parsons \& Daly, 1983; Hager et al., 1985). the increasingly vigorous flow results in lower amplitude, shorter-wavelength dynamic topography.

These first three runs are isoviscous. Introducing a viscosity increase of a factor of 30 across the $670 \mathrm{~km}$ discontinuity causes a further drop in the r.m.s. amplitude to $0.84 \mathrm{~km}$ (Figure 2d). This also causes the upwellings, which initiate in the thermal boundary layer at the base of the lower mantle, to become more widely spaced and have more localised, higher amplitude peaks than the more elongated lows above downwellings (peaks of $+8.4 \mathrm{~km}$ versus lows of $-3.5 \mathrm{~km}$ ), as previously found by Bunge et al. (1996). Finally, introducing a high viscosity lithosphere causes the downwellings to concentrate into wide bands separated by more closely spaced upwellings with broader swells (Figure 2e).

These simple examples illustrate that the potential impacts of mantle convection on vertical motions of Earth's surface are highly diverse and likely to be variable through time. An important corollary is that making accurate observations of dynamic topography can provide unique insights into the structure and dynamics of Earth's interior. Parallel advances between numerical modelling, the quantity and accuracy of observational constraints, and the efficiency at which they can be assimilated, are key for better reconstructions of dynamic topography. Several excellent review papers in the last decade have highlighted various improvements from a modelling perspective (e.g. Braun, 2010; Flament et al., 2013; Coltice et al., 2017). Here, we briefly revisit these advances, but mainly choose to focus on providing a complementary overview of the methods that are used to reconstruct dynamic topography from observational constraints in the geological record.

\section{Early observational constraints on large-scale mantle flow and their role in past and present geodynamic modelling}

Our knowledge of Earth's present-day dynamic topography has undergone several major developments over the past 80 years as powerful new datasets have become available. The late 1950s saw the first measurements of the longwavelength component of Earth's gravity field, derived from orbit-tracking of rockets and satellites (Kaula, 1963). One common representation of this field is to map variations in the height of the equipotential surface that coincides with mean sea level, known as the geoid. The primary component of the observed field is stronger gravity near the equator compared to the poles, which is caused by excess flattening of the Earth due to its rotation (Nakiboglu, 1982). Once this hydrostatic component is removed, there remains a dominant spherical harmonic degree 2 pattern. Two major geoid highs of approximately $+100 \mathrm{~m}$ are centred over Africa and the western Pacific Ocean, encircled by a ring of $-100 \mathrm{~m}$ lows above the sites of Mesozoic and Cenozoic subduction zones. These anomalies were soon interpreted as being caused by flow within the mantle, and are generated by a combination of two competing effects (Runcorn, 1965). In the case of a buoyant upwelling, a negative gravity contribution arises from the hot, lower density thermal anomaly within the mantle, which is opposite in sign to the positive contribution generated by upwards deflection of the surface and core-mantle boundary (Pekeris, 1935; McKenzie, 1968; McKenzie et al., 1973). The reverse occurs for a dense, downwelling structure. Which of these two effects is the strongest (i.e. geoid contributions from driving mass anomalies versus boundary deflections) depends on the size of the buoyancy anomaly, its depth and and the viscosity of the mantle (Parsons \& Daly, 1983; Colli et al., 2016).

In the late 1970s, the first global seismic tomographic im- 


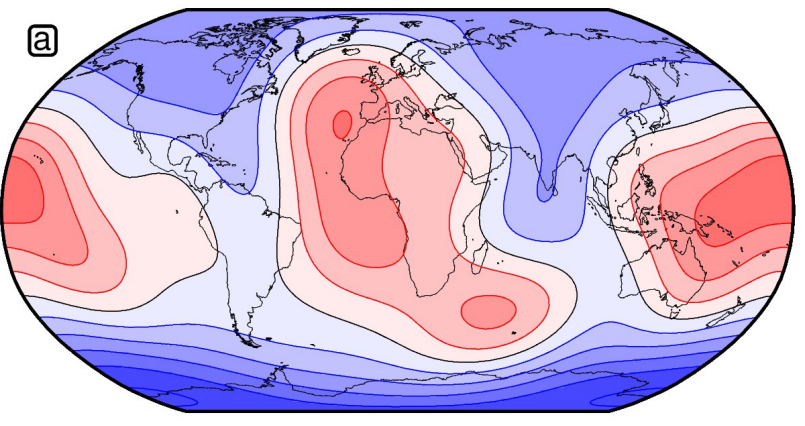

Observed Residual Geoid Height Anomaly (m)
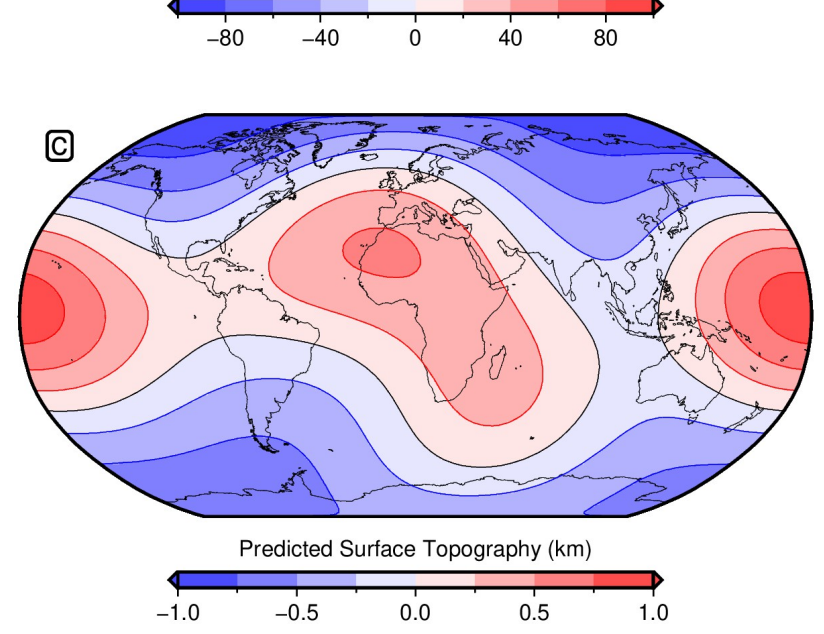

Figure 4: Results of present-day instantaneous flow calculations from Hager et al. (1985). (a) Observed geoid height anomaly, corrected for the effects of hydrostatic flattening due to Earth rotation and the presence of downwelling slabs beneath subduction zones (Hager, 1984); contoured every $20 \mathrm{~m}$. (b) Modelled geoid height anomaly using a lower mantle density structure derived from seismic tomography and a radial viscosity profile with a factor 10 increase across the $670 \mathrm{~km}$ discontinuity. (c) Predicted dynamic topography at the Earth's surface assuming a global water-load; contoured every 250 m. (d) Predicted vertical deflections of the core-mantle boundary (CMB); contoured every $500 \mathrm{~m}$.

ages were produced, mapping variations in shear-wave and bulk sound velocities throughout Earth's mantle (Dziewonski \& Anderson, 1984). In particular, underlying the geoid highs, two large, spherical harmonic degree 2 patches of slower than average shear wave velocities were observed in the lower mantle, now termed Large, Low-Velocity Provinces or LLVPs (Garnero et al., 2016). The simplest interpretation of these features is that they represent hotter-than-ambient, buoyant material that is rising, causing corresponding upwards deflections of the surface and core-mantle boundary $(\mathrm{CMB})$ and generating the observed non-hydrostatic geoid anomalies (Figure 3). In a seminal paper, Hager et al. (1985) tested this hypothesis using a spectral approach to calculate the solution of the instantaneous mantle flow field. A series of depth-varying sensitivity kernels, based upon Green's functions, are derived for the surface topography, CMB deflections and geoid undulations that depend upon the magnitude of relative jumps within a radial viscosity profile, but not the absolute viscosity (Forte \& Peltier, 1991). These kernels vary as a function of wavelength (or spherical harmonic degree) of the density anomaly that is driving viscous flow. As a general rule, short-wavelength dynamic topography kernels have sensitivity to density structure within the asthenosphere and upper mantle, whilst the longest wavelengths also show sensitivity to features in the lower mantle. For their density structure, Hager et al. (1985) used an early lower mantle Pwave tomography model that was linearly scaled into density variations. For any input radial viscosity profile, the resulting sensitivity kernels are convolved with this density model to predict geoid height variations. A satisfactory fit to geoid observations was obtained by adjusting the radial viscosity profile to have a factor of 10 increase at $670 \mathrm{~km}$ from the up-
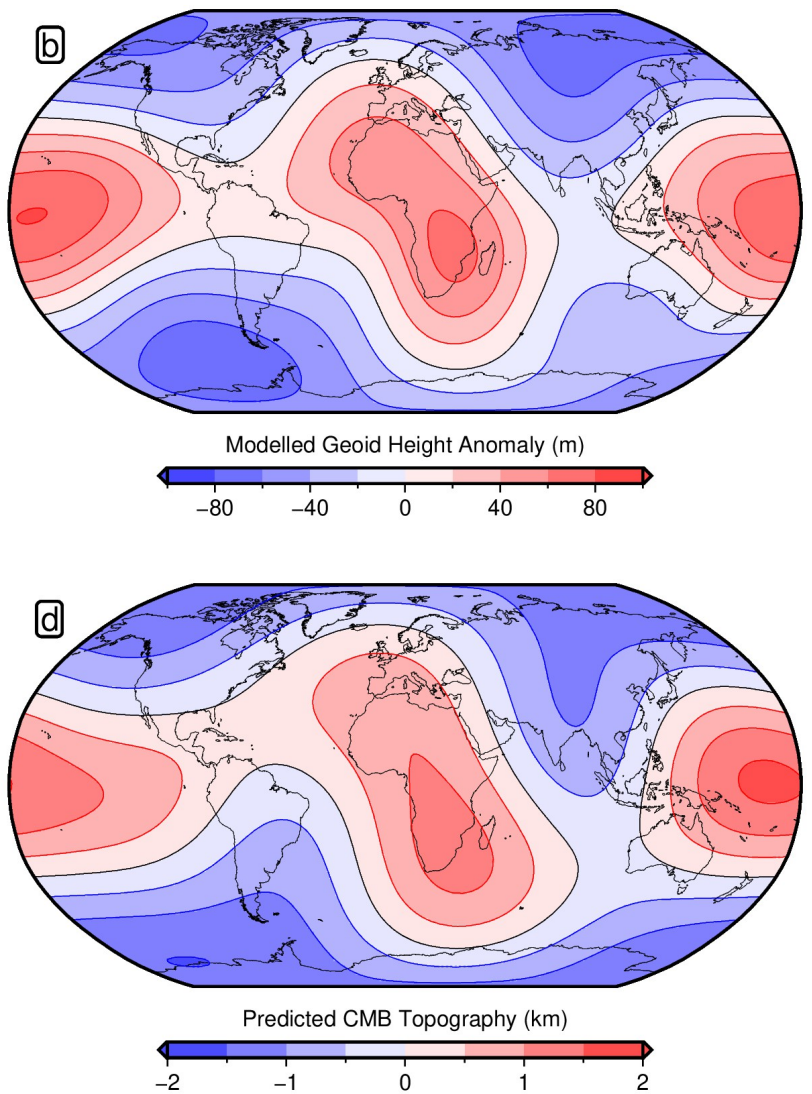

per into the lower mantle, which simultaneously yielded the first predictions of dynamic topography and CMB deflections arising from lower mantle flow (Figure 4). The predicted dynamic topography exhibits a dominant spherical harmonic degree 2 structure, with $\sim 1 \mathrm{~km}$ highs over Africa and the Pacific Ocean, ringed by $-1 \mathrm{~km}$ lows.

Many important theoretical advances have been made since this initial study. Mantle density models have been constructed based on updated seismic tomography models and conversion factors, assimilation of slab subduction histories from plate reconstructions, or a combination of both (e.g. Ricard et al., 1993; Conrad \& Husson, 2009; Spasojević \& Gurnis, 2012). The spectral instantaneous flow methodology has been improved to include the effects of self-gravitation and compressibility (Corrieu et al., 1995; Forte, 2007). Switching to fully numerical, time-dependent codes has allowed lateral variations in viscosity to be incorporated into the flow field (Zhong \& Davies, 1999). This move has also allowed the temporal evolution of mantle convection to be explored using forward, backward, and adjoint approaches (e.g. Gurnis et al., 1998; Conrad \& Gurnis, 2003; Bunge et al., 2003; Glišović \& Forte, 2014; Li et al., 2017; Colli et al., 2018). This development has the added bonus of allowing reconstructed plate velocities to be built in as boundary conditions, providing sensitivity to values of absolute mantle viscosity (LithgowBertelloni \& Richards, 1998; Gurnis et al., 2000; Bower et al., 2015; Glišović \& Forte, 2015). As a consequence, predictive models of present-day dynamic topography have steadily evolved. Although the shape of the dominant spherical harmonic degree 2 pattern is fixed by the requirement to fit the observed geoid, predicted peak amplitudes vary between \pm 1 $3 \mathrm{~km}$ between different models (Flament et al., 2013). One 
corollary of this long-wavelength pattern is that, as plates translate across the surface or the planform of convection evolves, predicted rates of vertical motion are slow (typically $\sim 0.01 \mathrm{~mm} \mathrm{yr}^{-1}$; Lithgow-Bertelloni \& Gurnis, 1997). However, despite these various computational and theoretical advances, there remains considerable non-uniqueness in model solutions that arises from trade-offs between parameters controlling buoyancy sources and those that govern rheological properties. These uncertainties emphasise the necessity of obtaining additional observational constraints to test predictive models.

\section{Estimating present-day dynamic topography}

The majority of predictive flow models of global dynamic topography are driven by convection in the sub-lithospheric mantle (processes $b$ and $c$ in Figure 1). In order to test them, observational constraints on present-day dynamic topography are required. A significant challenge in making these estimates arises from the requirement to remove the effects of lithospheric isostasy (process $a$ in Figure 1) from the observed topography. Given that this process often dominates surface topography, accurate and detailed knowledge of crustal and lithospheric density structure is required to successfully remove it (Guerri et al., 2015). Efforts to isolate isostatic topography from onshore elevations are hampered by the long-lived and complex geological histories of continents, which have resulted in complicated lithospheric architectures. For example, chemical depletion arising from melt extraction early in the Earth's history increased the buoyancy of residual lithospheric mantle (Jordan, 1978). To date, attempts to observe the pattern of present-day dynamic topography in the oceanic realm have proven more fruitful due to its relative geological youthfulness and simpler lithospheric density structure.

\subsection{Oceanic residual depth anomalies}

The first-order control on oceanic bathymetry is the pattern of subsidence with increasing age as plates spread laterally away from mid-ocean ridges. Many studies have focussed on this behaviour, and it is generally accepted to be driven by the progressive growth of a thermal boundary layer (Turcotte \& Oxburgh, 1967; McKenzie, 1967). As two plates separate at a mid-ocean ridge, hot asthenospheric material passively upwells and spreads laterally through time. Conductive heat loss through the surface steadily cools this material, increasing its density and thickening the lithosphere, which drives subsidence (Parsons \& Sclater, 1977). This process (panel $a$ in Figure 1) is clearly a consequence of mantle convection and this topographic component driven by thickening of oceanic lithosphere is therefore sometimes included in dynamic topography maps (e.g. Forte et al., 1993). However, it tends to dominate over bathymetric expressions caused by sub-lithospheric buoyancy and flow (processes $b$ and $c$ in Figure 1), so many maps of dynamic topography remove the average age-depth subsidence trend in order to isolate residual topographic anomalies (e.g. Cazenave et al., 1988; Panasyuk \& Hager, 2000).

We will focus on these sub-plate contributions to dynamic topography throughout the rest of Section 3.1, although there are a couple of important caveats that should be noted. First, the age-depth subsidence correction typically approximates local lithospheric isostasy with that expected for average oceanic lithosphere of equivalent age obtained from a thermal evolution model. Topography caused by regional lithospheric thickness variations away from this average background trend, such as thinning above a hot upwelling or thickening above a cold downwelling, will therefore still be present within residual depth estimates. Thus, residual bathymetry is likely to represent a maximum bound on the amplitude of deflections arising from deeper mantle flow (Hoggard et al., 2017). Secondly, there are multiple options for the choice of lithospheric cooling model including half-space, plate cooling, and thermal boundary layer instability models, which predominantly differ in whether and by what mechanism heat is resupplied to the base of the lithosphere as it ages (Korenaga \& Korenaga, 2008; Richards et al., 2020a; Crosby et al., 2006). These models yield similar results in lithosphere younger than $\sim 70 \mathrm{Ma}$, but residual depth anomalies can deviate by up to $\sim 1 \mathrm{~km}$ in the oldest parts of ocean basins (Zhong et al., 2007; Hoggard et al., 2016).

Notwithstanding these issues, Menard (1965) was the first to link anomalous bathymetric variations in the oceans to the vertical deflections expected from mantle convection. He identified several prominent mid-plate rises as likely surface expressions of sub-plate convection cells (Menard, 1969). In addition to age-depth subsidence, a component of oceanic bathymetry is controlled by flexural and isostatic responses to sedimentary loading, crustal thickness variations, and subduction zones. Correcting bathymetric data for these processes yields a map of residual depth anomalies that can be regarded as a proxy for present-day dynamic topography (Menard, 1973). Early attempts to map these anomalies were focused on central areas of large ocean basins where sediments are generally thinner, reducing uncertainty in sedimentary loading corrections (Cochran \& Talwani, 1977). The largest limitation on the accuracy of residual depth maps for many years was the absence of a correction for variable crustal isostasy, primarily due to the lack of accurate global grids of oceanic crustal thickness. However, a shift in focus from global grids to spot measurements at the sites of marine seismic experiments, where crustal thickness can be mapped in high resolution, has significantly reduced this uncertainty (Winterbourne et al., 2009, 2014).

The latest compilations include $\sim 2000$ seismic experiments of varying ages from a mixture of hydrocarbon industry and academic sources (Hoggard et al., 2017). There is good coverage on most passive margins and along active subduction zones, with scarcer spot measurements in central portions of the major basins due to a paucity of distal experiments. Fortunately, the generally thinner sedimentary cover in these regions results in lower uncertainty in global grids of sedimentary thickness in comparison to passive margins and major river deltas. Therefore the most accurate spot measurements are usually supplemented in distal settings with gridded residual depth estimates derived from these global compilations. Uncertainty arising from the absence of a correction for variable crustal isostasy in these grids has been partially mitigated by removing oceanic lithosphere that is clearly anomalous, such as at major fracture zones and seamounts, using high resolution bathymetry and gravity anomaly maps. Resulting sediment and crustal-corrected observations measure the difference in the observed depth of basement below the sea surface, compared to its expected depth from age-depth subsidence curves. However, an additional factor to consider is that the sea surface follows the geoid, which is also deflected by mantle convection. Therefore a final correction for height of the local geoid with respect to its hydrostatic equilibrium figure is applied, which is typically on the order of $100 \mathrm{~m}$ (Hoggard et al., 2017).

Our latest maps of oceanic residual topography with agedepth subsidence trends removed reveal striking patterns, particularly along passive margins with good data coverage (Figure 5). Rather than the spherical harmonic degree 2 

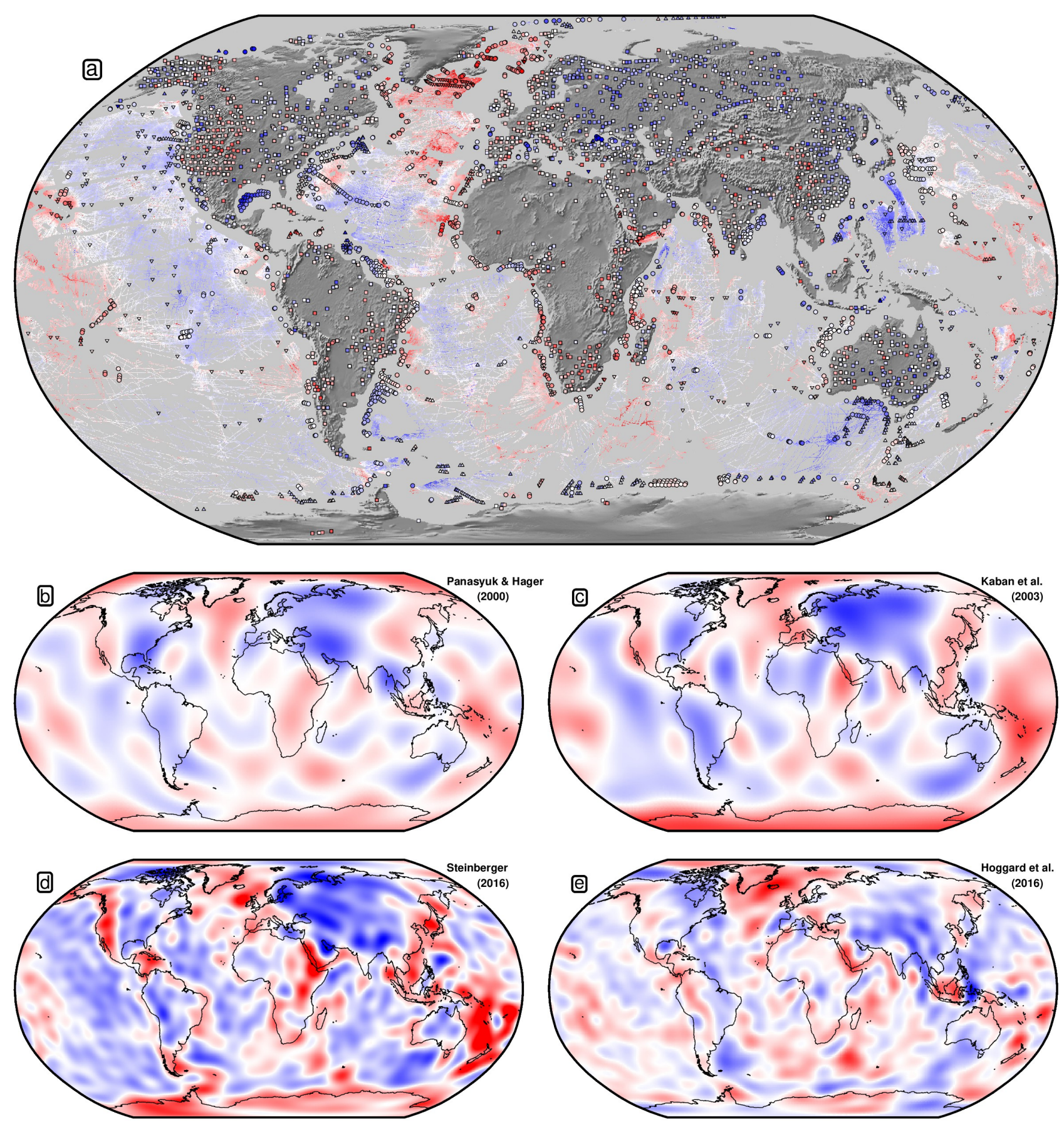

Residual Topography $(\mathrm{km})$

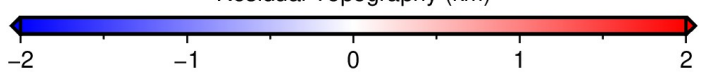

Figure 5: Estimates of present-day residual topography. All maps are air-loaded in the continents and water-loaded in the oceans, where the correction for age-depth subsidence assumes a plate or plate-like cooling model (i.e. flattening at old ages). These residuals are considered a proxy for dynamic topography caused by convection in the sub-lithospheric mantle (processes $b$ and $c$ in Figure 1). However, inaccurate removal of lithospheric isostasy (process $a$ in Figure 1) may also be present, alongside any other data errors. (a) Oceanic data from Hoggard et al. (2017), updated using the RHCW18 plate cooling curve and oceanic age model (Richards et al., 2018); circles = spot measurements with geoid height, sedimentary and crustal corrections; upwards/downwards pointing triangles $=$ minimum $/$ maximum spot measurements where no crustal correction has been made but its sign is estimated from nearby crustal thickness measurements; grid = shiptrack-derived measurements with no crustal correction. Squares $=1915$ new onshore spot estimates derived from seismic experiments and corrected for crustal and lithospheric isostasy (Section 3.2). (b) Panasyuk \& Hager (2000), expanded to a maximum spherical harmonic degree, $l_{\max }$, of 12 (Steinberger, 2007). (c) Kaban et al. (2003), expanded to $l_{\max }=12$ (Steinberger, 2007). (d) Steinberger (2016), expanded to $l_{\max }=31$. (e) Hoggard et al. $(2016)$, expanded to $l_{\text {max }}=30$.

pattern anticipated from predictive flow models of dynamic topography (e.g. Figure 4c), the residual anomalies are significantly more variable, often changing over $\sim 1000 \mathrm{~km}$ wavelengths. The highest water-loaded amplitudes reach $+2 \mathrm{~km}$ in the vicinity of major magmatic hotspots such as Iceland, Afar and Cape Verde. The deepest drawdowns of $-2 \mathrm{~km}$ are generally, but not exclusively, associated with back-arc set- tings above subducting slabs, such as the Banda Sea, western Gulf of Mexico, and Argentine abyssal plain. Away from these areas, residual depth anomalies exhibit typical amplitudes of $\pm 1 \mathrm{~km}$. A particularly noteworthy example comes from the southwestern margin of Africa, where spot measurements capture at least two coherently varying $\pm 1 \mathrm{~km}$ cycles with $1500 \mathrm{~km}$ wavelengths along strike of the margin (Win- 
terbourne et al., 2009; Hoggard et al., 2017).

The broad characteristics of these anomalies were evident even in the earliest studies of oceanic residual topography (Menard, 1973; Cochran \& Talwani, 1977; Cazenave et al., 1988). However, the steady inclusion of higher accuracy measurements of sedimentary and crustal thickness, in combination with more formalised error propagation, has greatly improved resolution and reduced the associated uncertainties. At present, for the spot observations of Hoggard et al. (2017), the median size of the water-loaded crustal correction is $\sim 200 \mathrm{~m}$, which has propagated uncertainties of $\pm 70 \mathrm{~m}$, but can locally be as large as $800 \pm 150 \mathrm{~m}$ in regions of very thick oceanic crust such as around Iceland. The median waterloaded sedimentary correction is $\sim 1.25 \mathrm{~km}$, with uncertainty of $\pm 50 \mathrm{~m}$ for data obtained from seismic reflection profiles collected in two-way travel time (when uncertainty in porosity compaction parameters is minimised). The sedimentary loading correction is therefore typically larger than the crustal correction, but can vary from zero in sites with no sediment cover right up to $6.0 \pm 0.5 \mathrm{~km}$ on the most heavily-sedimented passive margins, where it dominates uncertainty estimates of oceanic residual topography.

\subsection{Continental residual topography}

Removal of isostatic topography arising from continental lithosphere (process $a$ in Figure 1) requires constraints on its density structure that have largely been obtained from seismology. Active source experiments such as reflection or wide-angle refraction profiles yield information on the local sub-surface velocity structure and major boundary depths including the sediment-basement interface and Moho (Mooney, 2015). Passive seismological methods are also widely used. For example, receiver function studies provide layer thicknesses and $\mathrm{V}_{P} / \mathrm{V}_{S}$ ratios beneath the site of seismometers, and combined inversion with surface wave data mitigates some of the trade-offs between these parameters (e.g. Julià et al., 2009). On a more regional scale, seismic tomography can constrain the broad velocity structure of the lithosphere. Higher resolution studies often combine body wave arrivals with fundamental and higher modes of surface waves, which are particularly sensitive to upper mantle structure (e.g. Schaeffer \& Lebedev, 2013). Resultant maps of seismic velocity are subsequently converted into density using a variety of laboratory-based calibrations, although these conversions are subject to considerable uncertainty arising from factors including the effect of minor phases such as water or melt on velocities, anisotropic fabrics, anelasticity, and the frequency content of seismic sources (e.g. Brocher, 2005; Jackson \& Faul, 2010; Yamauchi \& Takei, 2016). Final density maps can be calibrated using observed gravity anomalies, although the high non-uniqueness of this technique means that it is of limited use in isolation (Cowie et al., 2015; Afonso et al., 2019).

Some studies have used global grids of crustal thickness and density compiled from local spot measurements to generate continuous maps of continental residual topography (e.g. Pari \& Peltier, 2000; Panasyuk \& Hager, 2000; Steinberger et al., 2019). Here however, we deliberately return to the original spot measurements in order to avoid using areas in the global grids that are poorly constrained due to a lack of input data (following Davis et al., 2012). We adopt a simple isostatic approach to calculating continental residual topography using a global compilation of 11,062 local crustal thickness estimates derived from a mixture of active and passive seismic experiments (Szwillus et al., 2019, and other sources). The isostatically corrected elevation, $e_{c o r r}$, at each location is given by

$$
e_{c o r r}=e_{o b s}-\left(\frac{\rho_{a}-\overline{\rho_{c}}}{\rho_{a}}\right) z_{c}-\left(\frac{\rho_{a}-\overline{\rho_{l}}}{\rho_{a}}\right) z_{l}
$$

where $e_{o b s}$ is the observed elevation, $\rho_{a}=3200 \mathrm{~kg} \mathrm{~m}^{-3}$ is the density of asthenospheric mantle, $\overline{\rho_{c}}$ is the bulk density of crust with thickness $z_{c}$, and $\overline{\rho_{l}}$ is the bulk density of lithospheric mantle with thickness $z_{l}$. The bulk crustal density is obtained by integrating the interval density profile of Christensen \& Mooney (1995), extended beyond $40 \mathrm{~km}$ up to $50 \mathrm{~km}$ depth using a constant value of $3100 \mathrm{~kg} \mathrm{~m}^{-3}$. Crustal thickness measurements above $50 \mathrm{~km}$ have been rejected due to growing uncertainty in this crustal density. Lithospheric thickness is taken from the global grid of Hoggard et al. (2020), which is derived from the SL2013sv surface wave tomography model (Schaeffer \& Lebedev, 2013). The bulk lithospheric density is given by

$\overline{\rho_{l}}= \begin{cases}3250 \mathrm{~kg} \mathrm{~m}^{-3} & {\left[z_{c}+z_{l}\right] \leq 100 \mathrm{~km}} \\ 3280-0.0003\left[z_{c}+z_{l}\right] \mathrm{kg} \mathrm{m}^{-3} & 100<\left[z_{c}+z_{l}\right]<300 \\ 3190 \mathrm{~kg} \mathrm{~m}^{-3} & {\left[z_{c}+z_{l}\right] \geq 300 \mathrm{~km}}\end{cases}$

which approximates the effect of temperature-dependent density variations and increasing chemical depletion in thick lithosphere (Jordan, 1978). We convert corrected elevation to residual topography by subtracting the median value of the entire dataset, which assumes that the sub-lithospheric components of dynamic topography (processes $b$ and $c$ in Figure 1) average to zero in the continents, and spatially average the results by taking the median value within $2^{\circ} \times 2^{\circ}$ bins. Finally, we add the correction for non-hydrostatic geoid deflections introduced in Section 3.1.

The resulting dataset of 1915 onshore points is shown in Figure $5 \mathrm{a}$ and has typical air-loaded amplitudes of $\pm 2 \mathrm{~km}$. It is substantially noisier than the oceanic residual depths, which is a direct result of the larger uncertainties in crustal and lithospheric thickness and density structure, particularly for measurements obtained from receiver functions. The sensitivity of results to each of these parameters can be tested by propagating a realistic range of uncertainties through Equation (4). Random $10 \%$ errors in crustal thickness produce typical residual topography changes of approximately $\pm 400 \mathrm{~m}$, whilst the same errors in lithospheric thickness produce $\pm 150 \mathrm{~m}$. Crustal densities probably vary by at least $\sim 100 \mathrm{~kg} \mathrm{~m}^{-3}$ (Guerri et al., 2015), which introduces $\pm 1.1 \mathrm{~km}$ residual topography changes, whilst $30 \mathrm{~kg} \mathrm{~m}^{-3}$ local variations in the density of the lithospheric mantle yield $\pm 1.3 \mathrm{~km}$ changes. Thus it seems that continental residual topography results are particularly sensitive to the choice of densities for the crust and lithospheric mantle, and a more time consuming yet improved approach could exploit additional information, such as the local seismic velocity structure, to estimate these parameters (e.g. Brocher, 2005).

These overly simplistic continental residual topography estimates are less robust than their oceanic counterparts because they are severely hampered by uncertainty in the corrections for crustal and lithospheric isostasy (Guerri et al., 2015). Furthermore, they do not account for flexural loading effects that may occur around sites of volcanic emplacement or erosion and removal of crustal material (Sembroni et al., 2016). However, they do illustrate the great value of local seismic experiments and reveal that the current spatial coverage is fairly good, except for in Africa and in the vicinity of major ice caps (Figure 5). 

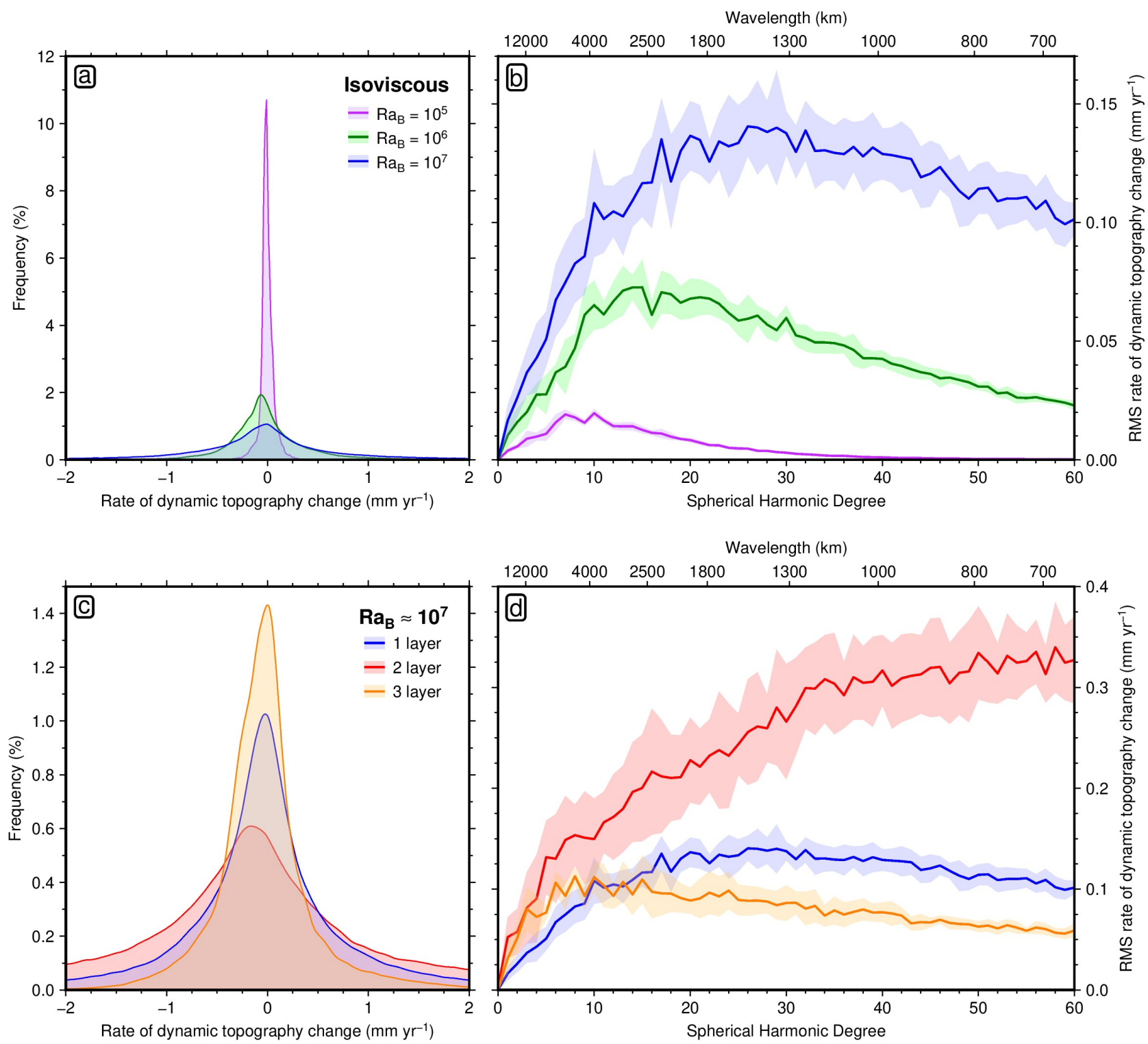

Figure 6: Rates of air-loaded dynamic topography change from simple convection simulations shown in Figure 2. Rates are calculated as changes in dynamic topography using Equation (3) between timesteps, which includes all five mechanisms $e-i$ from Figure 1. Note that these simulations do not include mechanism $d$ of Figure 1, since the reference frame is external to the mantle such that observation points are fixed in space and do not track across the surface at plate velocities. (a) Histogram of area-normalised rate of change of dynamic topography in the spatial domain for isoviscous runs at $R a_{B}=10^{5}, 10^{6}$ and $10^{7}$ (Figures 2a- 2c). (b) Spectral decomposition of field of evolving dynamic topography, labelled with equivalent wavelengths at the surface. (c) and (d) Same for runs with $R a_{B} \approx 10^{7}$ for isoviscous mantle, two-layer mantle with factor of 30 viscosity jump across $670 \mathrm{~km}$ boundary, and a three-layer mantle including a $100 \mathrm{~km}$ lithospheric lid that is 1000 times more viscous than the underlying upper mantle (Figures 2c-2e). Data are included in the associated OSF database.

\section{Observational estimates of time-evolving dynamic topography}

In addition to constraining the absolute amplitude of dynamic topography at the present day, accurate measurements of its rate of change provide important insights into the dynamics of convection and rheological properties of the mantle. We can illustrate this phenomenon using the simple convection simulations from Section 1.3. For isoviscous runs, increasing the Rayleigh number causes higher rates of vertical motion that are dominated by increasingly shorter wavelengths (higher spherical harmonic degrees; Figures $6 \mathrm{a}$ and $6 \mathrm{~b}$ ). Introducing a low viscosity upper mantle over a higher viscosity lower mantle has a similar effect, with rates of vertical motion increasing (Figures $6 \mathrm{c}$ and $6 \mathrm{~d}$ ). In contrast, when a high viscosity lithospheric lid is also added, the rate of change of dynamic topography is reduced and the spectral properties flatten significantly. Thus, inferring rates of dynamic topography from observational constraints is an important problem in geodynamics that yields information concerning the fluid dynamical properties of Earth's interior.

Investigating the temporal evolution of dynamic topography requires identification of markers that can track changes in elevation. Despite the difficulty in isolating absolute amplitudes of present-day dynamic topography in continetal areas, the onshore geological record does contain many useful recorders of changing vertical motion, provided that sufficiently accurate dating can be carried out (Figure 7). However, a significant interpretational challenge involves isolating the desired signal from other geological processes. Relative changes between local sea level and the solid Earth can also result from active tectonics, volcanic emplacement, sedimentation, eustatic sea-level variations, and ongoing glacial isostatic adjustment (GIA). Careful analysis of the total amplitude, rate, duration, and spatial extent of uplift and subsidence events yields insights into the relative contributions of these different driving mechanisms (Miller et al., 2005; Lovell, 
2010).

\subsection{Satellite observations}

The advent of the satellite-era has led to two promising new avenues for constraining present-day changes in dynamic topography. Firstly, the earliest satellites for the Global Positioning System (GPS) were launched in the late 1970s, and the system became widely available for civilian use in the 1990s (Bock \& Melgar, 2016). GPS allows for the direct measurement of both horizontal and vertical ground motion with respect to Earth's centre of mass. Decadal rates of motion have been obtained from stations that are either continuously recording or are repeatedly visited as part of campaigns (e.g. Feigl et al., 1993). Hunting for signals associated with dynamic topography is aided by avoiding locations where other processes are likely to dominate, including regions that are actively deforming via earthquakes and faulting, such as at plate boundaries, or locations that are near obvious local loading changes, such as in the vicinity of volcanoes, river deltas and groundwater reservoirs (Bock \& Melgar, 2016). However, ongoing viscoelastic deformation of the solid Earth in response to the evolving ice-water loads of glacial cycles is a global phenomenon and unfortunately cannot be avoided in this manner (Farrell \& Clark, 1976). Although the most significant GIA-induced changes occur in the vicinity of glaciated regions, modelled present-day rates of vertical motion from the last glacial period are still $\pm 0.5 \mathrm{~mm} \mathrm{yr}^{-1}$ at far-field sites, which is an order of magnitude larger than typical rates expected for dynamic topography (Milne et al., 2001; Mitrovica \& Milne, 2002). Thankfully, the spatial pattern of GIA motions is well-understood and quite distinct from expectations for dynamic topography. Nevertheless, GIA models with highly accurate ice histories and viscoelastic mantle structure are essential before secondary signals associated with mantle convection might be reliably extracted. Obtaining such models is an area of considerable ongoing research (e.g. Whitehouse, 2018), and so GPS rates are yet to be exploited to constrain Earth's dynamic topography.

The second relevant satellite-derived observation is temporal evolution of the gravity field, which has been recorded by the GRACE mission over the period 2002-2017. This dataset has been successfully used to quantify mass changes associated with ice melting, hydrological cycles, and postseismic deformation following large earthquakes (e.g. Shepherd et al., 2012; Crowley et al., 2006; Han et al., 2006; Chao \& Liau, 2019). Mantle convection simulations predict associated long-wavelength changes in geoid height to occur at rates of $\sim 0.005 \mathrm{~mm} \mathrm{yr}^{-1}$, which is close to, but unfortunately just below the threshold of detection for GRACE (Ghelichkhan et al., 2018). Future gravity missions in the coming decade should lower this measurement threshold and potentially allow investigation of evolving dynamic topography, again provided that these signals can be successfully isolated from larger contributions associated with GIA and hydrology.

The great value of obtaining signals associated with evolving mantle convection from GPS and satellite-gravity is the high resolution spatial coverage afforded by these datasets. The limit for GPS comes down to on-the-ground station spacing, which in continental areas is easily shorter than the $\sim 500 \mathrm{~km}$ length scales associated with dynamic topography. The horizontal resolution of satellite gravity depends both on flight path spacing and the orbital elevation, as short-wavelength signals attenuate more quickly with measurement height (Wahr et al., 1998). The $\sim 500 \mathrm{~km}$ orbit height for GRACE and its follow-on missions should be sufficient for observing expected mantle convection signals. How- ever, the principal issue to date with both of these datasets is the short duration of their observation windows. Thus long-term dynamic topography signals operating on millionyear timescales are dwarfed by faster, shorter duration processes such as GIA and hydrologic cycles. In order to isolate changes caused by mantle convection, we must turn to longer-duration markers of vertical motion from the geological record.

\subsection{Sea-level markers}

The clearest elevation marker in the geological record is sea level, which marks a transition between the broadly erosive onshore regime and the predominantly depositional offshore environment. Morphological features such as wave-cut platforms, sea cliffs, marine terraces, and beach deposits form in a narrow palaeo-elevation band (Lyell, 1830). The same is true for biological markers such as coral reefs and other marine fauna that grow in shallow water (Darwin, 1842). Postformation uplift or subsidence therefore yield measurements of the relative change of sea level with respect to land, and can be converted into rates of relative vertical motion providing that these features can be dated.

Some of the earliest and best constraints on long-term vertical motion of the continents have come from observations of exposed marine sediments. In a seminal paper, Bond (1978b) used the position of several Cretaceous, Eocene, and Miocene shorelines in different continents to constrain the extent of continental flooding at these times. In combination with the present-day distribution of topography within each continent (known as hypsometry), they were able to separate global variations in relative sea level seen simultaneously on all continents from local changes arising from differential vertical motions. Distinct subsidence and uplift events were indicated for Europe, Australia, North America, and Africa (Bond, 1978a, 1979). This approach was extended by Sahagian (1988), who considered nearshore or low-elevation sediments in addition to purely shoreline deposits in an attempt to reconstruct the full two-dimensional surface representing Cenomanian ( $\sim 95 \mathrm{Ma})$ sea level in Africa. This surface is now locally warped by up to $3 \mathrm{~km}$ of topography, including a series of $\sim 800 \mathrm{~km}$ diameter amagmatic and magmatic domes that are located far from recognised plate boundaries.

The first-order features of these global flooding and uplift histories have been successfully modelled using mantle convection simulations, as well as higher-level details in specific locations such as Australia, southeast Asia, and north Africa (Gurnis, 1993; Lithgow-Bertelloni \& Gurnis, 1997; Heine et al., 2010; Matthews et al., 2011; Zahirovic et al., 2016; Barnett-Moore et al., 2017; Cao et al., 2019). One of the most iconic examples of dynamic topography controlling the distribution of stranded marine rocks occurs in North America. Here, $\sim 3 \mathrm{~km}$ of Late Cretaceous subsidence caused westward tilting of a $1400 \mathrm{~km}$ wide region and produced a marine depocentre, known as the Western Interior Seaway, that subsequently rebounded in Cenozoic times (Sloss, 1963; Bond, 1976). The gradual lateral thickening and widespread nature of these sediments rules out standard basin forming processes alone, such as rifting or flexural loading, instead necessitating dynamic drawdown above the eastwardsubducting Farallon slab (Cross \& Pilger, 1978; Mitrovica et al., 1989). The subsequent rebound is attributed to passage of North America over the shallower parts of the slab and eventually its rear edge, and the broad pattern and timing of sedimentation has been successfully matched by models of mantle flow (Mitrovica et al., 1989; Burgess et al., 1997; Liu et al., 2008; Spasojević et al., 2009).

It is important to consider a couple of significant caveats in 
interpretation of sea-level markers. One complication is that each marker only constrains the integrated uplift or subsidence since its time of formation. For example, a Cretaceous marine limestone found $500 \mathrm{~m}$ above modern sea level indicates a minimum of $500 \mathrm{~m}$ of cumulative uplift has occurred since Cretaceous times. The actual history of vertical motion may be substantially more complicated, consisting of a non-uniform uplift rate or even multiple cycles of uplift and subsidence (Roberts et al., 2018; Conway-Jones et al., 2019). For this reason, to place tighter constraints on the temporal evolution of vertical motion at a given location, a series of sea-level markers are desirable that have various ages and therefore cover a range of durations (e.g. Fernandes et al., 2019; Fernandes \& Roberts, 2020).

A further issue is that there are variations in global mean sea level that are driven by changes in the volume of ocean basins and the mass of ice sheets through time. These processes will generate changes in eustatic sea level of up to $\sim 300 \mathrm{~m}$, even in locations where the solid Earth undergoes no vertical motion. For example, estimated eustatic variations resulting from variable sea-floor spreading rates and associated ocean volume changes are controversial but are believed to have amplitudes on the order of $\pm 100 \mathrm{~m}$, based upon analysis of both sea-floor age distributions and passive margin stratigraphy from ice-free periods such as the mid-Cretaceous (e.g. Rowley, 2002; Miller et al., 2005; Müller et al., 2008). Meanwhile, the total eustatic sea level rise associated with ice melt between the last glacial maximum and today is $\sim 130 \mathrm{~m}$ (e.g. Austermann et al., 2013). This is in addition to remaining present-day ice that is thought to have a volume equivalent to $\sim 74 \mathrm{~m}$ of further eustatic sea level rise when spread uniformly over the area of present-day oceans (Peltier et al., 2015). In the absence of tight constraints on sea level at time of formation, large amplitude, long duration recorders of relative vertical motion therefore yield dynamic topography rates that are the least affected by these eustatic uncertainties.

Over short timescales (durations less than $\sim 3$ Myr), the typical amplitude of dynamic topography change is expected to be outweighed by glacial isostatic effects. Despite this issue, however, the relative ubiquity and enhanced preservation of recent sea level markers from Quaternary and Neogene interglacial periods has led to several attempts to extract elevation components associated with evolving dynamic topography. For example, dynamic topographic signals act in addition to GIA effects in warping Pliocene shorelines on the eastern US, southern African, and southern Australian coastlines (Moucha et al., 2008; Müller et al., 2008; Rowley et al., 2013; Flament et al., 2013; Rovere et al., 2014, 2015). In a global analysis, Austermann et al. (2017) found that this signal can also be detected in the elevations of shorelines from the last interglacial period $(\sim 125 \mathrm{ka})$, as has recently been confirmed in a local study from northern Madagascar (Stephenson et al., 2019). Concentrated investigation of continental margins exhibiting flights of marine terraces of variable age should greatly elucidate the temporal resolution and reduce uncertainties on uplift rate histories.

\subsection{Sedimentary flux and the stratal architecture of basins}

Relative sea level changes also influence the supply of clastic material into the offshore and the large-scale stratal architecture of sediments in basins. Pulses of high sedimentary flux occur at times of increased uplift, whilst topographic quiescence suppresses the supply of clastic material to river deltas, promoting the growth of carbonates (Lavier et al., 2001; Walford et al., 2005; Richards et al., 2016). Provided that the rules governing stratigraphic relationships can be understood, sedimentation patterns can be further used to investigate long-term vertical motion and infer evolving dynamic topography at sites of sediment deposition (e.g. Eakin \& Lithgow-Bertelloni, 2018). Diagnostic stratigraphic patterns develop primarily in response to a competition between changes in the available accommodation space versus the rate at which sediment is supplied to infill (Beelen et al., 2019). This latter component leads to slightly different behaviour in settings that are dominated by deposition of siliciclastic versus carbonate sediments.

In clastic systems, sedimentation is controlled by the external supply of material eroded onshore and transported by rivers. When influx is high, such as at large deltas, sediments infill available accommodation space up to wave base. If accommodation space remains constant, this results in progradation, as new material can only be deposited on the leading edge of the delta and the sedimentary packages build outwards into more distal areas (Catuneanu, 2006). A relative drop in sea level also causes sediment depocentres to move further out into deeper water, accompanied by erosion of older topset material that is now above wave base, and the development of unconformities with missing section. These features can be highly angular and often cover large areas of the basin or shelf. Significant examples from uplifting passive margins have been found off Angola, South Africa, and west India (Al-Hajri et al., 2009; Baby et al., 2018; Richards et al., 2016). Conversely, a relative sea level rise increases accommodation space and produces aggradation as sediments build upwards. The difference in sediment-starved settings is that insufficient material is available to infill this new space, resulting in a proximal shift of the depocentre known as retrogradation. Analysis of these cyclical sedimentation patterns is called sequence stratigraphy and has been used to produce histories of relative sea-level change at various passive margins (Vail et al., 1977; Haq et al., 1987; Miller et al., 2005).

The principal difference in carbonate settings is that sedimentary material is grown in situ by various marine organisms rather than supplied externally (N.B. influx of clastic material generally tends to inhibit carbonate production). Euphotic and oligophotic biota (e.g. corals, stromatolites, formanaifera, algae) create flat-topped shelves because they grow in the photic zone, with their depth extent depending upon the penetration of sunlight (Pomar, 2001). In these settings, sediment supply rate is usually governed by the surface area of the shelf that occupies this photic zone. Stratal architectures associated with either constant or falling relative sea level are similar to clastic systems (Sarg, 1988). However, during increases in accommodation space, if growth rates cannot keep up with relative sea level rise, entire carbonate platforms can become drowned (Kendall \& Schlager, 1981). Such a process has been documented to have occurred at $\sim 9$ Ma across the entire Northwest Shelf of Australia (Czarnota et al., 2013). These sudden increases in accommodation space are sometimes associated with highstand carbonate shedding, whereby siginificant erosional channeling develops due to rapid vertical growth of platforms and reefs, as organisms try to keep up with the photic zone, leading to oversteepening and gravitational instability (Schlager et al., 2003). This is in contrast to clastic systems, where the formation of erosional gullies predominantly occurs during periods of low sea level.

One of the most striking manifestations of transient vertical motion occurs when shallow marine settings are uplifted above sea level and exposed to subaerial erosion, before subsiding back beneath the waves. This cycle results in 


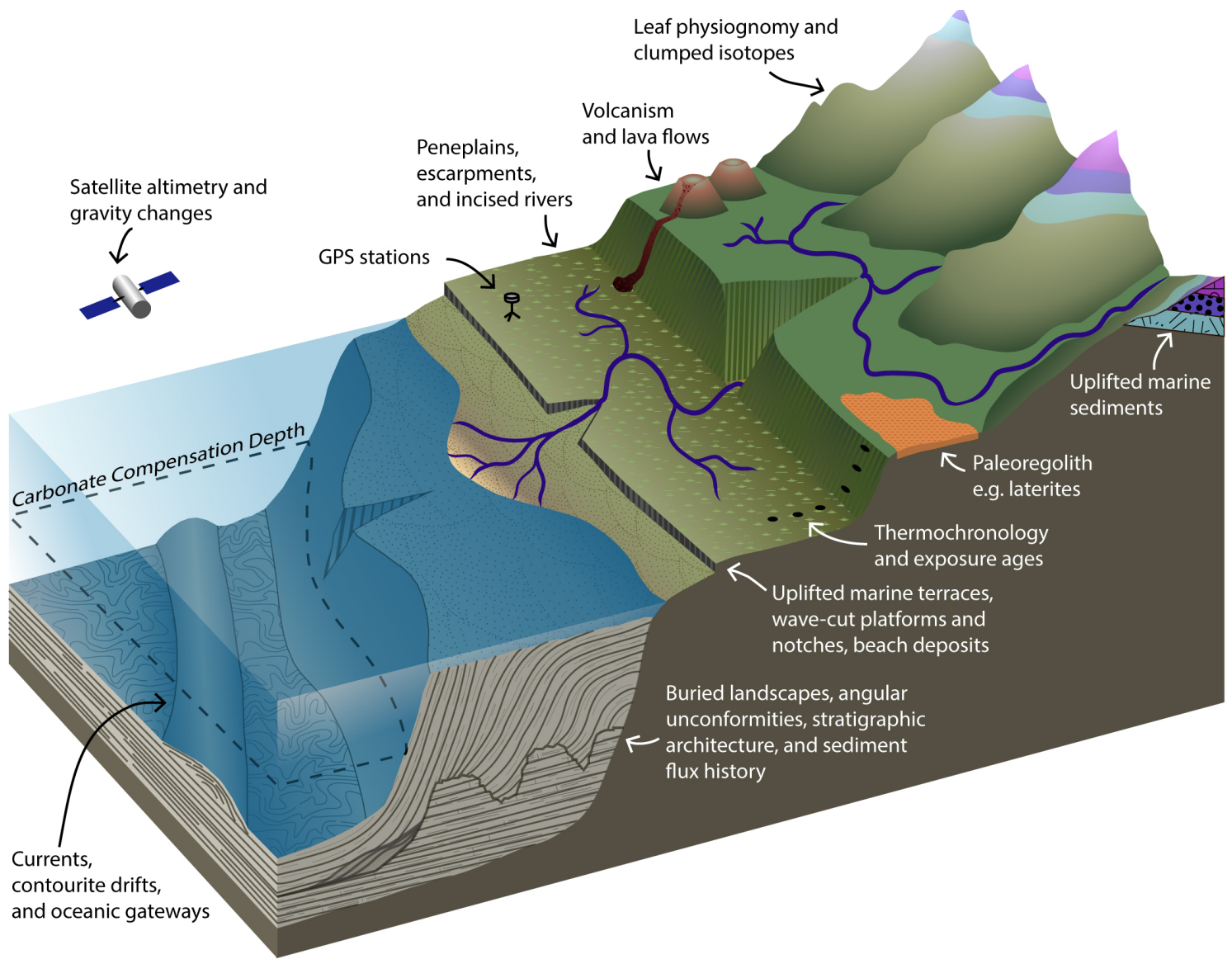

Figure 7: Geological observations recording a history of evolving relative vertical motion. This is a passive margin setting, but some of these techniques are applicable on active margins, in continental interiors, and in deep ocean basins. These features generally record relative changes between elevation of the land surface and sea level, except for GPS which measures solid Earth deformation alone. Care must be taken to separate eustatic variations in sea-level height from uplift and subsidence of the solid Earth. Cartoon is not drawn to scale.

ephemeral landscapes, whereby the initial marine sediments are often dissected by river channels, whose bases and deltas can contain terrestrial deposits such as coarse siliciclastics and coals, before a marine depositional setting is gradually restored. The height of any resulting valley incision places minimum bounds on the amplitude of uplift, whilst biostratigraphic dating of fossils either side of the unconformity places tight bookends on the event duration. Candidates for these landscapes have been observed in stratigraphy of the Grand Canyon in western USA, Bass Strait of Australia, and all across the North Atlantic region in the vicinity of the Icelandic plume (Billingsley \& Beus, 1999; Holdgate et al., 2003; Underhill, 2001; Smallwood \& Gill, 2002; Millett et al., 2016; Stucky de Quay et al., 2017). The most impressive of these occurs in the Faroe-Shetland Basin, where an Eocene uplift and subsidence event generated and infilled a fluvial landscape with $\sim 1 \mathrm{~km}$ of topography over a period of only 3 Myr (Hartley et al., 2011). The amplitude of this event is significantly larger than glacial-eustatic sea-level cycles, whilst its transient nature rules out other geological mechanisms that would result in permanent uplift, such as crustal thickening or magmatic underplating. The inferred vertical motion rates of $\sim 0.5 \mathrm{~mm} \mathrm{yr}^{-1}$ mark this landscape as one of the fastest examples of dynamic topography inferred from observational constraints. Furthermore, the rapidity of the subsidence phase rules out driving mechanisms involving the cooling of an asthenospheric temperature anomaly or thermal growth of the lithosphere (mechanisms $h$ or $i$ in Figure 1), as these processes operate on conductive timescales (at least 30 Myr for a $100 \mathrm{~km}$ thick layer of lithosphere or asthenosphere; McKenzie, 1978). Lateral advection of an astheno- spheric temperature anomaly from the proto-Icelandic plume beneath the basin is most compatible with these constraints (mechanism $f$ in Figure 1; Rudge et al., 2008). Observations of $\mathrm{V}$-shaped ridges of thickened crust down the Reykjanes oceanic spreading centre provide independent support for this Poiseuille-type flow within the Icelandic plume head (Vogt, 1971; Parnell-Turner et al., 2017).

\subsection{Peneplanation and palaeosurfaces}

A distinct advantage of reconstructing vertical motions to infer changes in dynamic topography in regions of drawdown is that they tend to be dominated by sediment deposition, often leading to continuous subsidence records. Conversely, constraining histories of vertical motion in locations of dynamic uplift is often challenging, as subaerial erosion acts to destroy the geological record. Nevertheless, when early geomorphologists explored the interiors of supposedly tectonically quiescent continents such as Africa, they found evidence for $1000 \mathrm{~km}$-scale doming of ancient erosional surfaces that appeared to be surprisingly youthful, based in part upon the ages of overlying marine strata (e.g. King, 1942). Whilst controversial at the time, it is now generally accepted that this basin-and-swell morphology can be directly attributed to convective circulation of the underlying mantle, with the clearest example of this expression occurring on the African continent (Burke \& Gunnell, 2008; Moucha \& Forte, 2011).

Stable continental interiors in both glaciated and nonglaciated areas often contain large, low relief surfaces that can be identified and mapped over large distances. These features are variably referred to as peneplains or pediplains and are attributed to former base levels at which erosion becomes 
negligible. Initially, the conceptual model of their formation involved a steady, simultaneous erosion of all hillslopes in a process analogous to diffusion (e.g. Davis, 1899, 1930). However, observed preservation of older relict surfaces in stepped terraces or isolated remnants, known as inselbergs and monadnocks, suggested that the dominant process is actually advective retreat of scarps, whereby erosion is concentrated in locations of steepest hillslope that backwear into the landscape (King, 1953).

The simplest interpretation is that these former base levels were in the vicinity of sea level at the time of their formation and were subsequently uplifted (King, 1962). At sea level, the potential energy of water is at a minimum and sediment transportation and deposition dominate, inhibiting further vertical erosion and promoting lateral mobility of river channels (Schumm, 1993). An important corollary is that the relative height above sea level or the elevation difference between two surfaces represents a discrete uplift event of this magnitude, from which a rate can be calculated if the surfaces can be dated.

In reality, understanding erosional surfaces can be substantially more complicated and the resulting interpretations more controversial (e.g. Pelletier, 2010). For example, obtaining absolute age measurements requires careful consideration of the geological processes involved. An erosional surface will cut across rocks of various ages, the youngest of which provides a maximum age for peneplanation. Volcanic material is often suitable for radiometric dating and so can be used in this way if it is eroded as part of the surface (e.g. Stanley \& Flowers, 2016). Alternatively, lava flows can yield a minimum age if deposited unconformably on top of the erosion surface. The same is true for sedimentary rocks containing marker fossils that yield biostratigraphic ages. Some surfaces subsequently undergo intense chemical weathering, whereby all but the most immobile elements are leached away by groundwater to leave thick lateritic or bauxitic soils (e.g. Chowdhury et al., 1965). Associated precipitation of potassium-manganese oxides, such as cryptomelane, enables ${ }^{40} \mathrm{Ar} /{ }^{39} \mathrm{Ar}$ dating of these weathering events (e.g. Vasconcelos et al., 1992). Thus a variety of measurements may be available that pre- and post-date the formation of erosional surfaces and thereby bracket their age. An added complication is that the escarpment retreat mechanism can generate diachronous dates across the surface (e.g. Stanley et al., 2015). Indeed, a second uplift event may result in simultaneous erosion of two distinct elevation surfaces as their respective escarpments continue to back-wear. Finally, there is also significant debate over the mechanism of planation, including whether the postulated base level is sea level or whether surfaces can form in situ at higher elevations (e.g. Phillips, 2002; Clark et al., 2006; Yang et al., 2015; Chardon et al., 2016; Guillocheau et al., 2018). It is worth emphasising that rock uplift can be driven by dynamic or tectonic uplift, but is amplified by any erosion and associated isostatic rebound (England \& Molnar, 1990). Thus care is required when using rock uplift rates to infer changes in dynamic topography (e.g. Richards et al., 2016).

Notwithstanding these complex issues, there are prominent planation surfaces bounded by great escarpments on most continents. Where these occur in the vicinity of coastlines, the approximation of base level representing sea level is likely to be valid and uplift histories can be inferred. The classic example is the so-called 'African Surface', which had formed as a result of erosion and extensive weathering by Oligocene times ( $30 \mathrm{Ma})$, and has since been warped upwards to form topographic domes and downwards to form basins infilled with sediments (King, 1953; Burke \& Gun- nell, 2008). In northwest Africa, radiometric dating of laterites suggests that a series of stepped erosional surfaces were formed in discrete peneplanation events that have since been warped during growth of the Hoggar Dome (Chardon et al., 2006, 2016). Reinterpretation of the African surface by Guillocheau et al. (2018) suggests that there is actually a staircase of composite surfaces, dated using cross-cutting relationships, which document epeirogenic uplift of the basin and swell topography of central Africa since 30 Ma. Sembroni et al. (2016) reconstructed the basal and surface topography of flood basalts erupted from 40-20 Ma in Ethiopia to show that large-scale doming above the upwelling Afar plume both partially pre-dated basalt emplacement, but has also continued to grow since.

A couple of important examples from other continents include a series of K-Mn oxides that reside on the coastal planation surface of western peninsular India and have been dated to Mid Eocene - Miocene times (Beauvais et al., 2016; Bonnet et al., 2016). In light of independent evidence from margin stratigraphy, sea-level markers, and thermochronology, these ages have been interpreted by Richards et al. (2016) to indicate Neogene uplift and denudation of the Western Ghats escarpment. A set of three striking paleosurfaces in Greenland, which cut across a range of underlying formations, have been interpreted to represent discrete, kilometer-scale uplift events at $\sim 60 \mathrm{Ma}, 33 \pm 3 \mathrm{Ma}$ and $10-4 \mathrm{Ma}$, using a combination of thermochronologic and stratigraphic constraints (Japsen et al., 2006). The most important factor to bear in mind when interpreting the age of incision events is that erosion occurs in response to uplift. As a result, the oldest geological evidence for incision dissecting an uplifted surface places a limit on the youngest possible age of the onset of uplift.

\subsection{Landscape denudation and thermochronology}

Prominent erosional surfaces are limited in spatial extent, and determining their absolute ages can be challenging. In the absence of these large-scale features, local constraints on the timing and magnitude of denudation (the amount of overburden stripped off) are still valuable for inferring changes in dynamic topography, as erosion is isostatically related to the amplitude of tectonic or dynamic uplift (England \& Molnar, 1990; Brodie \& White, 1994; Japsen et al., 2006; Łuszczak et al., 2018; Jess et al., 2018). In order to extract quantitative estimates of denudation, the last few decades have seen a proliferation of geochronologic techniques that exploit radioactive decay, either induced by bombardment of atoms by cosmogenic radiation or from spontaneous alpha, beta, and fission decay of radionuclides. Here, we briefly outline the principal techniques that are commonly used to constrain the temporal history of erosion and exposure on the $100 \mathrm{kyr}$ to million-year timescales relevant to the study of dynamic topography.

Low temperature thermochronology exploits temperaturedependent processes operating as a result of radioactive decay (Wagner, 1968; Gallagher et al., 1998; Reiners et al., 2005; Reiners \& Brandon, 2006). First, parent radionuclides within a mineral undergo alpha- or beta-decay to produce a daughter according to a decay chain with a known half-life. The decay products subsequently diffuse through and out of the crystal lattice at a rate governed by the absolute temperature, which is commonly represented using an Arrhenius relationship, and effectively drops to zero below the closure temperature (e.g. Wolf et al., 1998; Farley, 2000; Harrison et al., 2009). Thus, the observed concentration of parent and daughter isotopes within the crystal volume is affected by the cooling history experienced by the host mineral. Techniques that exploit this 
effect include the (U-Th-Sm)/He system in apatite and zircon, ${ }^{40} \mathrm{Ar} /{ }^{39} \mathrm{Ar}$ in mica and feldspar, and the $\mathrm{U}-\mathrm{Pb}$ system in a range of minerals (e.g. Farley, 2000; Harrison et al., 2009; Godin et al., 2001). Secondly, the much rarer spontaneous fission of naturally occurring heavy radionuclides (nearly exclusively ${ }^{238} \mathrm{U}$ ) results in energetic ejection of two daughter nuclides, causing damage to the crystal lattice (fission tracks) that steadily anneal through time (Wagner, 1968). The healing rate of these fission tracks is temperature-dependent, such that the damage trails shorten as a function of both temperature and time following an empirically derived relationship (e.g. Green et al., 1985, 1986; Laslett et al., 1987; Ketcham et al., 1999, 2007). Fission track analysis therefore exploits the distribution of track lengths, in combination with the absolute concentrations of fission tracks and parent isotopes, to constrain a mineral's thermal history (e.g. Gallagher, 1995; Ketcham, 2005; Gallagher, 2012).

Two commonly exploited low temperature thermochronometers are the apatite fission track (AFT) system, which is sensitive to temperatures between $60-110{ }^{\circ} \mathrm{C}$, and the apatite helium system (AHe or apatite $(\mathrm{U}-\mathrm{Th}-\mathrm{Sm}) / \mathrm{He}$ ), which is sensitive to temperatures between $40-70{ }^{\circ} \mathrm{C}$ (Wagner, 1968; Gleadow \& Duddy, 1981; Gallagher et al., 1998; Farley, 2000, 2002; Reiners \& Brandon, 2006; Ketcham et al., 2007). Inverse modeling of these thermochronologic data can approximate the thermal history experienced by a rock sample, which can be turned into an equivalent burial depth beneath the surface through time by applying an assumed geothermal gradient (e.g. Ketcham et al., 2007; Gallagher \& Brown, 1999; Gallagher, 2012; Braun et al., 2013). The temperature sensitivity ranges of these two thermochronologic systems are such that, given standard continental geothermal gradients, they are able to constrain the burial and exhumation histories of the uppermost $\sim 2-7 \mathrm{~km}$ of the crust. Application of such analyses to the problem of landscape denudation can bracket the timing of the onset of incision, peneplanation episodes, burial by sedimentary deposition, or active tectonic processes, all of which may be associated with regional epeirogenic uplift (e.g. Japsen et al., 2006; Stanley et al., 2015; Łuszczak et al., 2018; Wildman et al., 2016; Guillaume et al., 2013). Landscape evolution models indicate that the maximum magnitudes of denudation associated with dynamic topographic motions should be on the order of 2-3 km (e.g. Braun et al., 2013). In locations with typical geothermal profiles of $15-25^{\circ} \mathrm{C} \mathrm{km}^{-1}$, these amplitudes place the AHe and AFT closure temperatures at the limits of resolution for samples found at the surface today. Current research is focused on exploiting alternative systems with lower closure temperatures, which should elucidate cooling histories and therefore denudation to within a few hundred metres of the surface. Such approaches include ${ }^{4} \mathrm{He} /{ }^{3} \mathrm{He}$ thermochronology, with a closure temperature around $30-40{ }^{\circ} \mathrm{C}$ (Shuster \& Farley, 2004; Flowers \& Farley, 2012).

Over shorter timescales, a widely used method to reconstruct recent rates of denudation is cosmogenic exposure dating. The Earth is continuously bombarded by cosmic rays sourced from the sun and outside the solar system, the majority of which are stopped in the atmosphere. The radiation that reaches the land surface is primarily composed of neutrons, which collide with atoms within the top $\sim 2 \mathrm{~m}$ to produce cosmogenic isotopes, some of which undergo radioactive decay (Davis \& Schaeffer, 1955; Lal \& Peters, 1967). Provided that the production rate and half-life of these radionuclides is known, the observed isotopic composition within a surficial sample can be inverted to estimate the time elapsed since its exposure. As well as depth-dependence, the pro- duction rate is also a function of latitude, elevation, geometry of surrounding topography, and mineral composition, which are the source of the principal uncertainties in these techniques. Due to high abundance of their parent nuclides in silicate minerals, the two most commonly exploited isotopes are ${ }^{10} \mathrm{Be}$ (produced from ${ }^{16} \mathrm{O}$ ) and ${ }^{26} \mathrm{Al}$ (produced from ${ }^{28} \mathrm{Si}$ ), with half-lives suitable for investigating landscape incision on hundred-thousand year timescales (Nishiizumi et al., 1993). Cosmogenic exposure dating has been widely used to obtain spot measurements of local incision rate, but can also be applied to estimate integrated erosion across an entire drainage catchment by analysing the sediments carried within its rivers, provided that incision localisation and hillslope processes are also carefully considered (Bierman \& Steig, 1996; Codilean et al., 2018; Tofelde et al., 2018; Riley et al., 2019).

A final related technique that is commonly used in landscape evolution analysis is optically stimulated luminescence. In contrast to cosmogenic exposure dating, which constrains erosion rates, this approach can be used to date the time of sample burial and therefore age of landscape features. The method exploits the fact that the decay of radionuclides generates ionising radiation that causes a build up of charge within a feldspar or quartz crystal. This charge can either be released by heating the sample, or more commonly by exposure to solar radiation at the surface (Huntley et al., 1985). When sediments that were exposed to sunlight become buried by overlying material, this charge begins to accumulate, and can therefore be used to measure the time elapsed up to a maximum age of $\sim 100$ ka for quartz, beyond which charge traps become saturated (Aitken, 1998; Wallinga, 2002; Duller \& Wintle, 2012). Sand deposited in fluvial or marine terraces is a common target for these studies. For example, terraces along the Angolan coast have been dated using this approach and indicate rapid Quaternary uplift rates of up to $\sim 1.4 \mathrm{~mm} \mathrm{yr}^{-1}$ associated with growth of the Bié dome (Walker et al., 2016). Age overestimation is the principal issue in fluvial environments, where inadequate exposure to sunlight during transport can cause incomplete resetting of the accumulated charge (Wallinga, 2002).

A long-standing problem which inhibits our understanding of landscape denudation is the significant time gap between the $10^{3}-10^{5}$-year sensitivity of optically stimulated luminescence in quartz and cosmogenic exposure techniques, and the $>10^{6}$-year sensitivity of existing thermochronologic approaches. Furthermore, the low amplitude of denudation in response to epeirogenic uplift requires sensitivity to low, upper crustal temperatures. Exciting new research is attempting to bridge these gaps by exploiting multi-optically stimulated luminescence on feldspar and electron spin resonance as thermochronometers. These systems are potentially sensitive to ages back to $\sim 1 \mathrm{Ma}$ and to temperatures as low as $25{ }^{\circ} \mathrm{C}$, making them ideal for investigating shallow burial and exhumation histories (Guralnik et al., 2015; King et al., 2016; Bartz et al., 2018).

\subsection{Drainage analysis}

The elevations of peneplains, paleosurfaces, marine rocks, and sea level markers yield constraints on time-integrated uplift or subsidence since their formation, providing spot estimates of dynamic topography changes over specific timeframes. Higher resolution spatio-temporal reconstructions are desirable, and require a more continuous record of evolving vertical motion. Drainage networks are a ubiquitous feature of terrestrial landscapes, and the elevation of river profiles along their lengths has long been known to record the interplay of uplift and erosion (Howard et al., 1994). Recent 
spectral analyses of African drainage patterns indicates that river elevation changes are dominanted by power at wavelengths $\gtrsim 100 \mathrm{~km}$, suggesting that large coherent signals, such as regional uplift caused by dynamic topography, are potentially recoverable despite overprinting by shorter wavelength complexities, such as variations in lithology, precipitation and biota (Roberts, 2019; Roberts et al., 2019; Faccenna et al., 2019).

In order to extract quantitative information about the spatio-temporal history of vertical motions from fluvial landscapes, it is necessary to understand and parameterise the processes of erosion responsible for sculpting the observed remnant features. The early qualitative descriptions of peneplanation, river incision, and escarpment retreat have steadily transformed into mathematical formulations. Most models of fluvial erosion take the form of kinematic wave equations, and some also consider erosional 'diffusion' (e.g. Luke, 1972; Howard \& Kerby, 1983; Rosenbloom \& Anderson, 1994; Whipple \& Tucker, 1999). The phenomenological stream power erosional model, for example, relates the incision rate at any point on a river to its local slope, $\frac{\partial z}{\partial x}$, and upstream drainage area, $A$, which is a proxy for the water flux or stream discharge (Howard \& Kerby, 1983). By parameterising erosional processes, the change in elevation of any point on a river through time, $\frac{\partial z}{\partial t}$, can be written as a competition between the local uplift rate and erosion rate. Thus,

$$
\frac{\partial z}{\partial t}=U-v A^{m}\left[\frac{\partial z}{\partial x}\right]^{n}+\kappa \frac{\partial^{2} z}{\partial x^{2}}
$$

where $U$ is the rock uplift rate and $v, m, n$, and $\kappa$ are erosional coefficients that include the effects of bedrock erodibility, precipitation, sediment cover, catchment shape, and channel geometry (Stock \& Montgomery, 1999). All parameters could potentially vary as a function of space and time. The advective erosional term (second on the right-hand side) represents the back-wearing velocity of concavities known as knickzones as they retreat upstream, whilst the third term acts to smooth sharp changes in river slope in a process analogous to diffusion (Howard \& Kerby, 1983; Rosenbloom \& Anderson, 1994; Whipple \& Tucker, 2002; Dietrich et al., 2003). In a simple sense, the river can be thought of as a tape recorder, where information about the history of regional uplift becomes stored within the fluvial landscape and can be extracted, provided that the erosion history can be reconstructed with sufficient accuracy (Pritchard et al., 2009).

Three main approaches have been developed to extract quantitative information about rock uplift histories using Equation (6) and the shape of observed river profiles. Each method has its own assumptions and limitations, and is variously championed or vilified within the geomorphological community. The first approach is slope-area analysis, which has been typically applied in small catchments draining across faults (e.g. Whipple, 2001; Schoenbohm et al., 2004). The key assumptions of this method are that each river is in steady state, such that uplift is balanced by erosion at all locations at any given time (i.e. $\frac{\partial z}{\partial t}=0$ ), and that the diffusional term is negligible $\left(\kappa \frac{\partial^{2} z}{\partial x^{2}} \rightarrow 0\right.$ for a detachment-limited channel with little to no basal sediment cover). Incorporating these assumptions into Equation (6) and rearranging yields

$$
\log \left[\frac{\partial z}{\partial x}\right]=-\frac{m}{n} \log [A]+\frac{1}{n} \log \left[\frac{U}{v}\right]
$$

This formulation means that a logarithmic plot of local slope versus upstream drainage area for multiple points along the profile should have a slope of $-\frac{m}{n}$ and intercept of $\frac{1}{n} \log \left[\frac{U}{v}\right]$.
In reality, these points often define multiple sets of linear arrays. Provided that $v, m$ and $n$ can be considered invariant for each linear trend, differences in the intercept can therefore be interpreted as variations in uplift rate along the river. The value of $\left(\frac{U}{v}\right)^{\frac{1}{n}}$ is referred to as the channel steepness index, $k_{s}$, a common proxy for uplift rate (e.g. Kirby \& Whipple, 2001). Problematically, uplift rates that vary as a function of space and time can violate the steady-state assumption, resulting in transient changes in slope which do not reflect the value of $U$ (e.g. Whittaker, 2012). The timing and spatial location of the formation of these transient knickpoints trade-off, such that prior information on the spatial pattern of uplift (such as the locations of faults) is required for successful interpretation (Whipple \& Tucker, 2002; Whittaker et al., 2008; Pritchard et al., 2009; Whittaker, 2012). Furthermore, this approach involves differentiating profile elevation with respect to distance, and is therefore susceptible to amplification of noise present in the digital elevation model used to extract the river profile (e.g. Roberts et al., 2012b).

This noise issue can be suppressed by solving Equation (6) using an integrative approach (Luke, 1972; Weissel \& Seidl, 1998; Pritchard et al., 2009). The most widely applied methodology was described by Perron \& Royden (2013) and is known as chi analysis. Making the same assumptions concerning elevation steady state and absence of diffusional erosion, Equation (6) can be rearranged and integrated to give

$$
z=z_{b l}+\left(\frac{U}{v A_{0}^{m}}\right)^{\frac{1}{n}} \int_{x_{b l}}^{x}\left(\frac{A_{0}}{A}\right)^{\frac{m}{n}} d x
$$

where $z_{b l}$ is the elevation of local base level, $x_{b l}$ is the distance upstream that this base level extends from the river mouth, and $A_{0}$ is a reference drainage area introduced to force the integral term (referred to as $\chi$ ) to have dimensions of length. By choosing values of $m$ and $n, \chi$ can be calculated along the length of the river. Plots of elevation as a function of $\chi$ should therefore have a slope of $\left(\frac{U}{v A_{0}^{m}}\right)^{\frac{1}{n}}$ (equivalent to the channel steepness index when $A_{0}=1 \mathrm{~m}^{2}$ ), which yields values for uplift rate if $v$ is independently known and upstream drainage area is assumed not to have varied through time (Perron \& Royden, 2013; Willett et al., 2014; Yang et al., 2015). In addition to suppressing noise, another clear advantage of this approach over slope-area analysis is that this procedure of normalising by the upstream drainage area makes transient uplift signals appear as discontinuities in elevation that stack at the same value of $\chi$ across multiple tributaries, thereby placing minimum constraints on how far downstream uplift signals must have been inserted. However, whilst transient uplift events that violate the steady-state elevation assumption can be identified using this approach, it remains challenging to extract continuous uplift histories at the regional to continental scales that are driven by dynamic topography.

A third, alternative methodology has been demonstrated by Roberts \& White (2010), whereby Equation (6) is directly solved numerically in a forward sense, in response to a given uplift history. The observed shape of any real river profile can then be matched by inversion to find a best-fitting history of uplift. This approach avoids the steady-state elevation assumption and can include the term associated with diffusional erosion, but is substantially more computationally expensive. Whilst $v, m, n, \kappa$ and $A$ could all potentially be varied through space and time, as with previous approaches it is necessary to fix these parameters to extract a unique history of uplift. Application of this method to individual African rivers suggests much of the continent's basin-andswell topography grew during the Neogene period (Roberts 
\& White, 2010). This initial study also assumed that the uplift rate was spatially invariant, with uplift events generating knickzones at the river mouth that propagate upstream. This set up is only applicable when the length of a river is small in comparison to the wavelength of uplift signals.

When uplift is also allowed to vary with distance along the profile, the trade-off returns between the location a signal is inserted on the river versus the time it has taken to retreat upstream. This issue has been tackled in two ways. First, damping parameters are applied that force the uplift history to be smooth as a function of space and time, consistent with expectations for uplift signals caused by dynamic topography. Secondly, multiple rivers in the region are simultaneously inverted. This step has the added bonus of emphasising signals that are coherent between different channels and catchments, therefore reducing the impact of local streamcapture events, lithological variation and fault-induced knickzones. The first such regional-scale spatio-temporal uplift history was obtained for Madagascar, where $\sim 1.5 \mathrm{~km}$ of uplift was inferred to have occurred since $20 \mathrm{Ma}$ at rates of 0.2-0.4 $\mathrm{mm} \mathrm{yr}^{-1}$ (Roberts et al., 2012a). Importantly, summing up incision rates across catchments also yields simple estimates of the sedimentary flux carried by rivers into deltas. Observed histories of solid clastic flux into both the Gulf of Mexico and Amazon Cone have been successfully predicted by this methodology, suggesting that regional uplift is a primary control on sedimentation in major deltas (Stephenson et al., 2014; Rodríguez Tribaldos et al., 2017).

It is important to note that these continental-scale histories of uplift depend fundamentally upon the erosion parameters assumed in Equation (6), requiring careful calibration against independent constraints on uplift and incision, such as the aforementioned sea-level markers, denudation estimates, and sedimentary flux histories. One of the tightest examples of calibration comes from the Snowy Mountains of southeast Australia, where a series of basaltic lavas flowed down river valleys and recorded the shape of the profiles at $20 \mathrm{Ma}$, yielding measurements of total incision over the intervening period by comparison to the modern channel elevation (Young \& McDougall, 1993). These data have been modelled using Equation (6) to constrain the best-fitting local erosion parameters and explore their trade-offs, before being extended to drainage analysis of the full Australian continent (Stock \& Montgomery, 1999; Czarnota et al., 2014).

This Australian example illustrates the great benefit of drainage analysis, in that disparate and diverse spot observations of uplift and incision are interpolated through space and time within a self-consistent framework. However, several major issues remain that must be considered when interpreting the validity of inferred uplift histories. For example, the computational efficiency and number of river profiles analysed can be significantly increased by assuming that $\kappa=0$ and $n=1$, allowing Equation (6) to be linearised (Goren et al., 2014; Fox et al., 2014; Rudge et al., 2015). However, considerable debate surrounds these assumptions and the possibility of spatio-temporal variability of erosional parameters in response to variations in climate and bedrock lithology. The methods outlined so far generally assume that the locations of drainage basins are static, and that there are minimal changes in upstream drainage area arising from capture events and stream piracy. They also ignore the effects of subsidence and sedimentation, assume channels have fixed locations, and are highly dependent on water discharge and sedimentary flux, both of which can vary by more than an order of magnitude (e.g. Sklar \& Dietrich, 2001; Bufe et al., 2016). Furthermore, whilst river profiles can provide an im- portant continuous record of uplift, they constitute only a small proportion of the landscape. The majority of the land surface resides on hillslopes, interfluves, and plateaux, and it is increasingly being recognised that the interplay of these settings and the fluvial channels in response to long-wavelength uplift is important in controlling erosional processes (e.g. Fernandes \& Dietrich, 1997; Tucker \& Hancock, 2010; Braun et al., 2013).

Naturalistic full landscape evolution simulations are able to calculate erosion rates across whole landscapes in response to a given uplift history, not just within the fluvial channels, by solving Equation (6) in two dimensions (e.g. Tucker et al., 2001; Salles \& Hardiman, 2016; Hobley et al., 2017). Unfortunately, significant trade-offs exist between erosional parameters, such that inverse modeling of entire landscapes including hillslope processes, drainage capture, and both channel and divide migration remains challenging. Nevertheless, a number of studies have hinted at the new information such simulations can provide about continental-scale uplift and sedimentation patterns (e.g. Ruetenik et al., 2016; Salles et al., 2017; Chang \& Liu, 2019; Ding et al., 2019). For example, simulations have suggested that uplift histories recovered from inverse modelling river profiles are consistent with observed regional erosional histories (Fernandes et al., 2019). The effects of climatic variations on the ability of river profiles to recover long-wavelength uplift histories is also being investigated (O'Malley et al., 2021, in review). The complex and relatively under-explored series of trade-offs between different erosional parameters and the choice of damping coefficients used in inverse schemes has also been tested (Croissant \& Braun, 2014; McNab et al., 2018). Thus, suites of independent measurements of uplift and incision constrained with available morphologic and stratigraphic observations are essential for advancing these promising early results and inferring the temporal evolution of continental dynamic topography.

\subsection{Paleoaltimetry}

Many inferences of the temporal evolution of dynamic topography rely upon sea level as a geological marker to reconstruct relative vertical motions. There are, however, a couple of alternative techniques that exploit physical or biological processes that change as a function of increasing elevation. Whilst these approaches remain underutilised from the perspective of dynamic topography, they are being actively explored and represent promising avenues for future studies.

Firstly, it has long been recognised that temperature influences the fractionation of isotopes in some near-surface geological processes (Urey, 1947; McCrea, 1950). Since the temperature of the atmosphere steadily decreases with increasing elevation, variations in the isotopic composition of a sample can be converted into a paleo-temperature history and therefore used as a proxy for paleo-elevation (e.g. Poage \& Chamberlain, 2001; Rowley \& Garzione, 2007; Eiler, 2007). For example, during formation of a calcium carbonate shell $\left(\mathrm{CaCO}_{3}\right)$, the ratio of ${ }^{18} \mathrm{O}$ to ${ }^{16} \mathrm{O}$ (often presented as $\delta^{18} \mathrm{O}$ ) depends both upon the temperature at time of mineral precipitation and the isotopic composition of the solution from which it forms (Emiliani, 1950). If the composition of the mineralising fluid can be independently constrained, the inferred temperature can be converted into a paleo-elevation at formation using an assumed vertical temperature gradient. This technique relies upon accurate reconstruction of the average atmospheric temperature gradient, which has a present-day global average reduction of $\sim 5.5{ }^{\circ} \mathrm{C}$ per kilometer of increasing elevation, but can locally vary from 3$8{ }^{\circ} \mathrm{C} \mathrm{km}^{-1}$ (Meyer, 2007). 
Table 1: Summary of techniques available for inferring changes in dynamic topography, including approximate timescales for which they yield information, key benefits, and important limitations.

\begin{tabular}{|c|c|c|c|}
\hline Technique & Timescale (yr) & Benefits & Limitations \\
\hline GPS & Present day & $\begin{array}{l}\text { Measures absolute vertical motion } \\
\text { of surface w.r.t. centre of mass, } \\
\text { rather than relative sea level } \\
\text { change }\end{array}$ & $\begin{array}{l}\text { Decadal duration means convection signals swamped by } \\
\text { glacial isostatic adjustment, hydrology, active tectonics }\end{array}$ \\
\hline $\begin{array}{l}\text { Satellite } \\
\text { gravity }\end{array}$ & Present day & $\begin{array}{l}\text { Complete, time-evolving global } \\
\text { coverage }\end{array}$ & $\begin{array}{l}\text { Decadal duration means convection signals swamped by } \\
\text { glacial isostatic adjustment, hydrology, active tectonics }\end{array}$ \\
\hline $\begin{array}{l}\text { Sea-level } \\
\text { markers }\end{array}$ & $10^{4}-10^{8}+$ & $\begin{array}{l}\text { Direct evidence of relative vertical } \\
\text { motion, narrow paleoelevation } \\
\text { range }\end{array}$ & $\begin{array}{l}\text { Dating limitations, restricted spatial extent and poor } \\
\text { preservation potential, yields only time-integrated } \\
\text { vertical motion histories }\end{array}$ \\
\hline $\begin{array}{l}\text { Sedimentary } \\
\text { flux and } \\
\text { provenance }\end{array}$ & $10^{6}-10^{9}+$ & $\begin{array}{l}\text { Timing of major exhumation } \\
\text { events and drainage } \\
\text { reorganisations }\end{array}$ & $\begin{array}{l}\text { Poor constraint on magnitude of uplift, causes can also } \\
\text { be other tectonic and climatic processes }\end{array}$ \\
\hline $\begin{array}{l}\text { Stratigraphic } \\
\text { architecture }\end{array}$ & $10^{5}-10^{8}+$ & $\begin{array}{l}\text { Deep time records, widespread, } \\
\text { well preserved }\end{array}$ & $\begin{array}{l}\text { Requires amplitudes of relative motion greater than } \\
\text { paleowater depth uncertainties, borehole samples } \\
\text { necessary for horizon dating }\end{array}$ \\
\hline Paleosurfaces & $10^{6}-10^{8}+$ & $\begin{array}{l}\text { Extensive coverage of continental } \\
\text { interiors }\end{array}$ & $\begin{array}{l}\text { Challenging to date, base levels may not represent sea } \\
\text { level }\end{array}$ \\
\hline Thermochronology & y $10^{6}-10^{8}+$ & $\begin{array}{l}\text { Continuous, quantitative histories } \\
\text { of sample temperature }\end{array}$ & $\begin{array}{l}\text { Depends on mineralogy/lithology, uncertainty over } \\
\text { kinetics, paleogeothermal gradients, and how to infer } \\
\text { uplift from denudation, currently insensitive to } \\
\text { temperatures }<60^{\circ} \mathrm{C}\end{array}$ \\
\hline $\begin{array}{l}\text { Cosmogenic } \\
\text { exposure } \\
\text { dating }\end{array}$ & $10^{4}-10^{5}$ & $\begin{array}{l}\text { Dates precise time of sample } \\
\text { exposure }\end{array}$ & $\begin{array}{l}\text { Production rate of radionuclides poorly constrained as } \\
\text { depends on several unknowns, uncertainty in relating } \\
\text { exposure to history of vertical motions, currently limited } \\
\text { to } \sim 10^{5} \text { yr timescales }\end{array}$ \\
\hline $\begin{array}{l}\text { Optically } \\
\text { stimulated } \\
\text { luminescence }\end{array}$ & $10^{4}-10^{5}$ & $\begin{array}{l}\text { Dates sample burial and age of } \\
\text { landscape features, useful where } \\
\text { no biological material for } \\
\text { radiometric dating }\end{array}$ & $\begin{array}{l}\text { Potentially incomplete resetting during exposure, } \\
\text { saturation of charge traps beyond } \sim 100 \text { ka for quartz }\end{array}$ \\
\hline $\begin{array}{l}\text { Drainage } \\
\text { analysis }\end{array}$ & $10^{5}-10^{7}+$ & $\begin{array}{l}\text { Nearly ubiquitous in the } \\
\text { continents, continuous temporal } \\
\text { record of relative vertical motion }\end{array}$ & $\begin{array}{l}\text { Erosion parameterisations require independent data for } \\
\text { calibration, tradeoffs between location and timing of } \\
\text { uplift events, duration limited by river lengths, sensitive } \\
\text { to climatic variations and drainage capture events, } \\
\text { subsidence poorly constrained }\end{array}$ \\
\hline $\begin{array}{l}\text { Clumped } \\
\text { isotopes }\end{array}$ & $10^{5}-10^{8}+$ & $\begin{array}{l}\text { Sensitive to relative changes in sea } \\
\text { level even away from coastal } \\
\text { areas, such as in mountainous } \\
\text { regions and continental interiors }\end{array}$ & $\begin{array}{l}\text { Uncertainty over paleo-atmospheric temperature gradient } \\
\text { necessitates high amplitude of relative vertical motion } \\
\text { change, potential for diagenetic alteration of isotopic } \\
\text { ratios }\end{array}$ \\
\hline $\begin{array}{c}\text { Leaf } \\
\text { physiognomy }\end{array}$ & $10^{6}-10^{7}+$ & $\begin{array}{l}\text { Sensitive to relative changes in sea } \\
\text { level even away from coastal } \\
\text { areas, such as in mountainous } \\
\text { regions and continental interiors }\end{array}$ & $\begin{array}{l}\text { Limited preservation potential, requires calibration on } \\
\text { extant fauna (limits to Eocene or younger), sensitive to } \\
\text { climatic factors, high paleoelevation uncertainties }\end{array}$ \\
\hline $\begin{array}{l}\text { Carbonate } \\
\text { compensation } \\
\text { depth }\end{array}$ & $10^{6}-10^{8}$ & $\begin{array}{l}\text { Sensitive to relative sea-level } \\
\text { changes in the deep ocean basins }\end{array}$ & $\begin{array}{l}\text { Also affected by sediment accumulation rates and the } \\
\text { chemistry of deep ocean waters, limited by deep sea } \\
\text { borehole locations and age of ocean floor }\end{array}$ \\
\hline $\begin{array}{l}\text { Contourites } \\
\text { and ocean } \\
\text { circulation }\end{array}$ & $10^{5}-10^{7}+$ & $\begin{array}{l}\text { Sensitive to relative sea-level } \\
\text { changes in the ocean basins }\end{array}$ & $\begin{array}{l}\text { Difficulty fingerprinting water masses, accurately } \\
\text { reconstructing sedimentation rates, and ruling out other } \\
\text { climatic causes }\end{array}$ \\
\hline
\end{tabular}

Unfortunately, changes in global ice volume, seawater salinity, and hydrological cycles lead to significant uncertainty in reconstructing original fluid compositions that limit the accuracy of inferred paleo-elevations. It is therefore desirable to use an approach that is independent of fluid composition, allowing this major weakness to be circumvented. To this end, Ghosh et al. (2006a) developed a method that exploits the small thermodynamic inclination for the rarer heavier isotopes to clump preferentially together with each other, rather than bond with the lighter isotopes. Given their relative isotopic abundances, the number of ${ }^{13} \mathrm{C}-{ }^{18} \mathrm{O}$ bonds will be higher than expected from a stochastic (random) distribution of $\mathrm{C}-\mathrm{O}$ bonds, and the amount of this 'clumping' increases at lower temperature. This process is independent of $\delta^{18} \mathrm{O}$ and $\delta^{13} \mathrm{C}\left({ }^{13} \mathrm{C}\right.$ to $\left.{ }^{12} \mathrm{C}\right)$ values, and so does not depend upon original fluid compositions. The technique is known as clumped isotope paleothermometry, has an accuracy of approximately $\pm 2^{\circ} \mathrm{C}$, and has been most successfully applied to study uplift histories of mountain belts that have undergone large elevation changes, where the uncertainty introduced by natural variability in the vertical temperature gradient is minimised. For example, analysis of paleosol carbon- 
ates in the Bolivian Andes records a series of discrete $\sim 1 \mathrm{~km}$ Miocene uplift events that have been independently predicted using drainage analysis (Ghosh et al., 2006b; Garzione et al., 2014; Rodríguez Tribaldos et al., 2017).

Despite some success, paleo-altimetric estimates derived from analysis of clumped isotopes remain controversial for a variety of reasons. Care must be taken in cases where carbonate precipitation did not occur at thermodynamic equilibrium, or where the original isotopic signal has been modified by diagenetic alteration and mineral reprecipitation (Affek, 2012). Furthermore, lateral temperature differences and climate variability introduce significant uncertainty into the temperature-elevation relationships (Huntington \& Lechler, 2015).

A second branch of paleoaltimetric techniques exploit the impact of increasing elevation on biological systems. For example, there is a systematic reduction in the partial pressure of $\mathrm{CO}_{2}\left(p \mathrm{CO}_{2}\right)$ with height in the atmosphere, which is thought to place a physiological limit on photosynthesis in plants. Various elevation proxies have been suggested that involve interpreting compensating changes in leaf shape, and have been applied to fossil assemblages to infer uplift histories (e.g. Gregory \& Chase, 1992; Wolfe et al., 1997). Another promising approach takes advantage of the increasing number and density of stomata on leaves, with particular emphasis on the black oak species Quercus kelloggii, which is expected to yield some of the smallest paleo-elevation uncertainties of $\pm 300 \mathrm{~m}$ (McElwain, 2004). Since the elevation versus stomatal density relationship varies between different species, application to paleoaltimetric studies requires calibration on living examples and is therefore limited to Eocene and younger fossil leaves that are represented by extant flora today. Additional limitations of the method include the possibility of saturation of stomatal density at high values of $p \mathrm{CO}_{2}$, and the narrow elevation range of most species that reduces calibration accuracy and the magnitude of uplift events that can be reconstructed. Nevertheless, paleoaltimetric techniques have the potential to yield inferences of changing dynamic topography at sites that have not been directly influenced by sea level, such as in mountain belts and deep continental interiors (e.g. Huyghe et al., 2020).

\subsection{Bathymetric indicators}

Given that it covers more than two-thirds of the Earth's surface, it would be highly desirable to obtain reconstructions of evolving vertical motion in the oceanic realm. Transient $\sim 1 \mathrm{~km}$ uplift and subsidence events associated with dynamic topography might be expected to have little to no visible record on old ocean floor, the majority of which resides at depths of 4-7 km. However, it has recently been suggested that such signals may be preserved in the style of sedimentation, as seafloor rises above and sinks below a paleobathymetric marker known as the carbonate compensation depth (CCD; Campbell et al., 2018). The existence of the CCD was first postulated based upon the general decrease in the quantity of carbonate observed in seafloor sediments as a function of increasing water depth (Murray \& Renard, 1891). Above the CCD, seawater is oversaturated with carbonate such that biological material (such as dead plankton) can sink to the seafloor and become preserved, whereas below this level, seawater is undersaturated and any sinking carbonate is redissolved (Ben-Yaakov et al., 1974). Temporal variations in the carbonate content of sediments returned from deep-sea drill cores can therefore potentially be used to infer bathymetric evolution. However, the absolute depth of the CCD also varies as a function of factors affecting both carbonate accumulation rates (e.g. primary productivity in surface waters) and the chemistry of deep ocean waters (e.g. concentration of dissolved carbon dioxide), making the isolation of dynamic topography signals a significant ongoing challenge (Campbell et al., 2018).

Elsewhere, it has been suggested that uplift and subsidence of oceanic gateways can impact the pattern of oceanic circulation, with deep water currents shifting their location or even becoming blocked. The type example comes from the North Atlantic region, where periodic Neogene uplift of the Greenland-Scotland Ridge by temperature anomalies within the Icelandic plume is believed to have prevented overflow of Northern Component Water from the Arctic Ocean (Wright \& Miller, 1996). Analysis of carbon isotopes in benthic foraminifera indicates up to two cycles of waxing and waning overflow within the last $10 \mathrm{Ma}$, subject to significant uncertainties related to site selection and variations in the location and composition of water masses through time (Poore et al., 2006). The latter of these cycles has been partially corroborated by careful reconstruction of sedimentation rates in the contourite drifts deposited by these currents (ParnellTurner et al., 2015).

Despite these advances, there remains a paucity of constraints on the temporal evolution of dynamic topography in oceanic settings in comparison to continental observations. This situation is in marked contrast to information regarding the amplitude of present-day dynamic topography, which is comparatively well-constrained in the oceanic realm but remains highly uncertain for the continents. This discrepancy highlights the importance of passive margins to studies of dynamic topography (e.g. Moucha et al., 2008). In these locations, the benefits of observations made in both marine and terrestrial settings can be interwoven to reconstruct both the present amplitude and history of vertical motions.

\section{Frontiers and outstanding challenges}

It is clear that the geological record contains abundant recorders of evolving dynamic topography, but a significant challenge remains in extracting the necessary measurements with associated uncertainties, integrating diverse observational datasets, and interpreting the results. This review is focused on providing brief overviews of some of the most widely-used techniques for estimating vertical motions and discussing some of their limitations (see Table 1 for summary). It is by no means an exhaustive list, and there are many excellent pre-existing and exciting upcoming studies that provide complimentary constraints (e.g. Friedrich et al., 2018; Vibe et al., 2018; Hayek et al., 2020). In order to motivate future research and promote interdisciplinary discussions, we finish by outlining some outstanding methodological issues that need to be tackled, as well as some of the big open questions that remain in the field of dynamic topography.

A: Continental residual topography. As illustrated by our simplistic approach in Section 3.2, the complex lithospheric architecture of continental regions and active margins significantly hampers attempts to constrain the present-day amplitude of dynamic topography (Guerri et al., 2016). Dynamic topography arising from density anomalies and flow within the convecting mantle (processes $b$ and $c$ in Figure 1) should be relatively insensitive to whether the overlying plate is composed of oceanic or continental lithosphere. Thus, peak water-loaded amplitudes of $\pm 2 \mathrm{~km}$ in the oceans might be expected to roughly translate into $\pm 1.4 \mathrm{~km}$ when air-loaded in the continents. However, this conversion does not include dynamic topography arising from lithospheric isostasy (process $a$ in Figure 1), which may be substantially larger than in oceanic regions due to the generally greater thickness and 
age of continental lithosphere, and is certainly harder to determine. Regional seismic experiments are key to constraining the local lithospheric structure, and understanding the effects of buoyancy arising from variable chemical depletion in the mantle requires integration of these datasets with geochemical observations on mantle xenoliths and melt products (e.g. Afonso et al., 2016; Plank \& Forsyth, 2016; Klöcking et al., 2018; Celli et al., 2020; Klöcking et al., 2020). Furthermore the filtering effect of the lithosphere on the expression of deeper buoyancy remains poorly understood (Golle et al., 2012; Sembroni et al., 2017).

B: Integrated landscape evolution analysis. In Section 4 , we outline the great wealth of information from disparate sources pertaining to the uplift and erosion of landscapes. A substantial challenge involves integrating these datasets into a single coherent history of rock uplift and incision, which must also account for thermal evolution of the sub-surface if thermochronological data are to be included (e.g. Glotzbach, 2015). The development of thermochronometric systems that are sensitive to lower temperatures is expected to enable detection of denudation related to lowamplitude dynamic topography. This work will be aided by improved understanding of the dominant erosional processes, their mathematical formulation, and sensitivity analysis to test how well they are represented by the relatively simplistic vertical incision laws currently used to invert fluvial systems for a history of regional uplift (Section 4.6).

C: Spectral properties of dynamic topography. Many predictive models driven by sub-lithospheric flow, such as Figure 4c, indicate that dynamic topography is dominated by spherical harmonic degree 2 structure that varies on $10,000 \mathrm{~km}$ lengthscales. However, residual topography suggests dynamic topography can vary on lengthscales down to $1000 \mathrm{~km}$ (Figure 5; Hoggard et al., 2016). These shorterwavelength features must be sourced from shallow buoyancy structure, either within the convecting asthenospheric mantle or from variations in lithospheric thickness, and disentangling these two sources is the focus on ongoing research (e.g. Ball et al., 2019; Davies et al., 2019; Richards et al., 2020b; Lamb et al., 2020). Nevertheless, this discovery has important ramifications for the rates of change of dynamic topography. Whilst lithospheric isostasy will travel with the plates, surface deflections arising from short-wavelength buoyancy variations in the convecting mantle (processes $b$ and $c$ in Figure 1) will uplift and subside significantly faster than previously expected as the planform of convection evolves or plates translate across the surface. Recent numerical simulations of Earth-like convection have also begun to reproduce this behaviour (Arnould et al., 2018). Attempts to link inferred observations of dynamic topography to our latest images of mantle structure obtained from modern seismic tomography methods are proving fruitful (e.g. Steinberger, 2016). Higher-resolution tomography models combined with improved experimental constraints on how to map seismic velocities into temperature and density should help to further illuminate this issue (e.g. Priestley \& McKenzie, 2013; Yamauchi \& Takei, 2016; Richards et al., 2020b).

A more controversial topic concerns the amplitude of dynamic topography caused by sub-plate buoyancy at long wavelengths (processes $b$ and $c$ in Figure 1). The earliest predictive flow models had peak amplitudes of $\pm 0.9 \mathrm{~km}$ at spherical harmonic degrees $0-3$ (wavelengths $\gtrsim 10,000 \mathrm{~km}$; Figure 4c; Hager et al., 1985; Ricard et al., 1993). Notably, predictions of this amplitude generally increased over the following 20 years (e.g. $\pm 2.0 \mathrm{~km}$ in Steinberger, 2007; $\pm 2.2 \mathrm{~km}$ in Spasojević \& Gurnis, 2012; $\pm 1.7 \mathrm{~km}$ in Flament et al., 2013). However, Hoggard et al. (2016) suggested that spot estimates of residual topography, water-loaded in the oceans and air-loaded in the continents, infer only $\pm 0.5 \mathrm{~km}$ of this dynamic topography at degrees $0-3$. Sparse data coverage means that this exact value depends strongly upon the choice of continental constraints, and how the spherical harmonic fitting procedure is regularised (Hoggard et al., 2016; Yang \& Gurnis, 2016; Hoggard et al., 2017; Yang et al., 2017). Inclusion of a previously missing residual topography correction that accounts for deflections of the sea surface by the non-hydrostatic geoid increases peak amplitudes by $\sim 100 \mathrm{~m}$ (Hoggard et al., 2017). Applying a more advanced regularisation procedure to only the oceanic constraints has yielded the most robust observationally-inferred value to date of $\pm 0.7 \mathrm{~km}$, although this amplitude assumes a global waterload such that continental values have been amplified in comparison to other residual topography studies (Davies et al., 2019). Amplitudes of $\pm 0.5 \mathrm{~km}$ at long-wavelengths have also been shown to be consistent with patterns of asymmetric subsidence either side of Atlantic and Pacific mid-ocean ridge spreading centres (Watkins \& Conrad, 2018). Thus, there appears to remain an intriguing mismatch between observational inferences and flow predictions of long-wavelength dynamic topography caused by sub-plate buoyancy, requiring further exploration of seismic tomography to density scalings, phase boundary topography, thermochemical heterogeneity and viscosity variations in the mantle, as well as theoretical assumptions in convection simulations (Steinberger et al., 2019; Flament, 2019).

D: Flow regime in the asthenosphere. Considerable uncertainty surrounds the degree of coupling between plate motions and horizontal flow in the underlying asthenosphere. In one endmember scenario known as Couette flow, translation of the plate shears the asthenosphere, which therefore travels in the same direction with a velocity profile that decreases from the plate speed at the top to zero at some base. The other end member is Poiseuille flow, whereby lateral pressure gradients in an asthenospheric channel drive horizontal flow that is significantly faster and can be highly oblique to velocities of the overriding plate. Numerical experiments have shown that these behaviours are strongly dependent upon the rheology of the lithosphere and asthenosphere, as well as the wavelength of convection (e.g. Höink \& Lenardic, 2010; Osei Tutu et al., 2018). The fact that convection simulations using mantle density anomalies derived from either seismic tomography or slab subduction histories can successfully reproduce the first-order characteristics of surface plate motions implies a degree of coupling between deep mantle flow and plates (Hager \& Connell, 1981; Lithgow-Bertelloni \& Richards, 1998; Conrad et al., 2013; Stotz et al., 2018). However, observational evidence, particularly in the vicinity of plumes such as the V-shaped ridges south of Iceland, indicate flow can locally be strongly decoupled, with asthenospheric velocities an order of magnitude faster than plate spreading (Vogt, 1971; Conder et al., 2002; Hartley et al., 2011; Ballmer et al., 2013; Lin et al., 2016; Bredow et al., 2017).

Flow regimes are highly sensitive to the rheology of mantle rocks, and these somewhat contrasting observations may potentially be reconciled if viscosity is strongly controlled by temperature, such that hot plume head material in the asthenosphere produces more decoupling than the longerwavelength, cold downwellings. A further consideration is that these flow regimes interact with basal topography of the lithosphere, which can lead to small-scale circulation across lithospheric steps through edge-driven convection and shear- 
driven upwelling (Elder, 1976; King \& Anderson, 1998; Conrad et al., 2010; Ballmer et al., 2015).

One approach for investigating the role of these different flow regimes in generating dynamic topography involves comparing and contrasting patterns and rates of change in vertical motion on fast- versus slow-moving plates. Africa is relatively stationary with respect to the underlying mantle, whereas Australia is travelling rapidly northwards and transits across the top of the mantle flow field (Burke \& Gunnell, 2008; Sandiford, 2007). The former should therefore predominantly record temporal evolution of the underlying convective planform, whilst the latter will also be sensitive to differential plate translation (mechanism $d$ in Figure 1) and variations in edge-related flow on the leading and trailing portions of thick lithosphere (e.g. Davies \& Rawlinson, 2014). An important caveat to consider in these analyses is that numerical models and laboratory convection experiments have shown that the surface expression of basal stresses caused by mantle flow is strongly modulated by the rheology of the lithosphere, including its effective elastic thickness and any viscosity layering (Burov \& Gerya, 2014; Sembroni et al., 2017).

E: Numerical convection models and rheology of the upper mantle. New insights into dynamic topography and subsurface processes will come from high-resolution numerical experiments that can incorporate realistic physical processes, such as plate-like behaviour, by introducing additional model complexity. Examples of such properties include the highly heterogeneous composition of the mantle, viscoelastic rheologies, temporal evolution of grain size, the effects of latent heat, porous flow, full compressibility, and inclusion of thermodynamically self-consistent mineralogical properties, all of which must be captured at the necessary spatial resolution using techniques such as adaptive mesh refinement (e.g. Burstedde et al., 2013; Wilson et al., 2017; Heister et al., 2017; Dannberg et al., 2017; Patočka et al., 2019; Flament, 2019). Uncertainties in input rheological parameters in particular remain a major challenge in predictive flow models.

One approach to overcoming this limitation is improving rheological constraints on mantle materials using laboratory experiments. The dominant mechanism of crystal lattice deformation varies strongly as a function of properties such as the strain rate, temperature, and grain size. Effects of

\section{References}

Affek, H. P. (2012). Clumped isotope paleothermometry: Principles, applications, and challenges. The Paleontological Society Papers, $18,101-114$.

Afonso, J. C., N. Rawlinson, Y. Yang, D. L. Schutt, A. G. Jones, J. Fullea, \& W. L. Griffin (2016). 3-D multiobservable probabilistic inversion for the compositional and thermal structure of the lithosphere and upper mantle: III. Thermochemical tomography in the WesternCentral U.S. Journal of Geophysical Research: Solid Earth, 121, 7337-7370.

Afonso, J. C., F. Salajegheh, W. Szwillus, J. Ebbing, \& C. Gaina (2019). A global reference model of the lithosphere and upper mantle from joint inversion and analysis of multiple data sets. Geophysical Journal International, 217, 1602-1628.

Aitken, M. J. (1998). An introduction to optical dating: The dating of Quaternary sediments by the use of photon-stimulated luminiscence. Oxford University Press, Oxford.

Al-Hajri, Y., N. J. White, \& S. Fishwick (2009). Scales of transient convective support beneath Africa. Geology, 37 (10), 883-886.

Anderson, D. L. (1982). Hotspots, polar wander, Mesozoic convection and the geoid. Nature, 297, 391-393.

Arnould, M., N. Coltice, N. Flament, V. Seigneur, \& R. D. Müller (2018). On the scales of dynamic topography in whole-mantle convection models. Geochemistry, Geophysics, Geosystems, 19, 31403163. polycrystalline materials, anisotropic viscosity, and the timedependent accumulation of damage and healing are underexplored (Zhao et al., 2018; Wheeler, 2010; Bercovici \& Ricard, 2014). Furthermore, applying the results of lab experiments to mantle conditions necessarily requires extrapolation across many orders of magnitude for properties such as the strain rate or grain size, and associated uncertainties need to be carefully considered (Jackson \& Faul, 2010; Yamauchi \& Takei, 2016; Richards et al., 2018).

A second approach to improving our understanding of mantle rheology is to use observational inferences of dynamic topography as constraints in numerical convection simulations. Data assimilation methods that have been explored include machine learning schemes (Atkins et al., 2016; Shahnas et al., 2018), adjoint-based inversions (Liu et al., 2008; Worthen et al., 2014; Ratnaswamy et al., 2015; Li et al., 2017), and conjugate direction misfit minimisation (Yang \& Gurnis, 2016). Studies vary not only in inversion scheme, but also in model complexity and choice of surface observations. In general, inversions for realistic Earth-like properties remain computationally expensive and non-unique due to trade-offs between parameters (e.g. rheology versus buoyancy). This problem highlights the immense value of placing observational constraints on the amplitude and rate of change of dynamic topography, necessitating a thorough assessment of the geological record and its associated uncertainties using techniques outlined in this review.

\section{Closing Remarks}

In summary, observational estimates of present-day dynamic topography and its evolution through space and time provide a unique window into processes operating in the Earth's interior. In turn, convection simulations that can accurately satisfy available constraints on dynamic topography will yield predictive insights into previous Earth states. This interdisciplinary review reflects our increasing understanding of the influence of dynamic topography in shaping the rock record, which has important implications for volcanic systems, oceanic circulation, ice sheet dynamics, and interpretation of paleoclimatic records (e.g. Mitrovica et al., 2020). Improving observational, computational and theoretical constraints on mantle convection is therefore a fundamental goal of our community, with important ramifications for many areas of Earth sciences.

Atkins, S., A. P. Valentine, P. J. Tackley, \& J. Trampert (2016). Using pattern recognition to infer parameters governing mantle convection. Physics of the Earth and Planetary Interiors, 257, 171-186.

Austermann, J. \& J. X. Mitrovica (2015). Calculating gravitationally self-consistent sea level changes driven by dynamic topography. Geophysical Journal International, 203, 1909-1922.

Austermann, J., J. X. Mitrovica, P. Huybers, \& A. Rovere (2017). Detection of a dynamic topography signal in last interglacial sea-level records. Science Advances, 3 (7).

Austermann, J., J. X. Mitrovica, K. Latychev, \& G. A. Milne (2013). Barbados-based estimate of ice volume at Last Glacial Maximum affected by subducted plate. Nature Geoscience, 6, 553-557.

Austermann, J., D. Pollard, J. X. Mitrovica, R. Moucha, A. M. Forte, R. M. DeConto, D. B. Rowley, \& M. E. Raymo (2015). The impact of dynamic topography change on Antarctic ice sheet stability during the mid-Pliocene warm period. Geology, 43 (10), 927-930.

Baby, G., F. Guillocheau, J. Morin, J. Ressouche, C. Robin, O. Broucke, \& M. Dall'Asta (2018). Post-rift stratigraphic evolution of the Atlantic margin of Namibia and South Africa: Implications for the vertical movements of the margin and the uplift history of the South African Plateau. Marine and Petroleum Geology, 97, 169-191.

Balachandar, S., D. A. Yuen, \& D. Reuteler (1992). Time-dependent three dimensional compressible convection with depth-dependent properties. Geophysical Research Letters, 19 (22), 2247-2250.

Ball, P. W., N. J. White, A. Masoud, S. Nixon, et al. (2019). Quanti- 
fying asthenospheric and lithospheric controls on mafic magmatism across North Africa. Geochemistry, Geophysics, Geosystems, 20, 3520-3555.

Ballmer, M. D., C. P. Conrad, E. I. Smith, \& N. Harmon (2013). Non-hotspot volcano chains produced by migration of shear-driven upwelling toward the East Pacific Rise. Geology, 41 (4), 479-482.

Ballmer, M. D., C. P. Conrad, E. I. Smith, \& R. Johnsen (2015). Intraplate volcanism at the edges of the Colorado Plateau sustained by a combination of triggered edge-driven convection and shear-driven upwelling. Geochemistry Geophysics Geosystems, 16, 366-379.

Barnett-Moore, N., R. Hassan, R. D. Müller, S. E. Williams, \& N. Flament (2017). Dynamic topography and eustasy controlled the paleogeographic evolution of northern Africa since the mid-Cretaceous. Tectonics, 36 (5), 929-944.

Bartz, M., G. Rixhon, M. Duval, G. E. King, C. Álvarez Posada J. M. Parés, \& H. Brückner (2018). Successful combination of electron spin resonance, luminescence and palaeomagnetic dating methods allows reconstruction of the Pleistocene evolution of the lower Moulouya river (NE Morocco). Quaternary Science Reviews, 185 153-171.

Beauvais, A., N. J. Bonnet, D. Chardon, N. Arnaud, \& M. Jayananda (2016). Very long-term stability of passive margin escarpment constrained by ${ }^{40} \mathrm{Ar} /{ }^{39} \mathrm{Ar}$ dating of K-Mn oxides. Geology, 44, 299-302.

Beelen, D., C. A.-L. Jackson, S. Patruno, D. M. Hodgson, \& J. P. Trabucho Alexandre (2019). The effects of differential compaction on clinothem geometries and shelf-edge trajectories. Geology, 47 (11), 1011-1014.

Ben-Yaakov, S., E. Ruth, \& I. R. Kaplan (1974). Carbonate compensation depth: Relation to carbonate solubility in ocean waters. Science, 184, 982-984.

Bercovici, D. \& Y. Ricard (2014). Plate tectonics, damage and inheritance. Nature, 508, 513-516.

Bierman, P. \& E. J. Steig (1996). Estimating rates of denudation using cosmogenic isotope abundances in sediment. Earth Surface Processes and Landforms, 21, 125-139.

Billingsley, G. H. \& S. S. Beus (1999). Geology of the Surprise Canyon Formation of the Grand Canyon, Arizona. Museum of Northern Arizona, Flagstaff, Arizona.

Bock, Y. \& D. Melgar (2016). Physical applications of GPS geodesy: A review. Reports on Progress in Physics, 79 (106801).

Bond, G. C. (1976). Evidence for continental subsidence in North America during the Late Cretaceous global submergence. Geology, 4, 557-560.

Bond, G. C. (1978a). Evidence for Late Tertiary uplift of Africa relative to North America, South America, Australia and Europe. The Journal of Geology, 86 (1), 47-65.

Bond, G. C. (1978b). Speculations on real sea-level changes and vertical motions of continents at selected times in the Cretaceous and Tertiary Periods. Geology, 6, 247-250

Bond, G. C. (1979). Evidence for some uplifts of large magnitude in continental platforms. Tectonophysics, 61, 285-305.

Bonnet, N. J., A. Beauvais, N. Arnaud, D. Chardon, \& M. Jayananda (2016). Cenozoic lateritic weathering and erosion history of Peninsular India from ${ }^{40} \mathrm{Ar} /{ }^{39} \mathrm{Ar}$ dating of supergene $\mathrm{K}$-Mn oxides. Chemical Geology, 446, 33-53.

Bower, D. J., M. Gurnis, \& N. Flament (2015). Assimilating lithosphere and slab history in 4-D Earth models. Physics of the Earth and Planetary Interiors, 238, 8-22.

Braun, J. (2010). The many surface expressions of mantle dynamics. Nature Geoscience, 3 (12), 825-833.

Braun, J., X. Robert, \& T. Simon-Labric (2013). Eroding dynamic topography. Geophysical Research Letters, 40, 1494-1499.

Bredow, E., B. Steinberger, R. Gassmöller, \& J. Dannberg (2017). How plume-ridge interaction shapes the crustal thickness pattern of the Réunion hotspot track. Geochemistry, Geophysics, Geosystems, 18 (8), 2930-2948.

Brocher, T. M. (2005). Empirical relations between elastic wavespeeds and density in the Earth's crust. Bulletin of the Seismological Society of America, 95 (6), 2081-2092.

Brodie, J. \& N. J. White (1994). Sedimentary basin inversion caused by igneous underplating: Northwest European continental shelf. Geology, $22(2), 147-150$.

Bufe, A., C. Paola, \& D. W. Burbank (2016). Fluvial bevelling of topography controlled by lateral channel mobility and uplift rate. Nature Geoscience, 9 (9), 706-710.

Bunge, H.-P., C. R. Hagelberg, \& B. J. Travis (2003). Mantle circulation models with variational data assimilation: Inferring past mantle flow and structure from plate motion histories and seismic tomography. Geophysical Journal International, 152, 280-301.
Bunge, H.-P., M. A. Richards, \& J. R. Baumgardner (1996). Effect of depth-dependent viscosity on the planform of mantle convection. Nature, 379 (6564), 436-438.

Burgess, P. M., M. Gurnis, \& L. Moresi (1997). Formation of sequences in the cratonic interior of North America by interaction between mantle, eustatic, and stratigraphic processes. Bulletin of the Geological Society of America, 109 (12), 1515-1535.

Burke, K. \& Y. Gunnell (2008). The African erosion surface: A continental-scale synthesis of geomorphology, tectonics, and environmental change over the past 180 million years. Geological Society of America Memoirs, 201, 1-66.

Burov, E. \& T. Gerya (2014). Asymmetric three-dimensional topography over mantle plumes. Nature, 513, 85-89.

Burstedde, C., G. Stadler, L. Alisic, L. C. Wilcox, E. Tan, M. Gurnis, \& O. Ghattas (2013). Large-scale adaptive mantle convection simulation. Geophysical Journal International, 192, 889-906.

Busse, F. H. (1978). Non-linear properties of thermal convection. Reports on Progress in Physics, 41, 1929-1967.

Campbell, S. M., R. Moucha, L. A. Derry, \& M. E. Raymo (2018). Effects of dynamic topography on the Cenozoic carbonate compensation depth. Geochemistry, Geophysics, Geosystems, 19, 10251034

Cao, W., N. Flament, S. Zahirovic, S. Williams, \& R. D. Müller (2019). The interplay of dynamic topography and eustasy on continental flooding in the late Paleozoic. Tectonophysics, 761, 108-121.

Catuneanu, O. (2006). Principles of sequence stratigraphy. Elsevier, Amsterdam.

Cazenave, A., K. Dominh, M. Rabinowicz, \& G. Ceuleneer (1988). Geoid and depth anomalies over ocean swells and troughs: Evidence of an increasing trend of the geoid to depth ratio with age of plate. Journal of Geophysical Research, 93 (B7), 8064-8077.

Celli, N. L., S. Lebedev, A. J. Schaeffer, \& C. Gaina (2020). African cratonic lithosphere carved by mantle plumes. Nature Communications, 11 (92).

Chang, C. \& L. Liu (2019). Distinct responses of intraplate sedimentation to different subsidence mechanisms: Insights from forward landscape evolution simulations. Journal of Geophysical Research: Earth Surface, 124, 1139-1159.

Chao, B. F. \& J. R. Liau (2019). Gravity changes due to large earthquakes detected in GRACE satellite data via empirical orthogonal function analysis. Journal of Geophysical Research: Solid Earth, 3, 3024-3035.

Chardon, D., V. Chevillotte, A. Beauvais, G. Grandin, \& B. Boulangé (2006). Planation, bauxites and epeirogeny: One or two paleosurfaces on the West African margin? Geomorphology, 82, 273-282.

Chardon, D., J.-L. Grimaud, D. Rouby, A. Beauvais, \& F. Christophoul (2016). Stabilization of large drainage basins over geological time scales: Cenozoic West Africa, hot spot swell growth, and the Niger River. Geochemistry, Geophysics, Geosystems, 17, 1164-1181.

Chowdhury, M. K. R., V. Venkatesh, M. A. Anandalwar, \& D. K. Paul (1965). Recent concepts on the origin of Indian laterite. Memoirs of the Geological Survey of India, 31 A (6), 547-558.

Christensen, N. I. \& W. D. Mooney (1995). Seismic velocity structure and composition of the continental crust: A global view. Journal of Geophysical Research, 100 (B7), 9761-9788.

Clark, M. K., L. H. Royden, K. X. Whipple, B. C. Burchfiel, X. Zhang, \& W. Tang (2006). Use of a regional, relict landscape to measure vertical deformation of the eastern Tibetan Plateau. Journal of Geophysical Research, 111 (F03002).

Cochran, J. R. \& M. Talwani (1977). Free-air gravity anomalies in the world's oceans and their relationship to residual elevation. Geophysical Journal of the Royal Astronomical Society, 50, 495-552.

Codilean, A. T., H. Munack, T. J. Cohen, W. M. Saktura, A. Gray, \& S. M. Mudd (2018). OCTOPUS: An open cosmogenic isotope and luminescence database. Earth System Science Data, 10 (4), 2123-2139.

Colli, L., S. Ghelichkhan, \& H.-P. Bunge (2016). On the ratio of dynamic topography and gravity anomalies in a dynamic Earth. Geophysical Research Letters, 43, 2510-2516.

Colli, L., S. Ghelichkhan, H. P. Bunge, \& J. Oeser (2018). Retrodictions of Mid Paleogene mantle flow and dynamic topography in the Atlantic region from compressible high resolution adjoint mantle convection models: Sensitivity to deep mantle viscosity and tomographic input model. Gondwana Research, 53, 252-272.

Coltice, N., M. Gérault, \& M. Ulvrová (2017). A mantle convection perspective on global tectonics. Earth-Science Reviews, 165, 120150.

Conder, J. A., D. W. Forsyth, \& E. M. Parmentier (2002). Asthenospheric flow and asymmetry of the East Pacific Rise, MELT area. Journal of Geophysical Research: Solid Earth, 107 (B12), 2344. 
Conrad, C. P. \& M. Gurnis (2003). Seismic tomography, surface uplift and the breakup of Gondwanaland: Integrating mantle convection backwards in time. Geochemistry, Geophysics, Geosystems, 4 (3).

Conrad, C. P. \& L. Husson (2009). Influence of dynamic topography on sea level and its rate of change. Lithosphere, 1 (2), 110-120.

Conrad, C. P., B. Steinberger, \& T. H. Torsvik (2013). Stability of active mantle upwelling revealed by net characteristics of plate tectonics. Nature, 498, 479-482.

Conrad, C. P., B. Wu, E. I. Smith, T. A. Bianco, \& A. Tibbetts (2010). Shear-driven upwelling induced by lateral viscosity variations and asthenospheric shear: A mechanism for intraplate volcanism. Physics of the Earth and Planetary Interiors, 178, 162-175.

Conway-Jones, B. W., G. G. Roberts, A. Fichtner, \& M. J. Hoggard (2019). Neogene epeirogeny of Iberia. Geochemistry, Geophysics, Geosystems, 20, 1138-1163.

Corrieu, V., C. Thoraval, \& Y. Ricard (1995). Mantle dynamics and geoid Green functions. Geophysical Journal International, 120, $516-523$.

Cowie, L., N. Kusznir, \& G. Manatschal (2015). Determining the COB location along the Iberian margin and Galicia Bank from gravity anomaly inversion, residual depth anomaly and subsidence analysis. Geophysical Journal International, 203, 1355-1372.

Croissant, T. \& J. Braun (2014). Constraining the stream power law: A novel approach combining a landscape evolution model and an inversion method. Earth Surface Dynamics, 2, 155-166.

Crosby, A. G., D. P. McKenzie, \& J. G. Sclater (2006). The relationship between depth, age and gravity in the oceans. Geophysical Journal International, 166, 553-573.

Cross, T. A. \& R. H. Pilger (1978). Tectonic controls of late Cretaceous sedimentation, western interior, USA. Nature, 274, 653-657.

Crowley, J. W., J. X. Mitrovica, R. C. Bailey, M. E. Tamisiea, \& J. L. Davis (2006). Land water storage within the Congo Basin inferred from GRACE satellite gravity data. Geophysical Research Letters, $33(19), 2-5$.

Czarnota, K., M. J. Hoggard, N. J. White, \& J. Winterbourne (2013). Spatial and temporal patterns of Cenozoic dynamic topography around Australia. Geochemistry, Geophysics, Geosystems, 14, 634658

Czarnota, K., G. G. Roberts, N. J. White, \& S. Fishwick (2014). Spatial and temporal patterns of Australian dynamic topography from river profile modeling. Journal of Geophysical Research: Solid Earth, 119, 1384-1424.

Dannberg, J., Z. Eilon, U. Faul, R. Gassmöller, P. Moulik, \& R. Myhill (2017). The importance of grain size to mantle dynamics and seismological observations. Geochemistry, Geophysics, Geosystems, 18, 3034-3061.

Darwin, C. R. (1842). The structure and distribution of coral reefs. Being the first part of the geology of the voyage of the Beagle, under the command of Capt. Fitzroy, R.N. during the years 1832 to 1836. Smith Elder and Co, London.

Davies, D. R. \& J. H. Davies (2009). Thermally-driven mantle plumes reconcile multiple hot-spot observations. Earth and Planetary Science Letters, 278, 50-54.

Davies, D. R. \& N. Rawlinson (2014). On the origin of recent intraplate volcanism in Australia. Geology, 42 (12), 1031-1034.

Davies, D. R., A. P. Valentine, S. C. Kramer, N. Rawlinson, M. J. Hoggard, C. M. Eakin, \& C. R. Wilson (2019). Earth's multi-scale topographic response to global mantle flow. Nature Geoscience, 12, $845-850$.

Davis, M. W., N. J. White, K. F. Priestley, B. J. Baptie, \& F. J. Tilmann (2012). Crustal structure of the British Isles and its epeirogenic consequences. Geophysical Journal International, 190, $705-725$.

Davis, R. \& O. A. Schaeffer (1955). Chlorine-36 in nature. Annals of the New York Academy of Sciences, 62, 107-121.

Davis, W. M. (1899). The geographical cycle. The Geographical Journal, 14 (5), 481-504.

Davis, W. M. (1930). Rock floors in arid and in humid climates. I. The Journal of Geology, 38 (1), 1-27.

Dietrich, W. E., D. G. Bellugi, L. S. Sklar, J. D. Stock, A. M. Heimsath, \& J. J. Roering (2003). Geomorphic transport laws for predicting landscape form and dynamics. In: Geophysical Monograph Series: Prediction in Geomorphology (edited by P. R. Wilcock \& R. M. Iverson), vol. 135, pp. 103-132. American Geophysical Union.

Ding, X., T. Salles, N. Flament, C. Mallard, \& P. F. Rey (2019) Drainage and sedimentary responses to dynamic topography. Geophysical Research Letters, 46, 14,385-14,394.

Duller, G. A. T. \& A. G. Wintle (2012). A review of the thermally transferred optically stimulated luminescence signal from quartz for dating sediments. Quaternary Geochronology, 7, 6-20.
Dziewonski, A. M. \& D. L. Anderson (1984). Seismic tomography of the Earth's interior: The first three-dimensional models of the Earth's structure promise to answer some basic questions of geodynamics and signify a revolution in Earth science. American Scientist, 72 (5), 483-494.

Eakin, C. M. \& C. Lithgow-Bertelloni (2018). An overview of dynamic topography: The influence of mantle circulation on surface topography and landscape. In: Mountains, Climate, and Biodiversity (edited by C. Hoorn, A. Perrigo, \& A. Antonelli), chap. 3, pp. 3750. John Wiley and Sons Ltd, 1 edn.

Eakin, C. M., C. Lithgow-Bertelloni, \& F. M. Dávila (2014). Influence of Peruvian flat-subduction dynamics on the evolution of western Amazonia. Earth and Planetary Science Letters, 404, 250-260.

Eiler, J. M. (2007). "Clumped-isotope" geochemistry - The study of naturally-occurring, multiply-substituted isotopologues. Earth and Planetary Science Letters, 262, 309-327.

Elder, J. (1976). The bowels of the Earth. Oxford University Press, Glasgow.

Emiliani, C. (1950). Isotopic paleotemperatures. Science, 154 (3751), $851-857$.

England, P. \& P. Molnar (1990). Surface uplift, uplift of rocks, and exhumation of rocks. Geology, 18, 1173-1177.

Faccenna, C., P. Glišović, A. Forte, T. W. Becker, E. Garzanti, A. Sembroni, \& Z. Gvirtzman (2019). Role of dynamic topography in sustaining the Nile River over 30 million years. Nature Geoscience, 12 , 1012-1017.

Farley, K. A. (2000). Helium diffusion from apatite: General behavior as illustrated by Durango fluorapatite. Journal of Geophysical Research: Solid Earth, 105 (B2), 2903-2914.

Farley, K. A. (2002). (U-Th)/He dating: Techniques, calibrations, and applications. Reviews in Mineralogy and Geochemistry, 47, 819844.

Farrell, W. E. \& J. A. Clark (1976). On postglacial sea level. Geophysical Journal of the Royal Astronomical Society, 46, 647-667.

Feigl, K. L., D. C. Agnew, Y. Bock, D. Dong, et al. (1993). Space geodetic measurement of crustal deformation in central and southern California, 1984-1992. Journal of Geophysical Research, 98 (B12), $21,677-21,712$

Fernandes, N. F. \& W. E. Dietrich (1997). Hillslope evolution by diffusive processes: The timescale for equilibrium adjustments. Water Resources Research, 33 (6), 1307-1318.

Fernandes, V. M. \& G. G. Roberts (2020). Cretaceous to Recent net continental uplift from paleobiological data: Insights into sub-plate support. GSA Bulletin, pp. 1-20.

Fernandes, V. M., G. G. Roberts, N. White, \& A. C. Whittaker (2019) Continental-scale landscape evolution: A history of North American topography. Journal of Geophysical Research: Earth Surface, 124 2689-2722.

Flament, N. (2019). Present-day dynamic topography and lowermantle structure from palaeogeographically constrained mantle flow models. Geophysical Journal International, 216, 2158-2182.

Flament, N., M. Gurnis, \& R. D. Müller (2013). A review of observations and models of dynamic topography. Lithosphere, 5 (2), 189-210.

Flowers, R. M. \& K. A. Farley (2012). Apatite ${ }^{4} \mathrm{He} /{ }^{3} \mathrm{He}$ and (U$\mathrm{Th}) / \mathrm{He}$ evidence for an ancient Grand Canyon. Science, 338, 16161619 .

Forte, A. M. (2007). Constraints on seismic models from other disciplines - Implications for mantle dynamics and composition. Treatise on Geophysics, pp. 805-858.

Forte, A. M. \& R. Peltier (1991). Viscous flow models of global geophysical observables 1. Forward problems. Journal of Geophysical Research, 96 (B12), 20,131-20,159.

Forte, A. M., W. R. Peltier, A. M. Dziewonski, \& R. L. Woodward (1993). Dynamic surface topography: A new interpretation based upon mantle flow models derived from seismic tomography. Geophysical Research Letters, 20 (3), 225-228.

Fox, M., L. Goren, D. A. May, \& S. D. Willett (2014). Inversion of fluvial channels for paleorock uplift rates in Taiwan. Journal of Geophysical Research: Earth Surface, 119, 1853-1875.

Friedrich, A. M., H.-P. Bunge, S. M. Rieger, L. Colli, S. Ghelichkhan, \& R. Nerlich (2018). Stratigraphic framework for the plume mode of mantle convection and the analysis of interregional unconformities on geological maps. Gondwana Research, 53, 159-188.

Gallagher, K. (1995). Evolving temperature histories from apatite fission-track data. Earth and Planetary Science Letters, 136, 421435.

Gallagher, K. (2012). Transdimensional inverse thermal history modeling for quantitative thermochronology. Journal of Geophysical Research: Solid Earth, 117 (B02408). 
Gallagher, K. \& R. Brown (1999). Denudation and uplift at passive margins: The record on the Atlantic Margin of southern Africa. Philosophical Transactions of the Royal Society A, 357, 835-859.

Gallagher, K., R. Brown, \& C. Johnson (1998). Fission track analysis and its applications to geological problems. Annual Review of Earth and Planetary Sciences, 26, 519-572.

Garnero, E. J., A. K. McNamara, \& S.-H. Shim (2016). Continent-sized anomalous zones with low seismic velocity at the base of Earth's mantle. Nature Geoscience, 9 (7), 481-489.

Garzione, C. N., D. J. Auerbach, J. Jin-Sook Smith, J. J. Rosario B. H. Passey, T. E. Jordan, \& J. M. Eiler (2014). Clumped isotope evidence for diachronous surface cooling of the Altiplano and pulsed surface uplift of the Central Andes. Earth and Planetary Science Letters, 393, 173-181.

Ghelichkhan, S. \& H.-P. Bunge (2016). The compressible adjoint equations in geodynamics: Derivation and numerical assessment. International Journal on Geomathematics, 7, 1-30.

Ghelichkhan, S., M. Murböck, L. Colli, R. Pail, \& H. P. Bunge (2018). On the observability of epeirogenic movement in current and future gravity missions. Gondwana Research, 53, 273-284.

Ghosh, P., J. Adkins, H. P. Affek, B. Balta, W. Guo, E. A. Schauble, D. Schrag, \& J. M. Eiler (2006a). ${ }^{13} \mathrm{C}-{ }^{18} \mathrm{O}$ bonds in carbonate minerals: A new kind of paleothermometer. Geochimica et Cosmochimica Acta, 70, 1439-1456.

Ghosh, P., C. N. Garzione, \& J. M. Eiler (2006b). Rapid uplift of the Altiplano revealed through ${ }^{13} \mathrm{C}-{ }^{18} \mathrm{O}$ bonds in paleosol carbonates. Science, 311, 511-515.

Gleadow, A. J. \& I. R. Duddy (1981). A natural long-term track annealing experiment for apatite. Nuclear Tracks and Radiation Measurements, 5, 169-174.

Glišović, P. \& A. M. Forte (2014). Reconstructing the Cenozoic evolution of the mantle: Implications for mantle plume dynamics under the Pacific and Indian plates. Earth and Planetary Science Letters, $390,146-156$

Glišović, P. \& A. M. Forte (2015). Importance of initial buoyancy field on evolution of mantle thermal structure: Implications of surface boundary conditions. Geoscience Frontiers, 6, 3-22.

Glišović, P. \& A. M. Forte (2016). A new back-and-forth iterative method for time-reversed convection modeling: Implications for the Cenozoic evolution of 3-D structure and dynamics of the mantle. Journal of Geophysical Research: Solid Earth, 121 (6), 4067-4084.

Glotzbach, C. (2015). Deriving rock uplift histories from data-driven inversion of river profiles. Geology, 43 (6), 467-470.

Godin, L., R. R. Parrish, R. L. Brown, \& K. V. Hodges (2001) Crustal thickening leading to exhumation of the Himalayan metamorphic core of central Nepal: Insight from U-Pb Geochronology and ${ }^{40} \mathrm{Ar} /{ }^{39} \mathrm{Ar}$ Thermochronology. Tectonics, 20 (5), 729-747.

Golle, O., C. Dumoulin, G. Choblet, \& O. Čadek (2012). Topography and geoid induced by a convecting mantle beneath an elastic lithosphere. Geophysical Journal International, 189, 55-72.

Goren, L., M. Fox, \& S. D. Willett (2014). Tectonics from fluvial topography using formal linear inversion: Theory and applications to the Inyo Mountains, California. Journal of Geophysical Research F: Earth Surface, 119 (8), 1651-1681.

Green, P. F., I. R. Duddy, A. J. Gleadow, P. R. Tingate, \& G. M. Laslett (1985). Fission-track annealing in apatite: Track length measurements and the form of the Arrhenius plot. Nuclear Tracks and Radiation Measurements, 10 (3), 323-328.

Green, P. F., I. R. Duddy, A. J. Gleadow, P. R. Tingate, \& G. M. Laslett (1986). Thermal annealing of fission tracks in apatite 1. A qualitative description. Chemical Geology: Isotope Geoscience Section, 59, 237-253.

Gregory, K. M. \& C. G. Chase (1992). Tectonic significance of paleobotanically estimated climate and altitude of the late Eocene erosion surface, Colorado. Geology, 20 (7), 581-585.

Guerri, M., F. Cammarano, \& J. A. D. Connolly (2015). Effects of chemical composition, water and temperature on physical properties of continental crust. Geochemistry Geophysics Geosystems, $16,2431-2449$.

Guerri, M., F. Cammarano, \& P. J. Tackley (2016). Modelling Earth's surface topography: Decomposition of the static and dynamic components. Physics of the Earth and Planetary Interiors, 261, 172186.

Guillaume, B., C. Gautheron, T. Simon-Labric, J. Martinod, M. Roddaz, \& E. Douville (2013). Dynamic topography control on Patagonian relief evolution as inferred from low temperature thermochronology. Earth and Planetary Science Letters, 364, 157-167.

Guillocheau, F., B. Simon, G. Baby, P. Bessin, C. Robin, \& O. Dauteuil (2018). Planation surfaces as a record of mantle dynamics: The case example of Africa. Gondwana Research, 53, 82-98.
Guralnik, B., M. Jain, F. Herman, C. Ankjærgaard, et al. (2015). OSLthermochronometry of feldspar from the KTB borehole, Germany. Earth and Planetary Science Letters, 423, 232-243.

Gurnis, M. (1993). Phanerozoic marine inundation of continents driven by dynamic topography above subducting slabs. Nature, 364, 589593.

Gurnis, M., J. X. Mitrovica, J. Ritsema, \& H.-J. van Heijst (2000) Constraining mantle density structure using geological evidence of surface uplift rates: The case of the African Superplume. Geochemistry, Geophysics, Geosystems, 1 (7).

Gurnis, M., R. D. Müller, \& L. Moresi (1998). Cretaceous vertical motion of Australia and the Australian-Antarctic Discordance. Science, 279, 1499-1504.

Hager, B. H. (1984). Subducted slabs and the geoid: Constraints on mantle rheology and flow. Journal of Geophysical Research, 89 (B7), 6003-6015.

Hager, B. H., R. W. Clayton, \& M. A. Richards (1985). Lower mantle heterogeneity, dynamic topography and the geoid. Nature, 313, 541-545.

Hager, B. H. \& R. J. O. Connell (1981). A simple global model of plate dynamics and mantle convection. Journal of Geophysical Research, 86 (B6), 4843-4867.

Han, S.-C., C. K. Shum, M. Bevis, C. Ji, \& C.-Y. Kuo (2006). Crustal dilatation observed by GRACE after the 2004 Sumatra-Andaman earthquake. Science, 313, 658-662.

Haq, B. U., J. Hardenbol, \& P. R. Vail (1987). Chronology of fluctuating sea levels since the Triassic. Science, 235, 1156-1167.

Harrison, T. M., J. Célérier, A. B. Aikman, J. Hermann, \& M. T. Heizler (2009). Diffusion of ${ }^{40} \mathrm{Ar}$ in muscovite. Geochimica et Cosmochimica Acta, 73, 1039-1051.

Hartley, R. A., G. G. Roberts, N. White, \& C. Richardson (2011). Transient convective uplift of an ancient buried landscape. Nature Geoscience, 4, 562-565.

Hayek, J. N., B. Vilacís, H. P. Bunge, A. M. Friedrich, S. Carena, \& Y. Vibe (2020). Continent-scale hiatus maps for the Atlantic realm and Australia since the Upper Jurassic and links to mantle flow induced dynamic topography. Proceedings of the Royal Society A: Mathematical, Physical and Engineering Sciences, 476 (20200390).

Heine, C., R. D. Müller, B. Steinberger, \& L. DiCaprio (2010). Integrating deep Earth dynamics in paleogeographic reconstructions of Australia. Tectonophysics, 483, 135-150.

Heister, T., J. Dannberg, R. Gassmöller, \& W. Bangerth (2017). High accuracy mantle convection simulation through modern numerical methods - II: Realistic models and problems. Geophysical Journal International, 210, 833-851.

Hobley, D. E., J. M. Adams, S. Siddhartha Nudurupati, E. W. Hutton, N. M. Gasparini, E. Istanbulluoglu, \& G. E. Tucker (2017). Creative computing with Landlab: An open-source toolkit for building, coupling, and exploring two-dimensional numerical models of Earthsurface dynamics. Earth Surface Dynamics, 5, 21-46.

Hoggard, M. J., K. Czarnota, F. D. Richards, D. L. Huston, A. L. Jaques, \& S. Ghelichkhan (2020). Global distribution of sedimenthosted metals controlled by craton edge stability. Nature Geoscience, $13,504-510$.

Hoggard, M. J., N. J. White, \& D. Al-Attar (2016). Global dynamic topography observations reveal limited influence of large-scale mantle flow. Nature Geoscience, 9 (6), 456-463.

Hoggard, M. J., J. Winterbourne, K. Czarnota, \& N. White (2017) Oceanic residual depth measurements, the plate cooling model, and global dynamic topography. Journal of Geophysical Research: Solid Earth, 122, 2328-2372.

Höink, T. \& A. Lenardic (2010). Long wavelength convection, Poiseuille-Couette flow in the low-viscosity asthenosphere and the strength of plate margins. Geophysical Journal International, 180 23-33.

Holdgate, G. C. Rodriquez, E. Johnstone, M. Wallace, \& S. Gallagher (2003). The Gippsland Basin Top Latrobe unconformity, and its expression in other SE Australia basins. The APPEA Journal, 43 (1), 149-173.

Howard, A. D., W. E. Dietrich, \& M. A. Seidl (1994). Modeling fluvial erosion on regional to continental scales. Journal of Geophysical Research, 99 (B7), 13,971-13,986.

Howard, A. D. \& G. Kerby (1983). Channel changes in badlands. Geological Society of America Bulletin, 94, 739-752.

Huang, J. \& S. Zhong (2005). Sublithospheric small-scale convection and its implications for the residual topography at old ocean basins and the plate model. Journal of Geophysical Research: Solid Earth, 110 (B05404).

Huntington, K. W. \& A. R. Lechler (2015). Carbonate clumped isotope thermometry in continental tectonics. Tectonophysics, 647-648, 1 20 
Huntley, D. J., D. I. Godfrey-Smith, \& M. L. Thewalt (1985). Optical dating of sediments. Nature, 313, 105-107.

Huyghe, D., F. Mouthereau, L. Ségalen, \& M. Furió (2020). Long-term dynamic topographic support during post-orogenic crustal thinning revealed by stable isotope $\left(\delta^{18} \mathrm{O}\right)$ paleo-altimetry in eastern Pyrenees. Scientific Reports, 10, 2267.

Jackson, I. \& U. H. Faul (2010). Grainsize-sensitive viscoelastic relaxation in olivine: Towards a robust laboratory-based model for seismological application. Physics of the Earth and Planetary Interiors, 183, 151-163.

Jain, C., A. B. Rozel, \& P. J. Tackley (2019). Quantifying the correlation between mobile continents and elevated temperatures in the subcontinental mantle. Geochemistry, Geophysics, Geosystems, 20, $1358-1386$.

Japsen, P., J. M. Bonow, P. F. Green, J. A. Chalmers, \& K. LidmarBergström (2006). Elevated, passive continental margins: Longterm highs or Neogene uplifts? New evidence from West Greenland. Earth and Planetary Science Letters, 248, 315-324.

Jess, S., R. Stephenson, \& R. Brown (2018). Evolution of the central West Greenland margin and the Nuussuaq Basin: Localised basin uplift along a stable continental margin proposed from thermochronological data. Basin Research, 30 (6), 1230-1246.

Jordan, T. H. (1975). The continental tectosphere. Reviews of Geophysics, 13 (3), 1-12

Jordan, T. H. (1978). Composition and development of the continental tectosphere. Nature, 274, 544-548.

Julià, J., S. Jagadeesh, S. S. Rai, \& T. J. Owens (2009). Deep crustal structure of the Indian shield from joint inversion of $\mathrm{P}$ wave receiver functions and Rayleigh wave group velocities: Implications for Precambrian crustal evolution. Journal of Geophysical Research, 114 (B10313)

Kaban, M. K., P. Schwintzer, I. M. Artemieva, \& W. D. Mooney (2003). Density of the continental roots: Compositional and thermal contributions. Earth and Planetary Science Letters, 209, 53-69.

Kaula, W. M. (1963). Improved geodetic results from camera observations of satellites. Journal of Geophysical Research, 68 (18), $5183-5190$.

Kendall, C. G. S. C. \& W. Schlager (1981). Carbonates and relative changes in sea level. Marine Geology, 44, 181-212.

Ketcham, R. A. (2005). Forward and inverse modeling of lowtemperature thermochronometry data. Reviews in Mineralogy and Geochemistry, 58, 275-314.

Ketcham, R. A., A. Carter, R. A. Donelick, J. Barbarand, \& A. J. Hurford (2007). Improved modeling of fission-track annealing in apatite. American Mineralogist, 92, 799-810.

Ketcham, R. A., R. A. Donelick, \& W. D. Carlson (1999). Variability of apatite fission-track annealing kinetics: III. Extrapolation to geological time scales. American Mineralogist, 84, 1235-1255.

King, G. E., F. Herman, R. Lambert, P. G. Valla, \& B. Guralnik (2016). Multi-OSL-thermochronometry of feldspar. Quaternary Geochronology, 33, 76-87.

King, L. C. (1942). South African scenery: A textbook of geomorphology. Oliver and Boyd, Edinburgh, 1 edn.

King, L. C. (1953). Canons of landscape evolution. Bulletin of the Geological Society of America, 64, 721-752.

King, L. C. (1962). The morphology of the Earth: A study and synthesis of world scenery. Oliver and Boyd, Edinburgh.

King, S. D. \& D. L. Anderson (1998). Edge-driven convection. Earth and Planetary Science Letters, 160, 289-296.

Kirby, E. \& K. Whipple (2001). Quantifying differential rock-uplift rates via stream profile analysis. Geology, 29 (5), 415-418.

Klöcking, M., M. J. Hoggard, V. Rodríguez Tribaldos, F. D. Richards, A. R. Guimaraes, J. Maclennan, \& N. J. White (2020). Neogene to recent volcanism and dynamic uplift in northeast Brazil and southwest Africa. Earth and Planetary Science Letters, 547 (116464).

Klöcking, M., N. J. White, J. Maclennan, D. McKenzie, \& J. G. Fitton (2018). Quantitative relationships between basalt geochemistry, shear wave velocity, and asthenospheric temperature beneath western North America. Geochemistry, Geophysics, Geosystems, 19, 3376-3404.

Knopoff, L. (1964). The convection current hypothesis. Reviews of Geophysics, 2 (1), 89-122.

Korenaga, T. \& J. Korenaga (2008). Subsidence of normal oceanic lithosphere, apparent thermal expansivity, and seafloor flattening. Earth and Planetary Science Letters, 268, 41-51.

Kronbichler, M., T. Heister, \& W. Bangerth (2012). High accuracy mantle convection simulation through modern numerical methods. Geophysical Journal International, 191, 12-29.
Lal, D. \& B. Peters (1967). Cosmic ray produced radioactivity on the Earth. In: Cosmic Rays II (edited by K. Sitte), pp. 551-612. Springer Berlin Heidelberg, Berlin.

Lamb, S., J. D. Moore, M. Perez-Gussinye, \& T. Stern (2020). Global whole lithosphere isostasy: Implications for surface elevations, structure, strength, and densities of the continental lithosphere. Geochemistry, Geophysics, Geosystems, 21 (e2020GC009150).

Laslett, G. M., P. F. Green, I. R. Duddy, \& A. J. Gleadow (1987). Thermal annealing of fission tracks in apatite 2. A quantitative analysis. Chemical Geology: Isotope Geoscience Section, 65, 1-13.

Lavier, L. L., M. S. Steckler, \& F. Brigaud (2001). Climatic and tectonic control on the Cenozoic evolution of the West African margin. Marine Geology, 178, 63-80.

Lay, T., J. Hernlund, \& B. Buffett (2008). Core-mantle boundary heat flow. Nature Geoscience, 1 (1), 25-32.

Li, D., M. Gurnis, \& G. Stadler (2017). Towards adjoint-based inversion of time-dependent mantle convection with nonlinear viscosity. Geophysical Journal International, 209, 86-105.

Lin, P. Y. P., J. B. Gaherty, G. Jin, J. A. Collins, D. Lizarralde, R. L. Evans, \& G. Hirth (2016). High-resolution seismic constraints on flow dynamics in the oceanic asthenosphere. Nature, 535, 538-541.

Lithgow-Bertelloni, C. \& M. A. Richards (1998). The dynamics of Cenozoic and Mesozoic plate motions. Reviews of Geophysics, 36 (1), 27-78.

Lithgow-Bertelloni, C. R. \& M. Gurnis (1997). Cenozoic subsidence and uplift of continents from time-varying dynamic topography. $\mathrm{Ge}$ ology, 25 (8), 735-738.

Liu, L., S. Spasojević, \& M. Gurnis (2008). Reconstructing Farallon Plate subduction beneath North America back to the Late Cretaceous. Science, 322, 934-938.

Lovell, B. (2010). A pulse in the planet: Regional control of highfrequency changes in relative sea level by mantle convection. Journal of the Geological Society, London, 167, 637-648.

Luke, J. C. (1972). Mathematical models for landform evolution. Journal of Geophysical Research, 77 (14), 2460-2464.

Łuszczak, K., C. Persano, \& F. M. Stuart (2018). Early Cenozoic denudation of central west Britain in response to transient and permanent uplift above a mantle plume. Tectonics, 37, 914-934.

Lyell, C. (1830). Principles of geology, being an attempt to explain the former changes of the Earth's surface, by reference to causes now in operation. John Murray, London.

Machetel, P. \& D. A. Yuen (1986). The onset of time-dependent convection in spherical shells as a clue to chaotic convection in the Earth's mantle. Geophysical Research Letters, 13 (13), 1470-1473.

Matthews, K. J., A. J. Hale, M. Gurnis, R. D. Müller, \& L. DiCaprio (2011). Dynamic subsidence of Eastern Australia during the Cretaceous. Gondwana Research, 19, 372-383.

McCrea, J. M. (1950). On the isotopic chemistry of carbonates and a paleotemperature scale. The Journal of Chemical Physics, 18 (6), 849-857.

McElwain, J. C. (2004). Climate-independent paleoaltimetry using stomatal density in fossil leaves as a proxy for $\mathrm{CO}_{2}$ partial pressure. Geology, 32 (12), 1017-1020.

McKenzie, D. P. (1967). Some remarks on heat flow and gravity anomalies. Journal of Geophysical Research, 72 (24), 6261-6273.

McKenzie, D. P. (1968). The influence of the boundary conditions and rotation on convection in the Earth's mantle. Geophysical Journal of the Royal Astronomical Society, 15, 457-500.

McKenzie, D. P. (1978). Some remarks on the development of sedimentary basins. Earth and Planetary Science Letters, 40, 25-32.

McKenzie, D. P., J. Roberts, \& N. Weiss (1973). Numerical models of convection in the Earth's mantle. Tectonophysics, 19, 89-103.

McKenzie, D. P., J. M. Roberts, \& N. O. Weiss (1974). Convection in the Earth's mantle: Towards a numerical simulation. Journal of Fluid Mechanics, 62 (3), 465-538.

McNab, F., P. W. Ball, M. J. Hoggard, \& N. J. White (2018). Neogene uplift and magmatism of Anatolia: Insights from drainage analysis and basaltic geochemistry. Geochemistry, Geophysics, Geosystems, $19,175-213$.

Menard, H. W. (1965). Sea floor relief and mantle convection. Physics and Chemistry of the Earth, 6, 315-364.

Menard, H. W. (1969). Elevation and subsidence of oceanic crust. Earth and Planetary Science Letters, 6, 275-284.

Menard, H. W. (1973). Depth anomalies and the bobbing motion of drifting islands. Journal of Geophysical Research, 78 (23), 51285137.

Meyer, H. W. (2007). A review of paleotemperature lapse rate methods for estimating paleoelevation from fossil floras. Reviews in Mineralogy and Geochemistry, 66, 155-171. 
Miller, K. G., M. A. Kominz, J. V. Browning, J. D. Wright, et al. (2005). The Phanerozoic record of global sea-level change. Science, 310, 1293-1298.

Millett, J. M., M. J. Hole, D. W. Jolley, N. Schofield, \& E. Campbell (2016). Frontier exploration and the North Atlantic Igneous Province: New insights from a $2.6 \mathrm{~km}$ offshore volcanic sequence in the NE Faroe-Shetland Basin. Journal of the Geological Society, $173(2), 320-336$

Milne, G. A., J. L. Davis, J. X. Mitrovica, H. G. Scherneck, J. M. Johansson, M. Vermeer, \& H. Koivula (2001). Space-geodetic constraints on glacial isostatic adjustment in Fennoscandia. Science, $291,2381-2385$.

Mitrovica, J. X., J. Austermann, S. Coulson, J. R. Creveling, M. J. Hoggard, G. T. Jarvis, \& F. D. Richards (2020). Dynamic topography and ice age paleoclimate. Annual Review of Earth and Planetary Sciences, 48, 585-621.

Mitrovica, J. X., C. Beaumont, \& G. T. Jarvis (1989). Tilting of continental interiors by the dynamical effects of subduction. Tectonics, 8 (5), 1079-1094

Mitrovica, J. X. \& G. A. Milne (2002). On the origin of late Holocene sea-level highstands within equatorial ocean basins. Quaternary Science Reviews, 21, 2179-2190.

Molnar, P., P. C. England, \& C. H. Jones (2015). Mantle dynamics, isostasy, and the support of high terrain. Journal of Geophysical Research: Solid Earth, 120, 1932-1957.

Mooney, W. D. (2015). Crust and lithospheric structure - Global crustal structure. In: Treatise on Geophysics, vol. 1, pp. 339-390. Elsevier Inc., 2nd edn.

Moucha, R. \& A. M. Forte (2011). Changes in African topography driven by mantle convection. Nature Geoscience, 4 (10), 707-712.

Moucha, R., A. M. Forte, J. X. Mitrovica, D. B. Rowley, S. Quéré, N. A. Simmons, \& S. P. Grand (2008). Dynamic topography and long-term sea-level variations: There is no such thing as a stable continental platform. Earth and Planetary Science Letters, 271, 101-108.

Müller, R. D., M. Sdrolias, C. Gaina, B. Steinberger, \& C. Heine (2008). Long-term sea-level fluctuations driven by ocean basin dynamics. Science, 319, 1357-1362.

Murray, J. \& A. F. Renard (1891). Report on deep-sea deposits based on the specimens collected during the voyage of H.M.S. Challenger in the years 1872 to 1876 . In: Report on the scientific results of the voyage of H.M.S. Challenger during the years $1873-76$, p. 688. Eyre \& Spottiswoode, London.

Nakiboglu, S. M. (1982). Hydrostatic theory of the Earth and its mechanical implications. Physics of the Earth and Planetary Interiors, 28, 302-311.

Nimmo, F. (2015). Energetics of the core. In: Treatise on Geophysics (edited by G. Schubert), vol. 8, chap. 2. Elsevier, Amsterdam, 2 edn.

Nishiizumi, K., C. P. Kohl, J. R. Arnold, R. Dorn, J. Klein, D. Fink, R. Middleton, \& D. Lal (1993). Role of in situ cosmogenic nuclides ${ }^{10} \mathrm{Be}$ and ${ }^{26} \mathrm{Al}$ in the study of diverse geomorphic processes. Earth Surface Processes and Landforms, 18, 407-425.

Olson, P., G. Schubert, \& C. Anderson (1987). Plume formation in the D"-layer and the roughness of the core-mantle boundary. Nature, $327,409-413$.

O'Malley, C. P. B., N. J. White, G. G. Roberts, \& S. N. Stephenson (2021). Large-scale tectonic forcing of the African landscape and its drainage patterns. Journal of Geophysical Research: Earth Surface.

Osei Tutu, A., S. V. Sobolev, B. Steinberger, A. A. Popov, \& I. Rogozhina (2018). Evaluating the influence of plate boundary friction and mantle viscosity on plate velocities. Geochemistry, Geophysics, Geosystems, 19, 642-666.

Panasyuk, S. V. \& B. H. Hager (2000). Models of isostatic and dynamic topography, geoid anomalies, and their uncertainties. Journal of Geophysical Research: Solid Earth, 105 (B12), 28,199-28,209.

Pari, G. \& W. R. Peltier (2000). Subcontinental mantle dynamics: A further analysis based on the joint constraints of dynamic surface topography and free-air gravity. Journal of Geophysical Research, 105 (B3), 5635-5662.

Parmentier, E. M., C. Sotin, \& B. J. Travis (1994). Turbulent 3-D thermal convection in an infinite Prandtl number, volumetrically heated fluid: Implications for mantle dynamics. Geophysical Journal International, 116, 241-251.

Parmentier, E. M., D. L. Turcotte, \& K. E. Torrance (1976). Studies of finite amplitude non-Newtonian thermal convection with application to convection in the Earth's mantle. Journal of Geophysical Research, 81 (11), 1839-1846.

Parnell-Turner, R., N. White, T. J. Henstock, S. M. Jones, J. Maclennan, \& B. J. Murton (2017). Causes and consequences of di- achronous V-shaped ridges in the North Atlantic Ocean. Journal of Geophysical Research: Solid Earth, 122, 8675-8708.

Parnell-Turner, R. E., N. J. White, N. McCave, T. J. Henstock, B. J Murton, \& S. M. Jones (2015). Architecture of North Atlantic contourite drifts modified by transient circulation of the Icelandic mantle plume. Geochemistry, Geophysics, Geosystems, 16, 3414-3435.

Parsons, B. \& S. Daly (1983). The relationship between surface topography, gravity anomalies, and temperature structure of convection. Journal of Geophysical Research, 88 (B2), 1129-1144.

Parsons, B. \& J. G. Sclater (1977). An analysis of the variation of ocean floor bathymetry and heat flow with age. Journal of Geophysical Research, 82 (5), 803-827.

Patočka, V., H. Čížková, \& P. J. Tackley (2019). Do elasticity and a free surface affect lithospheric stresses caused by upper-mantle convection? Geophysical Journal International, 216, 1740-1760.

Pekeris, C. L. (1935). Thermal convection in the interior of the Earth Geophysical Supplements to the Monthly Notices of the Royal Astronomical Society, 3 (8), 343-367.

Pelletier, J. D. (2010). How do pediments form?: A numerical modeling investigation with comparison to pediments in southern Arizona, USA. Bulletin of the Geological Society of America, 122 1815-1829

Peltier, W. R., D. F. Argus, \& R. Drummond (2015). Space geodesy constrains ice age terminal deglaciation: The global ICE-6G_C (VM5a) model. Journal of Geophysical Research: Solid Earth, 120, 450-487.

Perron, J. T. \& L. Royden (2013). An integral approach to bedrock river profile analysis. Earth Surface Processes and Landforms, 38, 570-576.

Petersen, K. D., S. B. Nielsen, O. R. Clausen, R. Stephenson, \& T. Gerya (2010). Small-scale mantle convection produces stratigraphic sequences in sedimentary basins. Science, 329, 827-830.

Phillips, J. D. (2002). Erosion, isostatic response, and the missing peneplains. Geomorphology, 45, 225-241.

Plank, T. \& D. W. Forsyth (2016). Thermal structure and melting conditions in the mantle beneath the Basin and Range province from seismology and petrology. Geochemistry, Geophysics, Geosystems, 17 (4), 1312-1338.

Poage, M. A. \& C. P. Chamberlain (2001). Empirical relationships between elevation and the stable isotope composition of precipitation and surface waters: Considerations for studies of paleoelevation change. American Journal of Science, 301, 1-15.

Pomar, L. (2001). Types of carbonate platforms: A genetic approach. Basin Research, 13, 313-334.

Poore, H. R., R. Samworth, N. J. White, S. M. Jones, \& I. N. McCave (2006). Neogene overflow of Northern Component Water at the Greenland-Scotland Ridge. Geochemistry, Geophysics, Geosystems, 7 (6).

Priestley, K. \& D. P. McKenzie (2013). The relationship between shear wave velocity, temperature, attenuation and viscosity in the shallow part of the mantle. Earth and Planetary Science Letters, 381, 7891.

Pritchard, D., G. G. Roberts, N. J. White, \& C. N. Richardson (2009). Uplift histories from river profiles. Geophysical Research Letters 36 (L24301).

Ratnaswamy, V., G. Stadler, \& M. Gurnis (2015). Adjoint-based estimation of plate coupling in a non-linear mantle flow model: Theory and examples. Geophysical Journal International, 202, 768-786.

Rayleigh, L. (1916). LIX. On convection currents in a horizontal layer of fluid, when the higher temperature is on the under side. The London, Edinburgh, and Dublin Philosophical Magazine and Journal of Science, 32 (192), 529-546.

Reiners, P. W. \& M. T. Brandon (2006). Using thermochronology to understand orogenic erosion. Annual Review of Earth and Planetary Sciences, 34, 419-466.

Reiners, P. W., T. A. Ehlers, \& P. K. Zeitler (2005). Past, present, and future of thermochronology. Reviews in Mineralogy and Geochemistry, 58, 1-18.

Ricard, Y., M. A. Richards, C. Lithgow-Bertelloni, \& Y. Le Stunff (1993). A geodynamic model of mantle density heterogeneity. Journal of Geophysical Research, 98 (B12), 21,895-21,909.

Richards, F. D., M. J. Hoggard, L. R. Cowton, \& N. J. White (2018) Reassessing the thermal structure of oceanic lithosphere with revised global inventories of basement depths and heat flow measurements. Journal of Geophysical Research: Solid Earth, 123, 91369161.

Richards, F. D., M. J. Hoggard, A. G. Crosby, S. Ghelichkhan, \& N. J. White (2020a). Structure and dynamics of the oceanic lithosphereasthenosphere system. Physics of the Earth and Planetary Interiors, 308 (106559). 
Richards, F. D., M. J. Hoggard, \& N. J. White (2016). Cenozoic epeirogeny of the Indian peninsula. Geochemistry, Geophysics, Geosystems, 17, 4920-4954.

Richards, F. D., M. J. Hoggard, N. J. White, \& S. Ghelichkhan (2020b). Quantifying the relationship between short-wavelength dynamic topography and thermomechanical structure of the upper mantle using calibrated parameterization of anelasticity. Journal of Geophysical Research: Solid Earth, 125 (e2019JB019062).

Richter, F. M. (1973). Convection and the large-scale circulation of the mantle. Journal of Geophysical Research, 78 (35), 8735-8745.

Riley, K. E., T. M. Rittenour, J. L. Pederson, \& P. Belmont (2019). Erosion rates and patterns in a transient landscape, Grand Staircase, southern Utah, USA. Geology, 47 (9), 811-814.

Roberts, G. G. (2019). Scales of similarity and disparity between drainage networks. Geophysical Research Letters, 46, 3781-3790.

Roberts, G. G., J. D. Paul, N. White, \& J. Winterbourne (2012a). Temporal and spatial evolution of dynamic support from river profiles: A framework for Madagascar. Geochemistry, Geophysics, Geosystems, 13 (4).

Roberts, G. G., N. White, M. J. Hoggard, P. W. Ball, \& C. Meenan (2018). A Neogene history of mantle convective support beneath Borneo. Earth and Planetary Science Letters, 496, 142-158.

Roberts, G. G., N. White, \& B. H. Lodhia (2019). The generation and scaling of longitudinal river profiles. Journal of Geophysical Research: Earth Surface, 124, 137-153.

Roberts, G. G. \& N. J. White (2010). Estimating uplift rate histories from river profiles using African examples. Journal of Geophysical Research, 115 (B02406).

Roberts, G. G., N. J. White, G. L. Martin-Brandis, \& A. G. Crosby (2012b). An uplift history of the Colorado Plateau and its surroundings from inverse modeling of longitudinal river profiles. Tectonics, 31 (TC4022)

Rodríguez Tribaldos, V., N. J. White, G. G. Roberts, \& M. J. Hoggard (2017). Spatial and temporal uplift history of South America from calibrated drainage analysis. Geochemistry, Geophysics, Geosystems, 18, 2321-2353.

Rosenbloom, N. A. \& R. S. Anderson (1994). Hillslope and channel evolution in a marine terraced landscape, Santa Cruz, California. Journal of Geophysical Research, 99 (B7), 14,013-14,029.

Rovere, A., P. J. Hearty, J. Austermann, J. X. Mitrovica, J. Gale, R. Moucha, A. M. Forte, \& M. E. Raymo (2015). Mid-Pliocene shorelines of the US Atlantic coastal plain - An improved elevation database with comparison to Earth model predictions. EarthScience Reviews, 145, 117-131.

Rovere, A., M. E. Raymo, J. X. Mitrovica, P. J. Hearty, M. J. O'Leary, \& J. D. Inglis (2014). The Mid-Pliocene sea-level conundrum: Glacial isostasy, eustasy and dynamic topography. Earth and Planetary Science Letters, 387, 27-33.

Rowley, D. B. (2002). Rate of plate creation and destruction: $180 \mathrm{Ma}$ to present. Bulletin of the Geological Society of America, 114 (8), 927-933.

Rowley, D. B., A. M. Forte, R. Moucha, J. X. Mitrovica, N. A. Simmons, \& S. P. Grand (2013). Dynamic topography change of the eastern United States since 3 million years ago. Science, 340, 15601564.

Rowley, D. B. \& C. N. Garzione (2007). Stable isotope-based paleoaltimetry. Annual Review of Earth and Planetary Sciences, 35, 463-508.

Rudge, J. F., G. G. Roberts, N. J. White, \& C. N. Richardson (2015). Uplift histories of Africa and Australia from linear inverse modeling of drainage inventories. Journal of Geophysical Research: Earth Surface, 120, 894-914.

Rudge, J. F., M. E. Shaw Champion, N. White, D. P. McKenzie, \& B. Lovell (2008). A plume model of transient diachronous uplift at the Earth's surface. Earth and Planetary Science Letters, 267, $146-160$.

Ruetenik, G. A., R. Moucha, \& G. D. Hoke (2016). Landscape response to changes in dynamic topography. Terra Nova, 28, 289-296.

Runcorn, S. K. (1965). Changes in the convection pattern in the Earth's mantle and continental drift: Evidence for a cold origin of the Earth. Philosophical Transactions of the Royal Society A, $258,228-251$.

Sahagian, D. L. (1988). Epeirogenic motions of Africa as inferred from Cretaceous shoreline deposits. Tectonics, 7 (1), 125-138.

Salles, T., N. Flament, \& R. D. Muller (2017). Influence of mantle flow on the drainage of eastern Australia since the Jurassic Period. Geochemistry Geophysics Geosystems, 18, 280-305.

Salles, T. \& L. Hardiman (2016). Badlands: An open-source, flexible and parallel framework to study landscape dynamics. Computers and Geosciences, 91, 77-89.
Sandiford, M. (2007). The tilting continent: A new constraint on the dynamic topographic field from Australia. Earth and Planetary Science Letters, 261, 152-163.

Sarg, J. F. (1988). Carbonate sequence stratigraphy. SEPM Special Publications, 42, 155-181.

Schaeffer, A. J. \& S. Lebedev (2013). Global shear speed structure of the upper mantle and transition zone. Geophysical Journal International, 194, 417-449.

Schlager, W., J. J. G. Reijmer, \& A. Droxler (2003). Highstand shedding of carbonate platforms. Journal of Sedimentary Research, B64 (3), 270-281.

Schoenbohm, L. M., K. X. Whipple, B. C. Burchfiel, \& L. Chen (2004) Geomorphic constraints on surface uplift, exhumation, and plateau growth in the Red River region, Yunnan Province, China. Bulletin of the Geological Society of America, 116, 895-909.

Schumm, S. A. (1993). River response to baselevel change: Implications for sequence stratigraphy. The Journal of Geology, 101 (2) 279-294.

Sembroni, A., C. Faccenna, T. W. Becker, P. Molin, \& B. Abebe (2016). Long-term, deep-mantle support of the Ethiopia-Yemen Plateau. Tectonics, 35 (2), 469-488.

Sembroni, A., A. Kiraly, C. Faccenna, F. Funiciello, T. W. Becker, J. Globig, \& M. Fernandez (2017). Impact of the lithosphere on dynamic topography: Insights from analogue modeling. Geophysical Research Letters, 44 (6), 2693-2702.

Shahnas, M. H., D. A. Yuen, \& R. N. Pysklywec (2018). Inverse problems in geodynamics using machine learning algorithms. Journal of Geophysical Research: Solid Earth, 123, 296-310.

Shepherd, A., E. R. Ivins, A. Geruo, V. R. Barletta, et al. (2012). A reconciled estimate of ice-sheet mass balance. Science, 338, 11831189 .

Shuster, D. L. \& K. A. Farley (2004). ${ }^{4} \mathrm{He} /{ }^{3} \mathrm{He}$ thermochronometry. Earth and Planetary Science Letters, 217, 1-17.

Sklar, L. S. \& W. E. Dietrich (2001). Sediment and rock strength controls on river incision into bedrock. Geology, 29 (12), 1087-1090.

Sloss, L. L. (1963). Sequences in the cratonic interior of North America. Bulletin of the Geological Society of America, 74 (2), 93-114.

Smallwood, J. R. \& C. E. Gill (2002). The rise and fall of the FaroeShetland Basin: Evidence from seismic mapping of the Balder Formation. Journal of the Geological Society, 159, 627-630.

Spasojević, S. \& M. Gurnis (2012). Sea level and vertical motion of continents from dynamic Earth models since the Late Cretaceous. AAPG Bulletin, 96 (11), 2037-2064.

Spasojević, S., L. Liu, \& M. Gurnis (2009). Adjoint models of mantle convection with seismic, plate motion, and stratigraphic constraints: North America since the Late Cretaceous. Geochemistry, Geophysics, Geosystems, 10 (5).

Stanley, J. R. \& R. M. Flowers (2016). Dating kimberlite emplacement with zircon and perovskite (U-Th)/He geochronology. Geochemistry, Geophysics, Geosystems, 17 (11), 4517-4533.

Stanley, J. R., R. M. Flowers, \& D. R. Bell (2015). Erosion patterns and mantle sources of topographic change across the southern African Plateau derived from the shallow and deep records of kimberlites. Geochemistry, Geophysics, Geosystems, 16, 3235-3256.

Stein, C. \& S. Stein (1992). A model for the global variation in oceanic depth and heat flow with lithospheric age. Nature, 359 (9), 123-139.

Steinberger, B. (2007). Effects of latent heat release at phase boundaries on flow in the Earth's mantle, phase boundary topography and dynamic topography at the Earth's surface. Physics of the Earth and Planetary Interiors, 164, 2-20.

Steinberger, B. (2016). Topography caused by mantle density variations: Observation-based estimates and models derived from tomography and lithosphere thickness. Geophysical Journal International, 205, 604-621.

Steinberger, B., C. P. Conrad, A. Osei Tutu, \& M. J. Hoggard (2019) On the amplitude of dynamic topography at spherical harmonic degree two. Tectonophysics, 760, 221-228.

Stephenson, S. N., G. G. Roberts, M. J. Hoggard, \& A. C. Whittaker (2014). A Cenozoic uplift history of Mexico and its surroundings from longitudinal river profiles. Geochemistry, Geophysics, Geosystems, 15, 4734-4758.

Stephenson, S. N., N. J. White, T. Li, \& L. T. Robinson (2019). Disentangling intergalcial sea level and global dynamic topography: Analysis of Madagascar. Earth and Planetary Science Letters, 519, 61-69.

Stock, J. D. \& D. R. Montgomery (1999). Geologic constraints on bedrock river incision using the stream power law. Journal of Geophysical Research: Solid Earth, 104 (B3), 4983-4993.

Stotz, I. L., G. Iaffaldano, \& D. R. Davies (2018). Pressure-driven Poiseuille flow: A major component of the torque-balance governing Pacific plate motion. Geophysical Research Letters, 45, 117-125. 
Stucky de Quay, G., G. G. Roberts, J. S. Watson, \& C. A.-L. Jackson (2017). Incipient mantle plume evolution: Constraints from ancient landscapes buried beneath the North Sea. Geochemistry Geophysics Geosystems, 18, 973-993.

Szwillus, W., J. C. Afonso, J. Ebbing, \& W. D. Mooney (2019). Global crustal thickness and velocity structure from geostatistical analysis of seismic data. Journal of Geophysical Research: Solid Earth, $124,1626-1652$

Tofelde, S., W. Duesing, T. F. Schildgen, A. D. Wickert, H. Wittmann, R. N. Alonso, \& M. Strecker (2018). Effects of deep-seated versus shallow hillslope processes on cosmogenic ${ }^{10} \mathrm{Be}$ concentrations in fluvial sand and gravel. Earth Surface Processes and Landforms, 43, 3086-3098.

Tucker, G. E. \& G. R. Hancock (2010). Modelling landscape evolution. Earth Surface Processes and Landforms, 35, 28-50.

Tucker, G. E., S. Lancaster, N. Gasparini, \& R. Bras (2001). The channel-hillslope integrated landscape development model (CHILD). In: Landscape Erosion and Evolution Modeling (edited by R. S. Harmon \& W. W. Doe), chap. 12, pp. 349-388. Kluwer Academic/Plenum Publishers, New York.

Turcotte, D. L. \& E. R. Oxburgh (1967). Finite amplitude convective cells and continental drift. Journal of Fluid Mechanics, 28 (1), $29-42$.

Turcotte, D. L. \& G. Schubert (2002). Geodynamics. Cambridge University Press, Cambridge, 2nd edn.

Underhill, J. R. (2001). Controls on the genesis and prospectivity of Paleogene palaeogeomorphic traps, East Shetland Platform, UK North Sea. Marine and Petroleum Geology, 18, 259-281.

Urey, H. C. (1947). The thermodynamic properties of isotopic substances. Journal of the Chemical Society, pp. 562-581.

Vail, P. R., R. M. Mitchum, \& S. Thompson (1977). Seismic stratigraphy and global changes of sea level, Part 4: Global cycles of relative changes of sea level. American Association of Petroleum Geologists, 26, 83-97.

Vasconcelos, P. M., T. A. Becker, P. R. Renne, \& G. H. Brimhall (1992). Age and duration of weathering by K-Ar and Ar/Ar analysis of potassium-manganese oxides. Science, 258, 451-455.

Vibe, Y., A. M. Friedrich, H. Bunge, \& S. R. Clark (2018). Correlations of oceanic spreading rates and hiatus surface area in the North Atlantic realm. Lithosphere, 10 (5), 677-684.

Vogt, P. R. (1971). Asthenosphere motion recorded by the ocean floor south of Iceland. Earth and Planetary Science Letters, 13, 153-160.

Wagner, G. A. (1968). Fission track dating of apatites. Earth and Planetary Science Letters, 4, 411-415.

Wahr, J., M. Molenaar, \& F. Bryan (1998). Time variability of the Earth's gravity field: Hydrological and oceanic effects and their possible detection using GRACE. Journal of Geophysical Research: Solid Earth, 103 (B12), 30,205-30,229.

Walford, H. L., N. J. White, \& J. C. Sydow (2005). Solid sediment load history of the Zambezi Delta. Earth and Planetary Science Letters, 238, 49-63.

Walker, R. T., M. Telfer, R. L. Kahle, M. W. Dee, B. Kahle, J.-L. Schwenninger, R. A. Sloan, \& A. B. Watts (2016). Rapid mantledriven uplift along the Angolan margin in the late Quaternary. $\mathrm{Na}$ ture Geoscience, 9 (11), 909-914.

Wallinga, J. (2002). Optically stimulated luminescence dating of fluvial deposits: A review. Boreas, 31, 303-322.

Watkins, C. E. \& C. P. Conrad (2018). Constraints on dynamic topography from asymmetric subsidence of the mid-ocean ridges. Earth and Planetary Science Letters, 484, 264-275.

Weinstein, S. A. \& P. Olson (1990). Planforms in thermal convection with internal heat sources at large Rayleigh and Prandtl numbers. Geophysical Research Letters, 17 (3), 239-242.

Weissel, J. K. \& M. A. Seidl (1998). Inland propagation of erosional escarpments and river profile evolution across the southeast Australian passive continental margin. Geophysical Monograph Series, $107,189-206$

Wheeler, J. (2010). Anisotropic rheology during grain boundary diffusion creep and its relation to grain rotation, grain boundary sliding and superplasticity. Philosophical Magazine, 90 (21), 2841-2864.

Whipple, K. X. (2001). Fluvial landscape response time: How plausible is steady-state denudation? American Journal of Science, 301, $313-325$.

Whipple, K. X. \& G. E. Tucker (1999). Dynamics of the stream-power river incision model: Implications for height limits of mountain ranges, landscape response timescales, and research needs. Journal of Geophysical Research, 104 (B8), 17,661-17,674.

Whipple, K. X. \& G. E. Tucker (2002). Implications of sediment-fluxdependent river incision models for landscape evolution. Journal of Geophysical Research, 107 (B2-2039).
Whitehouse, P. L. (2018). Glacial isostatic adjustment modelling: Historical perspectives, recent advances, and future directions. Earth Surface Dynamics, 6, 401-429.

Whittaker, A. C. (2012). How do landscapes record tectonics and climate? Lithosphere, 4 (2), 160-164.

Whittaker, A. C., M. Attal, P. A. Cowie, G. E. Tucker, \& G. Roberts (2008). Decoding temporal and spatial patterns of fault uplift using transient river long profiles. Geomorphology, 100, 506-526.

Wildman, M., R. Brown, R. Beucher, C. Persano, F. Stuart, K. Gallagher, J. Schwanethal, \& A. Carter (2016). The chronology and tectonic style of landscape evolution along the elevated Atlantic continental margin of South Africa resolved by joint apatite fission track and (U-Th-Sm)/He thermochronology. Tectonics, 35, 511-545.

Willett, S. D., S. W. McCoy, J. Taylor Perron, L. Goren, \& C. Y. Chen (2014). Dynamic reorganization of river basins. Science, 343 (6175).

Wilson, C. R., M. Spiegelman, \& P. E. van Keken (2017). TerraFERMA: The transparent finite element rapid model assembler for multiphysics problems in Earth sciences. Geochemistry, Geophysics, Geosystems, 18, 769-810.

Winterbourne, J. R., A. G. Crosby, \& N. J. White (2009). Depth, age and dynamic topography of oceanic lithosphere beneath heavily sedimented Atlantic margins. Earth and Planetary Science Letters, $287,137-151$.

Winterbourne, J. R., N. J. White, \& A. G. Crosby (2014). Accurate measurements of residual topography from the oceanic realm. Tectonics, 33.

Wolf, R. A., K. A. Farley, \& D. M. Kass (1998). Modeling of the temperature sensitivity of the apatite $(\mathrm{U}-\mathrm{Th}) /$ He thermochronometer. Chemical Geology, 148, 105-114.

Wolfe, J. A., H. E. Schorn, C. E. Forest, \& P. Molnar (1997). Paleobotanical evidence for high altitudes in Nevada during the Miocene. Science, 276, 1672-1675.

Worthen, J., G. Stadler, N. Petra, M. Gurnis, \& O. Ghattas (2014). Towards adjoint-based inversion for rheological parameters in nonlinear viscous mantle flow. Physics of the Earth and Planetary Interiors, 234, 23-34.

Wright, J. D. \& K. G. Miller (1996). Control of North Atlantic Deep Water circulation by the Greenland-Scotland Ridge. Paleoceanography, 11 (2), 157-170.

Yamauchi, H. \& Y. Takei (2016). Polycrystal anelasticity at nearsolidus temperatures. Journal of Geophysical Research: Solid Earth, 121 (11), 7790-7820.

Yang, R., S. D. Willett, \& L. Goren (2015). In situ low-relief landscape formation as a result of river network disruption. Nature, 520, 526-529.

Yang, T. \& M. Gurnis (2016). Dynamic topography, gravity and the role of lateral viscosity variations from inversion of global mantle flow. Geophysical Journal International, 207 (2), 1186-1202.

Yang, T., L. Moresi, R. D. Müller, \& M. Gurnis (2017). Oceanic residual topography agrees with mantle flow predictions at long wavelengths. Geophysical Research Letters, 44, 10,896-10,906.

Young, R. \& I. McDougall (1993). Long-term landscape evolution: Early Miocene and modern rivers in southern New South Wales, Australia. The Journal of Geology, 101, 35-49.

Yuen, D. A., D. M. Reuteler, S. Balachandar, V. Steinbach, A. V. Malevsky, \& J. J. Smedsmo (1994). Various influences on threedimensional mantle convection with phase transitions. Physics of the Earth and Planetary Interiors, 86, 185-203.

Zahirovic, S., N. Flament, R. D. Müller, M. Seton, \& M. Gurnis (2016). Large fluctuations of shallow seas in low-lying Southeast Asia driven by mantle flow. Geochemistry, Geophysics, Geosystems, 17 (9), 3589-3607.

Zhao, N., G. Hirth, R. F. Cooper, S. C. Kruckenberg, \& J. Cukjati (2018). Low viscosity of mantle rocks link to enhanced phase boundary kinetics. Earth and Planetary Science Letters, 517, 83-94.

Zhong, S. \& G. F. Davies (1999). Effects of plate and slab viscosities on the geoid. Earth and Planetary Science Letters, 170, 487-496.

Zhong, S., M. Gurnis, \& G. Hulbert (1993). Accurate determination of surface normal stress in viscous flow from a consistent boundary flux method. Physics of the Earth and Planetary Interiors, 78, $1-8$.

Zhong, S., M. Ritzwoller, N. Shapiro, W. Landuyt, J. Huang, \& P. Wessel (2007). Bathymetry of the Pacific plate and its implications for thermal evolution of lithosphere and mantle dynamics. Journal of Geophysical Research, 112 (B06412).

Corresponding authors: Correspondence should be addressed to M. Hoggard (mark.hoggard@anu.edu.au).

Acknowledgments: Acknowledgment is made to the Donors of the American Chemical Society Petroleum Research Fund (59062DNI8) for partial support of this research. We thank editor 
Maxim Ballmer for his patience and comments, Bernhard Steinberger and Walter Mooney for sharing datasets, and Terry Plank for inspiring Figure 1. Aaron Bufe, Karol Czarnota, Tyler Mackey, Fergus McNab, Dorothy Peteet, Evelyn Powell, Fred Richards, and Gareth Roberts generously read early versions of the manuscript and provided feedback. Nicolas Flament and an anonymous reviewer wrote detailed and comprehensive reviews. We thank the Computational Infrastructure for Geodynamics (geodynamics.org) which is funded by the National Science Foundation under award EAR-0949446 and EAR-1550901, for supporting the development of ASPECT. We acknowledge computing resources from Columbia University's Shared Research Computing Facility project, which is supported by NIH Research Facility Improvement Grant 1G20RR030893-01, and associated funds from the New York State Empire State Development, Division of Science Technology and Innovation (NYSTAR) Contract C090171, both awarded $15^{\text {th }}$ April 2010.

Data availability: Digital copies of the dynamic topography simulations and ASPECT initialisation files are available on the accompanying OSF database (https://osf.io/u86ny).

Competing interests: The authors declare no competing financial interests. 